\title{
Staff development in higher education : working to improve practices of experts in educational development of teachers and transfer of learning to the workplace
}

Citation for published version (APA):

De Rijdt, C. C. E. (2011). Staff development in higher education : working to improve practices of experts in educational development of teachers and transfer of learning to the workplace. [Doctoral Thesis,

Maastricht University]. Datawyse / Universitaire Pers Maastricht. https://doi.org/10.26481/dis.20111222cd

Document status and date:

Published: 01/01/2011

DOI:

$10.26481 /$ dis.20111222cd

Document Version:

Publisher's PDF, also known as Version of record

\section{Please check the document version of this publication:}

- A submitted manuscript is the version of the article upon submission and before peer-review. There can be important differences between the submitted version and the official published version of record. People interested in the research are advised to contact the author for the final version of the publication, or visit the $\mathrm{DOI}$ to the publisher's website.

- The final author version and the galley proof are versions of the publication after peer review.

- The final published version features the final layout of the paper including the volume, issue and page numbers.

Link to publication

\footnotetext{
General rights rights.

- You may freely distribute the URL identifying the publication in the public portal. please follow below link for the End User Agreement:

www.umlib.nl/taverne-license

Take down policy

If you believe that this document breaches copyright please contact us at:

repository@maastrichtuniversity.nl

providing details and we will investigate your claim.
}

Copyright and moral rights for the publications made accessible in the public portal are retained by the authors and/or other copyright owners and it is a condition of accessing publications that users recognise and abide by the legal requirements associated with these

- Users may download and print one copy of any publication from the public portal for the purpose of private study or research.

- You may not further distribute the material or use it for any profit-making activity or commercial gain

If the publication is distributed under the terms of Article 25fa of the Dutch Copyright Act, indicated by the "Taverne" license above, 


\section{Staff Development in Higher Education}

Working to improve practices of

experts in educational development of teachers

and transfer of learning to the workplace 
ISBN: 9789461591074

(c) Catherine C.E. De Rijdt, Maastricht, Nederland, 2011

Cover: Nicolas Vanhaesebroeck en Juliana Faes Druk: Datawyse I Universitaire Pers Maastricht 


\title{
Staff Development in Higher Education Working to improve practices of experts in educational development of teachers and transfer of learning to the workplace
}

\author{
Proefschrift \\ ter verkrijging van de graad van doctor \\ aan de Universiteit Maastricht, \\ op gezag van de Rector Magnificus, Prof. mr. G.P.M.F. Mols, \\ volgens het besluit van het College van Decanen \\ in het openbaar te verdedigen \\ op donderdag 22 december 2011 om 12.00 uur \\ door
}

Catherine C.E. De Rijdt

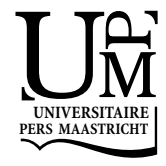




\section{Promotoren}

Prof. dr. F. Dochy (Katholieke Universiteit Leuven)

Prof. dr. C.P.M. van der Vleuten

\section{Beoordelingscommissie}

Prof. dr. J. Hage (voorzitter)

Prof. dr. H. Baert (Katholieke Universiteit Leuven)

Dr. W. de Grave

Prof. dr. P. Van Petegem (Universiteit Antwerpen)

Dr. mr. R. Wolleswinkel 


\section{Content}

$\begin{array}{ll}\text { 1. Introduction } & 7\end{array}$

2. Illuminating conceptions of staff development using a phenomenographic 17 approach

Submitted to Learning and Instruction as: De Rijdt, C., Dochy, F. \& van der Vleuten, C. Illuminating conceptions of staff development using a phenomenographic approach.

3. Classification of staff development programmes and effects perceived by teachers

Published as: De Rijdt, C.C.E., Dochy, F.J.R.C. \& Bamelis, S. (2007). Staff development in Hoger Onderwijs: Drie macromodellen en gepercipieerde effecten. Tijdschrift voor Hoger Onderwijs, 25(2), 58-68.

Submitted to Innovations in Education \& Teaching International as: De Rijdt, C.C.E. De, Dochy, F.J.R.C., Bamelis, S. \& van der Vleuten, C. Classification of staff development programmes and effects perceived by teachers

4. Teachers' perceptions of teaching portfolios in higher education: Content, conceptions and attitudes

Submitted to Teaching in Higher Education as: De Rijdt, C., Dochy, F. \& van der Vleuten, C. Teachers' perceptions of teaching portfolios in higher education: Content, conceptions and attitudes.

5. Teaching portfolios in higher education and their effects: An explorative study

Published as: De Rijdt, C.C.E., Tiquet, E., Dochy, F.J.R.C. \& Devolder, M. (2006). Teaching portfolios in higher education and their effects: an explorative study. Teaching and Teacher Education, 22, 1084-1093. 
6. Rigorously selected and well trained senior student tutors in problem based learning: Student perceptions and study achievements.

Published as: De Rijdt, C., van der Rijt, J., Dochy, F. \& van der Vleuten, C. (2011). Rigorously selected and well trained senior student tutors in problem based learning: student perceptions and study Achievements. Instructional Science, DOI 10.1007/s11251-011-9173-6 [on line first]

7. Predictors and moderators of transfer of learning to the workplace within $\mathbf{1 1 5}$ the area of staff development: Research review and critique

Submitted to Educational Research Review as: De Rijdt, C., Stes, A., van der Vleuten, C., \& Dochy, F. Predictors and moderators of transfer of learning to the workplace within the area of staff development: research review and critique (special issue on transfer)

8. General conclusions and discussion

Summary

Samenvatting

Dankwoord

Curriculum Vitae 
Chapter 1

Introduction 


\section{The critical role of staff development}

Optimal learning entails building upon knowledge in an active way, while teaching is helping students to actively construct knowledge by assigning them tasks that enhance the learning process (Tynjälä, 1999). Struyven and De Meyst (2010) describe teachers as continuously evolving professionals, who are critical of themselves, others and society, who are reflective practitioners while being eager to learn and who are able to make well-founded and responsible decisions within the classroom, the institution and the educational field. Different aspects of students such as individual characteristics, different learning styles (Kolb, 1984) and differences in their prior knowledge (Dochy, De Rijdt, \& Dyck, 2002) make the facilitating role of the teacher (Jonassen, Peck, \& Wilson, 1999; Biggs, 1999) a very interesting and particularly challenging one.

Hattie $(1987,2009)$ searched for the key factors that contribute to effective learning by setting up a meta-analysis of 337 meta-analyses and 180.000 research articles about educational innovation. In total, more than 50 million learners made up the subjects of the study. Hattie concluded that, besides learner-related variables like intelligence and motivation, the only variable that really makes a difference is the teacher.

This explains why the recognition of the importance of staff development has never been greater than it is today. Staff development can play a critical role in ensuring the quality of teaching and learning in universities (Devlin, 2006). Staff development is emphasised in proposals to reform, restructure or transform schools. Staff development is seen as the most important vehicle in efforts to bring about much-needed change (Guskey, 1995).

A wide range of other terms are used to describe the profession of staff development, being instructional development, instructional training, academic development, faculty development, faculty training, professional development, educational development, educational training, pedagogical training (De Rijdt, Stes, van der Vleuten and Dochy, submitted). In this dissertation we opt for the term staff development. Staff development is a general term that can encompass a whole set of processes (Fraser, 2001). According to Stefani (2003) the term staff development would refer to working to improve the capabilities and practice of educators.

In this dissertation, staff development is defined as the coherent sum of activities targeted to strengthen and extend the knowledge, skills and beliefs of the teachers in a way that will lead to changes in their way of thinking and their educational behaviour (Fenstermacher \& Berliner, 1985) and to the maximisation of the learning process of students (Sparks \& Loucks-Horsley, 1990). These changes take place continuously within the context of institutes of higher education as organisations, and are aimed at the school team as an organised group (Guskey, 1996). The focus is on the needs of the individual teacher and the school team. 
Cooperation and harmonisation between team members is essential (Roelofs, 1992). The teacher is required to explore his or her own knowledge, skills and beliefs in an active and reflective way (Lieberman, 1996; Richardson, 1990). Staff development is the sum of formal (e.g., workshops) and informal (e.g., the exchange of ideas among teachers) learning experiences (Fullan, 1990).

\section{Aspects of staff development}

\section{A shared language of different stakeholders}

With the recognition of the importance of staff development, a fundamental need for basic insights into the process of staff development has arisen. In order to attain a more profound understanding of staff development, an insider's perspective is needed.

Dewitt, Birrell, Egan, Cook, Oslund and Young (1998) stress the importance of a collaborative vision or shared language of teaching, learning and teacher education among different stakeholders as an important prior condition for making staff development work. Making conceptions of effective staff development explicit contributes to such a collaborative vision and shared language (Prosser, Trigwell, \& Taylor, 1994). A language shared by different stakeholders in staff development seems to be important, and yet hard to achieve.

Therefore, an exploration of the experiences which underpin staff developers' understandings of staff development is required in the search for the conditions and processes which are necessary in order to improve staff development. Furthermore, by understanding teachers' perceptions which affect teacher professionalisation, we can support and encourage the continuous professionalisation of teachers.

\section{The implementation of a teaching portfolio}

It has been recognised that reflective skills are a central element in the process of teachers' professional growth (Calderhead \& Gates, 1993; Korthagen, 1993; Korthagen \& Vasalos, 2005). The review by Mann, Gordon and MacLeod (2009) includes models of reflection and illustrates ways to conceptualise reflection. These authors report two major dimensions in the models of reflection: an iterative and a vertical dimension. The iterative dimension reveals a process of reflection (Boud, Keogh, \& Walker, 1985; Schön, 1983, 1987). The vertical dimension shows levels of reflection (Boud et al., 1985; Dewey, 1933; Hatton \& Smith, 1995; Mezirow, 1991; Moon, 1999).

When teachers develop themselves as reflective practitioners (Schön, 1987; Struyven \& De Meyst, 2010), they become aware of their personal qualities and 
shortcomings. Good teachers are effective life-long learners and self-regulating learners. Good teachers improve their practice through reflective inquiry. Teaching portfolios are a useful instrument with which to stimulate and document reflection and professional development in teaching.

A vital pre-condition to obtaining optimal results is a well-planned portfolio implementation process (Strijbos, Meeus, \& Libotton, 2007). In this kind of educational change, meaning must be established at every level of the system (Fullan, 2007). In order to successfully implement teaching portfolios and to minimise the resistance to the portfolio as an educational change within the organisation, it is interesting to gain information about teachers' conceptions and perceptions of teaching portfolios.

\section{Using the principles of staff development with regard to peer tutoring}

Peer teaching is a type of collaborative learning (Griffin \& Griffin, 1997; Topping, 1996) that still gains enthusiastic approval. Through a scaffolding process offered by their peers, students learn or co-construct (Decuyper, Dochy, \& Van den Bossche, 2010; Duran \& Monereo, 2005).

Peer learning has already proven to have a significant value in attempts to make learning more effective (Johnson, Johnson, \& Smith, 2007). In addition, the positive effects of problem-based learning - in which tutors guide discussions and promote in-depth discussions during group sessions - are well known (Dolmans \& Schmidt, 2006). By introducing students as tutors in problem-based learning, those students become a particular target group for staff development. In order to improve higher education, staff development with regard to peer tutors as a target group must be elaborated.

\section{Transfer}

As the definition of staff development indicates, effective staff development will lead to changes in teachers' way of thinking and their educational behaviour and to the maximisation of the students' learning process. Teachers have to translate their acquired knowledge, skills and beliefs into changes in their educational practice. However, this transfer of learning to the workplace seems to be rather complex. Saks and Belcourt (2006) reported a transfer of less than $50 \%$ of the knowledge and skills learnt during training activities. Other studies mention that only $10 \%$ of learning is actually transferred to teachers' job performance (Holton \& Baldwin, 2000; Fitzpatrick, 2001; Kupritz, 2002). These disappointing numbers make the transfer of learning a core issue. Unless we understand which factors influence the impact of staff development on the transfer of learning, it will be challenging to improve staff development. We need to understand which predictors actually lead 
to consequential effects. Furthermore, we have to gain insight into moderators in the relationship between predictors and the transfer of learning.

\section{Structure of the dissertation and research questions}

The dissertation consists of eight chapters. Chapter 1 gives an introduction to the different studies which were carried out for the purposes of this dissertation. The following section of Chapter 1 gives a short description of the studies and provides an overview of the research questions.

Chapters 2 and 3 concern the shared language of different stakeholders with regard to the concept of staff development in higher education. These chapters focus on two important stakeholders within the field of staff development: the staff developer and the teacher.

In Chapter 2, a phenomenographic perspective is taken. This study explores staff developers' experiences which have shaped their understanding of staff development. The main aim of the study is to provide a framework for understanding the way in which staff developers experience staff development. The research question is: "What are staff developers' underlying experienced meanings of staff development?".

The principal aim of Chapter 3 is to gain insight into teachers' perceptions of staff development using the three macro models devised by Smith (1992a, 1992b). Smith distinguishes between three macro models of staff development on the basis of who takes responsibility for implementing staff development activities: the management model; the shop-floor model and the partnership model. Chapter 3 investigates whether these models are recognised by teachers. Furthermore, this research examines the effects of these three staff development models as perceived by teachers in higher education. Two research questions are formulated: Does the teacher perceive staff development according to the management model, the shopfloor model or the partnership model? What effects of staff development according to the management model, the shop-floor model and the partnership model are perceived by teachers in higher education?

Chapters 4 and 5 focus on teachers' perceptions of teaching portfolios. Chapter 4 explores what teachers in higher education consider to be the relevant content of a teaching portfolio and looks into teachers' conceptions and attitudes (positive or negative) towards teaching portfolios. The following five research questions are answered in Chapter 4: What do teachers view as being valid information to be included in a teaching portfolio? What are teachers' conceptions of teaching portfolios? Are teachers' conceptions of teaching portfolios related to background variables, including educational institution, gender, age, years of experience, whether or not using a teaching portfolio, educational degree, university/school for 
higher education? What are teachers' attitudes (positive or negative) towards teaching portfolios? Do teachers' conceptions of teaching portfolios influence teachers' attitudes (positive or negative) towards teaching portfolios?

The research question in Chapter 5 is: Are teaching portfolios really used in higher education, and if so, what effects might they bring about?

Chapter 6 examines the issue of student tutors in problem-based learning environments from a new perspective. The extensive use of staff development, as an extra ingredient in the formula for peer learning, could improve higher education. In order to investigate this assumption, the following research question was formulated: Is there a difference between staff tutors and rigorously selected and well-trained student tutors with regard to students' achievements and perceptions?

In Chapter 7, we attempt to generate guidelines for further research in order to improve staff development, by revealing gaps in earlier research on the impact of staff development on the transfer of learning to educational practice. A large number of studies on transfer of learning to the workplace can be found in management research, which is closely related to staff development research. In management research, we find similar descriptions of transfer of learning as in the field of staff development. The management literature shows clear predictormoderator-transfer relationships, which are interesting in the context of research on the impact of staff development.

With this interdisciplinary review, we combine the findings of educational and management research. The findings of management research are used to review the research on the impact of staff development. We examine and evaluate the staff development literature with the goal of answering the following research questions: Which influencing factors - revealed in management, HRD and organisational psychology research - have an impact on transfer of learning?; Which moderating factors - revealed in management, HRD and organisational psychology research - have an impact on the relationship between predictors and transfer of learning?; Which of these influencing factors can be of importance within the context of staff development in higher education?; Which of these moderating factors can be of importance within the context of staff development in higher education?; Which influencing factors, additional to those found in management, HRD and organisational psychology research, can be found by studying the impact of staff development on transfer of learning to the workplace within the context of staff development in higher education?

Chapter 8 summarises and discusses the results of the different studies.

This dissertation contains six studies that are presented in chapters two to seven. Those studies have either been published in international journals or have 
been submitted for publication. Therefore, some parts of information may appear repeatedly in the different chapters.

\section{References}

Biggs, J. (1999). Teaching for quality learning at university. Buckingham: SRHE Open University Press.

Boud, D., Keogh, R., \& Walker, D. (1985). Reflection: Turning experience into learning. London: Kogan Page.

Calderhead, J., \& Gates, P. (Eds.). (1993). Conceptualizing reflection in teacher development. London: The Falmer Press.

Decuyper, S., Dochy, F., \& Van den Bossche, P. (2010). Grasping the dynamic complexity of team learning: An integrative model for effective team learning in organisations. Educational Research Review, 5(2), 111-133.

Devlin, M. (2006). Challenging accepted wisdom about the place of conceptions of teaching in university teaching improvement. International Journal of Teaching and Learning in Higher Education, 18(2), 112-119.

Dewey, J. (1933). How we think. A restatement of the relation of reflective thinking to the educative process (Revised edition). Boston: D.C. Heath.

Dewitt, P., Birrell, J. R., Egan, M. W., Cook, P. F., Oslund, M. F., \& Young, J. R. (1998). Professional development schools and teacher educators' beliefs: Challenges and change. Teacher Education Quarterly, 25(2), 63-80.

De Rijdt, C., Stes, A., van der Vleuten, C., \& Dochy, F. (submitted). Predictors and moderators of transfer of learning to the workplace within the area of staff development: research review and critique.

Dochy, F., De Rijdt, C., \& Dyck, W. (2002). Cognitive prerequisites and learning: A contribution to the renewed work of B. Bloom. Active Learning in Higher Education, 4, 124-136.

Dolmans, D. H., \& Schmidt, H. G. (2006). What do we know about cognitive and motivational effects of small group tutorials in problem-based learning? Advances in Health Sciences Education: theory and practice, 11(4), 321-36.

Duran, D., \& Monereo, C. (2005). Styles and sequences of cooperative interaction in fixed and reciprocal peer tutoring. Learning and Instruction, 15, 179-199.

Fenstermacher, G. D., \& Berliner, D. C. (1985). Determining the value of staff development. The Elementary School Journal, 85(3), 281-314.

Fitzpatrick, R. (2001). The strange case of the transfer of training estimate. Industrial-Organizational Psychologist, 39(2), 18-19.

Fullan, M. (1990). Staff development, innovation and institutional development. In B. Joyce (Ed.), Changing school culture through staff development (pp. 3-25). Virginia: Association for Supervision and Curriculum Development.

Fullan, M. (2007). The new meaning of educational change (4th edition). New York: Teachers College Press. 
Fraser, K. (2001). Australasian academic developers' conceptions of the profession. International Journal for Academic Development, 6, 54-64.

Griffin, B. W., \& Griffin, M. M. (1997). The effects of reciprocal peer tutoring on graduate students' achievement, test anxiety, and academic self-efficacy. The Journal of Experimental Education, 65, 197-209.

Guskey, T. R. (1996). Exploring the relationship between staff development and improving student learning. Journal of Staff Development, 17(4), 34-38.

Hattie, J. (1987). Identifying the salient facets of a model of student learning: A synthesis of metaanalyses. International Journal of Educational Research, 11, 187-212.

Hattie, J. (2009). Visible learning: A synthesis of over 800 meta-analyses relating to achievement. London: Routledge.

Hatton, N., \& Smith, D. (1995). Reflection in teacher education: Towards definition and implementation. Teaching and Teacher Education, 11, 33-49.

Holton III, E. F., \& Baldwin, T. T. (2000). Making transfer happen: An action perspective on learning transfer systems. Advances in Developing Human Resources, 2(4), 1-6.

Jonassen, D., Peck, K., \& Wilson, B. (1999). Learning with technology: A constructivist perspective. Upper Saddle River, NJ: Prentice Hall.

Kolb, D. A. (1984). Experiential learning: Experience as the source of learning and development. Englewood Cliffs, NJ: Prentice Hall.

Korthagen, F. A. J. (1993). Two models of reflection. Teaching and Teacher Education, 9(3), 317-326.

Korthagen, F., \& Vasalos, A. (2005). Levels in reflection: Core reflection as a means to enhance professional growth. Teachers and Teaching: Theory and Practice, 11(1), 47-71.

Kupritz, V. W. (2002). The relative impact of workplace design on transfer. Human Resource Development Quarterly, 13, 427-447.

Lieberman, A. (1996). Practices that support teacher development: Transforming conceptions of professional learning. In M. W. McLaughlin \& I. Oberman (Eds.), Teacher learning. New policies, new practices (pp. 185-201). New York: Teachers College.

Mann, K., Gordon, J., \& MacLeod, A. (2009). Reflection and reflective practice in health professions education: A systematic review. Advances in Health Sciences Education, 14, 595-621.

Mezirow, J. (1991). Transformative dimensions of adult learning. San Francisco: Jossey-Bass.

Moon, J. (1999). A handbook of reflective and experiential learning. London: Routledge.

Johnson, D. W., Johnson, R. T., \& Smith, K. (2007). The state of cooperative learning in postsecondary and professional settings. Educational Psychology Review, 19, 15-29.

Prosser, M., Trigwell, K., \& Taylor, P. (1994). A phenomenographic study of academics' conceptions of science teaching and learning. Learning and Instruction, 4, 217-231.

Richardson, V. (1990). Significant and worthwhile change in teaching practice. Educational Researcher, 19(7), 10-18.

Roelofs, E. (1992). Teamgerichte nascholing en coaching. Een experimentele studie in scholen met combinatieklassen [Team-focused refresher courses and coaching. An experimental study in colleges with combination classes]. Nijmegen: Universiteitsdrukkerij. 
Saks, A. M., \& Belcourt, M. (2006). An investigation of training activities and transfer of training in organizations. Human Resource Management, 45, 629-648.

Schön, D.A. (1983). The reflective practitioner. San Francisco: Jossey-Bass.

Schön, D. A. (1987). Educating the reflective practitioner: Toward a new design for teaching and learning in the professions. San Francisco: Jossey-Bass.

Smith, G. (1992a). A categorisation of models of staff development in higher education. British Journal of Educational Technology, 23(1), 39-47.

Smith, G. (1992b). Responsibility for staff development. Studies in Higher Education, 17(1), 27-41.

Sparks, D., \& Loucks-Horsley, S. (1990). Models of staff development. In W. R. Houston (Ed.), Handbook of research on teacher education (pp. 234-250). New York \& London: Macmillan.

Stefani, L. (2003), What is staff and educational development? In P. Kahn and D. Baume (Eds.), A Guide to Staff and Educational Development (9-23). London: Kogan Page.

Strijbos, J., Meeus, W., \& Libotton, A. (2007). Portfolio assignments in teacher education: A tool for selfregulating the learning process? International Journal for the Scholarship of Teaching and Learning, 1(2), 1-16.

Struyven, K., \& De Meyst, M. (2010). Competence-based teacher education: Illusion or reality? An assessment of the implementation status in Flanders from teachers' and students' point of view. Teaching and Teacher Education, 26, 1495-1510.

Topping, K. J. (1996) The effectiveness of peer tutoring in higher and further education: A typology and review of the literature. Higher Education, 32(3), 321-345.

Tynjälä, P. (1999). Towards expert knowledge? A comparison between a constructivist and a traditional learning environment in the university. International Journal of Educational Research, 33, 355-442. 

Chapter 2

Illuminating conceptions of staff

development using a phenomenographic approach 


\section{Introduction and theoretical background}

\section{Staff development, collaborative vision and shared language}

Staff development can play a critical role in ensuring the quality of teaching and learning in universities (Devlin, 2006). Never before in the history of education has there been a greater recognition of the importance of staff development. Proposals to reform, restructure or transform schools emphasise that staff development is the most important vehicle in the efforts to bring about necessary changes (Guskey, 1995).

Hattie $(2009,1987)$ searched for key factors that contribute to effective learning. Hattie conducted a meta-analysis of 337 meta-analyses and 180,000 research articles about educational innovation. In total, more than 50 million learners comprised the subjects of the study. Hattie concluded that after learnerrelated variables such as intelligence and motivation, the only variable that really makes a difference is the teacher. Therefore, we cannot deny the importance of staff development.

A wide range of terms are used to describe the profession of staff development. The review of De Rijdt, Stes, van der Vleuten and Dochy (submitted) determined several key words describing the profession, being staff development, instructional development, instructional training, academic development, faculty development, faculty training, professional development, educational development, educational training, pedagogical training.

In this study we opt for the term staff development. Staff development is a general term that can encompass a whole set of processes (Fraser, 2001). According to Stefani (2003) the term staff development would refer to working to improve the capabilities and practice of educators. Fraser (2001) studied the differences between three terms used to describe the profession, being academic, educational and staff development. The respondents disagreed about the meaning of these three terms. Fraser (2001, p. 61) concluded that however many individuals in the profession do similar work, we use quite different names to describe it. Fraser argued that it is more pertinently to think about who we are and how we act as a staff developer, than to agree on one specific name to describe the profession. Stefani (2003) argues that a simple definition of staff development is problematic. The reason for this is that staff development is constantly evolving in response to changing imperatives and the expectations of higher education stakeholders. Stefani (2003) emphasises the complex and dynamic nature of the profession of staff and educational development.

A collaborative vision or shared language between different stakeholders such as classroom teachers, teacher educators and their undergraduate students with regard to teaching, learning and teacher education is an important prior condition 
to making staff development work (Dewitt et al., 1998). Making conceptions of effective staff development explicit contributes to this collaborative vision and shared language. Conceptions are described as relations between individuals and a particular task and context. They are not stable entities within cognitive structures. They are dynamic and depend on the particular context and task in which they are being studied. They can nevertheless be identified within context, then decontextualised and expected to be found in broadly similar context (Prosser, Trigwell, \& Taylor, 1994).

\section{Conceptions of teachers}

Åkerlind (2003) presents teachers' conceptions of their own growth and development as university teachers. Three categories have been distinguished as variations of one primary key feature, which is a focus on either self or others. Category one is teaching development as a change within the teacher, thus increasing comfort and confidence within teaching. The second category is teaching development as a change in teaching practice, increasing teachers' skills, strategies and knowledge of the area. The final category is teaching development as a change in outcomes for the learner, by increasing student learning and development. Åkerlind (2003) also combines these results with the conceptions of teaching and thereby highlights the possibility that a broader understanding of teaching could precede a broader understanding of the growth and development of teachers.

\section{Conceptions of staff developers}

Staff developers themselves problemise the lack of a shared language and the difficulty of articulating conceptions that inform their practice (Trigwell, 2003). According to Trigwell (2003) good staff development could be considered to involve an awareness (1) of conceptions of staff development, (2) of approaches to academic development, (3) of teachers' conceptions of changing teaching, (4) of teachers' perceptions of teaching environment, (5) of what constitutes the space of learning in academic development.

However, only two studies that study conceptions of staff developers could be found. Fraser (2001) surveyed 71 professionals working in the field of staff development and interviewed 22 staff developers. All respondents agreed having a role in changing the teaching of academics in their institutions. Some respondents described their role as going beyond the teaching aspect, and impacting the entire role of the academic. Furthermore, some respondents conceived working at the institutional level as a part of their role.

An interesting result of the study of Fraser (2001) is the differences in conceptions on staff development as teaching. Some staff developers held quite 
traditional conceptions of teaching and others held broader conceptions of teaching, such as sharing ideas, giving support, mentoring, facilitating, catalysing, or consulting.

Jones (2010) supported this view of a multitude of conceptions. He studied the public written communication between staff developers and clients by examining the websites of 12 staff development centres. Three key frames are distinghuished by the author, being 'teaching as a problem', 'scientification' and 'appeal to notions of good teaching'.

\section{Aim and research question}

Previous research has mainly focussed on the conceptions of teaching and learning held by teachers or students. Conceptions of staff developers is still an underresearched area. Therefore, studying the conceptions of staff developers will be an important contribution to the existing literature (Trigwell, 2003). In addition to the contributions made by previous studies, the purpose of this study is to analyse and categorise the conceptualisations of staff development in higher education. In other words, it aims to identify the qualitatively different ways in which staff developers experience staff development. More specifically, the following research question has been formulated: in what ways do academic staff developers experience the phenomenon of staff development? This study could be seen as representing an optimisation perspective, by searching for the appropriate conditions and processes in order to improve staff development. The phenomenographic perspective taken in this study is described in the following section.

\section{Methods}

\section{Phenomenographic perspective}

Phenomenography is suitable for studying complex social phenomena like staff development (Säljo, 1996). We can see different conceptions of staff development as logically related in a nested hierarchy of inclusiveness. Therefore, a conceptual expansion approach or a phenomenographic perspective will be adopted. This is in contrast to the approach of defining conceptions as independent, even though they can be ordered on a continuum. Phenomenograpic research is not focussed on a process of verification, but is focussed instead on the pool of meanings discovered in the data (Åkerlind, 2005) and states that there is always a limited number of ways in which a phenomenon can be experienced (Marton, 1981). Conceptions are the variety of ways in which people experience these phenomena and can be presented as categories of description (Marton, 1981). Phenomenographic research is unique 
for its twofold aims. With the phenomenographic method variation in experiencing the same phenomenon is identified. Furhtermore, the aim is to identify differences in the variation that are critical for the phenomenon under study, being staff development (Runesson \& Mok, 2004).

\section{The research context}

Our phenomenographic outcomes could be used to bring about qualitative changes in the conception of staff development. Therefore it is important to address the issue of transferability, being the extent in which results can be used in other contexts. As suggested by $\operatorname{Sin}(2010)$, in this paragraph we elaborate on the study context with the goal of transferability of the findings.

The current study takes place in the Netherlands, where staff development refers to the teaching roles of staff members. That staff development is common sense in higher education in the Netherlands is visible through the national study group of staff developers and through the implementation of a national University Teaching Qualification (UTQ). Members of the national study group collaborate and share information. This study group meets several times a year. Between meetings members can share information and ideas using the on line community (67 members). In 2008 all Dutch university rectors signed a joint document which mutually committed them to starting UTQ programmes. The UTQ is intended for members of staff with teaching responsibilities. UTQ certificates will be awarded to members of staff who can demonstrate that competencies in respect of teaching have been acquired.

\section{Participants}

The purpose of this study is to obtain a sense of the variation of the ways in which staff developers experience the phenomenon of staff development. Therefore, staff developers who had been working within a university context for at least three years were invited to participate in the study. The success of phenomenographic research depends on decisions which are made in relation to data sources: the participants must be related to the overall developmental objective (Green \& Bowden, 2009). Furthermore, the participants must be willing to talk about the phenomenon (Sjöström \& Dahlgren, 2002). We opted for three years of experience because participants in a phenomenographic study should have a certain level of variance in their experience of the phenomenon in question, so that a variety of meanings can be presented. One staff developer per university was chosen at random in order to present as much variation as possible (Åkerlind, 2007) and was asked to participate. 
This procedure resulted in 13 staff developers from 13 different universities in the Netherlands taking part in this study, each with at least three years of experience in higher education. Previous phenomenographic research has indicated that a sample size of 10-20 interviewees is sufficiently large, without becoming unwieldy, to reveal most of the possible viewpoints and allow a defensible interpretation (Bruce \& Gerber, 1995; Gardner, 2008; Trigwell, 2000).

\section{Interviews}

In phenomenographic studies, data are generated using methods that permit openness and variation in the reactions of the respondent (Bowden, 2000a, 2000b). Semi-structured in-depth interviews were conducted with the aim of understanding the phenomenon in question.

In the interviews, the staff developers were asked to describe staff development, staff development activities, the characteristics of staff development activities, their own role as a staff developer, people who take initiative within the field of staff development and their experiences of successful staff development activities as if they were talking to a new colleague. The respondents were asked to elaborate on their answers using follow-up questions such as "Could you explain that further?", "Could you give an example?" and "You just mentioned $x$; why is this important for you?". The aim of every question was to provide opportunities for the interviewees to describe their experiences as freely as possible. If the respondent did not use the term staff development to describe their work, the term they were comfortable with was used during the interview.

All of the interviews were conducted within a time frame of four months. The interviews took approximately one hour each (Green \& Bowden, 2009).

In order to ensure the consistency of the questions and the interviewer's reactions, a pilot phase was implemented (Green \& Bowden, 2009). The interviewer conducted 11 pilot interviews with staff developers with the required amount of experience; however, this input did not form part of the actual data set for this study. These data were used exclusively as part of a fine-tuning procedure for the semi-structured interviews.

\section{Data analysis}

Each interview was audio-taped, transcribed verbatim and analysed phenomenographically using Atlas TI. As a careful researcher must recognise the limitations of transcription we listened to the recordings several times both before and after the transcription ( $\operatorname{Sin}, 2010$ ).

Harris (2011) reflects on two frameworks in phenomenographic research and reviews 56 studies. The first framework creates a distinction between what and how 
aspects. The second framework creates a distinction between referential and structural aspects which allows the parts and context of the phenomenon to be identified. Harris (2011) concludes that the theorising of the what/how framework seems weak and that the referential/structural framework is most used in previous research. Therefore, we use the referential/structural framework in the current study. This framework encourages researchers to contextualise people's conceptions and examines the parts that comprise them.

Our phenomenographic data analysis process is based on Sandberg (1997) and involves five phases. The first phase is becoming familiar with the transcripts. The second phase concerns discovering the referential dimensions of experiencing staff development. The next phase involves discovering the structural dimensions of experiencing staff development. In the fourth phase we established the categories of description and in the fifth phase we focus on the variation in the conceptions identified. The data analysis process is iterative in nature (Åkerlind, 2005). Each successive stage has implications for the phases that go after it, and also for the phases that come before (Marton, 1997).

In order to discern the different meanings in each transcript, the data analysis started (phase 1) with the researchers reading and re-reading the transcripts individually. Similarities and differences between the transcripts were noted. Gradually, an overview of the different meanings represented in the transcripts was formed.

The next phase (2) consisted of identifying segments in each transcript which portrayed particular meanings with regard to staff development. Each segment was coded and a short summary was formulated. Recurring codes formed categories. Repeated readings of the segments alongside the categories changed the composition of the categories. Some categories were also added or removed. The focus was on the placement of the segments in each category. In order to understand a specific quotation, this quotation was read in reference to the surrounding text in the transcript. This referential approach emphasises individual experiences.

Subsequently (phase 3), the relationship between the different categories was revealed, with regard to the structure within the pool of transcripts. The focus was on determining whether or not the categories which had been formed could be understood in relation to each other. Here, a structural approach was utilised; the quotation was read in reference to the structure of the results of the study at that moment in time.

As a result of this new view of the data, a set of logically related ways of experiencing staff development was formed. On the grounds of this analysis, a set of four categories was formed (phase 4). 
The fifth phase consisted of constituting an overview of the logical relationships between the different ways of experiencing staff development. We searched for logical relations among the four different categories.

Criteria for rigor and quality in phenomenographic research has been critiqued in literature (Sin, 2010). Therefore we elaborate on this issue in the current section. In the 80 's qualitative research was characterised by a shift from traditional criteria for evaluating research, such as validity and reliability, towards judging the trustworthiness of findings (Guba \& Lincoln, 1981). In the current literature we see a plea for a return to traditional terminology (Morse, Barrett, Mayan, Olson, \& Spiers, 2002; Sin, 2010). The reason here fore is that alternative terms could marginalise the research from mainstream science and scientific legitimacy. Following Morse et al. (2002) and $\operatorname{Sin}$ (2010) traditional terminology is used in the following discourse. In this study semi-structured interviews were used in an attempt to make room for the personal stories of the respondents. The anonymity of the participants was guaranteed in order to create a safe interview environment. A recapitulation of the participants' answers was presented to them (during the interview) in order to let them reconsider their answers. Subsequently, the participants had the opportunity to reformulate or to enrich their opinions. In the outcome space, accurate quotations are given.

As the basic idea of phenomenographic research is that knowledge of a phenomenon only exists in relation to our experience of that phenomenon, then different researchers looking at a pool of the individual experiences of participants cannot be expected to produce identical interpretations (Cope, 2004). In phenomenographic research, the results (the outcome space) are formed by the relationship between the researcher and the data (Åkerlind, 2005). This means that a researcher needs to address the concept of interpretative awareness (Sandberg, 1997) or, in other words, to manage the issue of subjectivity throughout the research process. Therefore, no literature about staff development was read during the collection and analysis of the data. Furthermore, we tried to interpret data from the participants' perspective (second order perspective). Codes were also generated from the transcripts. Prior to the data analysis, no codes were developed. During this process, we paid attention to the individual beliefs and knowledge of the researcher, the researcher's assumptions about the subjects and the experiences with the phenomenon of staff development and concerns about why these experiences had occurred while analysing the data (Ashworth, 1999). Instead of ensuring consistency in the data analysis and gaining a consensus between the interpretations of different researchers, we opted to enhance the acceptability of the outcome space between researchers. We ensured inter-audience communicability by presenting the categories which were formed during this study to other educational researchers and educational practitioners. Five expert educational researchers and experienced educational practitioners searched 
independently for a term that identified each category. We then reached a consensus by blending these different terms. Subsequently, five other educational researchers and educational practitioners were asked whether or not the distinctions between the different categories and the names of the categories could be easily understood. Feedback from these different audiences was taken into account. In every aspect of the research, a focal awareness (Dall'alba, 2000; Marton \& Booth, 1997) was maintained. Focus was maintained throughout the research process in order to help us to see the phenomenon just as the participants constituted their individual meaning with regard to their personal relationship with the phenomenon. Therefore, we also paid attention to reliability (Kvale, 1995) by describing the selection of the participants, the data collection process and the data analysis. Accurate quotations have been incorporated into the results section so that the meaning of the phenomenon arising from the participants' conceptions of the phenomenon could be emphasised.

The process of analysis and interpretation in phenomonographic research is a complex and demanding process. Therefore, supervision from a researcher with experience in the phenomenographic research method is necessary for quality insurance ( $\operatorname{Sin}, 2010)$. In this study one of the co-authors has experience in the research method. Therefore this author supervised the data analysis phase.

\section{Outcome space}

Phenomenographic findings are reported in an outcome space (Sin, 2010). First, categories of qualitatively different conceptions of the phenomenon are described. Quotations from the interviews are used to clarify and to support the meanings of the conceptions of staff development. Furthermore, an overview of the variation in the conceptions identified is presented.

\section{Categories of staff development}

The results of a phenomenographic study reveal a set of hierarchically structured categories of description of the phenomenon in question. The analysis in this study resulted in four main categories of description, being (1) Staff development as functional development, (2) Staff development as organisational competence development, (3) Staff development as self-directed reflective development, (4) Staff development as continuous personalised and experience-based holistic development. 


\section{Staff development as functional development}

This first category focuses on staff development as a way of improving teachers' educational knowledge and skills. Teachers have a great scope of knowledge and skills within their own field. However, in general, teachers do not have a vast amount of knowledge and skills about the principles of teaching. Staff developers see their role as transmitting information. A staff developer is an expert in education and determines the content and working method of the staff development session (staff developer focus). The emphasis is on new educational knowledge and skills, rather than on how this new knowledge and skills are related to the prior knowledge and already acquired competences of the teacher. The learning is functional for the teaching activities of the teacher. Context-related learning is a characteristic of effective staff development. Therefore, staff developers make use of authentic examples of real teaching practice. Staff development activities always consist of a combination of theory and practice. Theory is needed to underpin practice.

The characteristics of this category can be illustrated with the following quotations:

A good balance between theory and practice is typical for staff development. Educational theory must be used to ground practice. Using theory is really useful and necessary so that teachers can use it in their classroom practice. However, good staff development means not too much free-standing theory. For example, you ask teachers why things should be done in this way and not in that way. Subsequently, you provide teachers with the specific theory. Consequently, the staff developer is not just shouting things, but making grounded statements.

\section{Staff development as organisational competence development}

New in this category is the focus on the transfer of new knowledge and skills. The transfer of new insights into teachers' teaching practice is an important goal. One task of staff developers is to help teachers with this translation towards teaching practice. Staff developers see their role as helping teachers to acquire educational conceptions and to develop relations between them. Staff development encompasses guiding teachers in developing the competences formulated by the organisation. Finding a good balance between the role of the educational expert and guiding the process is important. Competences are formulated by the staff developer and the organisation. In order to make staff development work, it is important to have a clear view of the teacher competences which the organisation holds in great esteem. Developing and refining knowledge and skills is important. The conceptions of the staff developer and of the organisation are the most relevant. The conceptions of the learner are implicit. Active learning is standard during staff development sessions. Teachers should be constantly cognitively active and engaged during staff development sessions. 
The characteristics of this category can be illustrated using with the following quotations:

The idea of staff development is to map out the competences of the teacher and then to support the development of these competences. It is important that teachers pick up things, acquire an attitude; that is what it is all about. Staff development is everything a teacher needs to teach in a good way, following the philosophy or guidelines of the university. Staff development is not only about skills and tricks. It is also related to the curriculum and the vision of the organisation. The organisation needs clear quality criteria. Staff development is a part of human resource management and educational policy. One characteristic of staff development is to apply the frameworks and criteria of educational theory in other contexts. Almost instantly, the participants have to be active. Later on, you can judge what is necessary to tell them in your role as an expert.

Staff development as self-directed reflective development

In this third category, teachers should form their own teaching theory. Staff development activities offer the opportunity to develop personal insights into teaching. Teachers should make their own thought processes explicit. Teachers are directing their own development process. Developing the ability to reflect and to be self-improving as a teacher is a central component of this third category. Therefore, teaching portfolios are a highly valued instrument in staff development programs. Professionalism also encompasses expressing how things have gone; looking back and looking forward based on teachers' new knowledge and skills. It is about formulating new intentions for the future. Staff developers see their role as helping teachers to develop their conceptions in terms of further elaboration and extension. Through a process of reflection, staff developers should help teachers to grow in their different teaching roles. Developing and refining knowledge and skills, as well as transferring these new insights into the teachers' teaching practice, remains important. Examples of teachers' own teaching practices are used during staff development activities. Context-related learning is a characteristic of effective staff development. Therefore, staff developers make use of authentic examples of the teaching practices of the participants. This means that the examples used are totally relevant to the participants. Teachers can work with their own materials during staff development activities.

The following quotations will illustrate the characteristics of this category:

One characteristic of staff development is that teachers create their own theory of education. Staff development is to help teachers to gain their own insights. A good method is to help teachers to make their own thought processes explicit through discussion, exercises or other activities. One feature of staff 
development is to be able to reflect on a meta-level on your own skills. Practice is the starting point for staff development activities. Every teacher works with his own materials and own specific course goals, no matter how heterogeneous the group of teachers within staff development activities. This is important in order to work in an efficient way. Staff development is working within the context of the teacher and not within the context that I, as a staff developer, am thinking of. I can tell teachers what to do, but that does not work. Let teachers do things, experience things, that works. Another feature of staff development is the opportunity to take part in self-steering activities; for example, stimulating participants to bring up subjects.

\section{Staff development as continuous personalised and experience-based holistic development}

This fourth category emphasises the role of the staff developer in helping teachers to change their educational conceptions. The staff developer is a mentor who helps teachers with their own "screening processes". This entails stimulating teachers to reflect on their own practices and conceptions in a critical way. Moreover, staff development is about making implicit ideas become explicit. Staff development activities should highlight misconceptions. Developing the ability to reflect and to be self-improving as a teacher is a central component of staff development. Furthermore, the development of an increasing level of self-confidence and selfefficacy is a main goal of staff development. Teachers are self-directing professionals. This makes that the learning process is personalised. For the most part, the learner determines the content and conditions of a staff development session. The experience of the teacher occupies central place in staff development (experience-based learning). The new knowledge, pre-existing knowledge, current needs, level and conceptions of the teacher are relevant. Therefore, an intake procedure is of the utmost importance. The staff developer can adjust the programme accordingly. The staff developer and the teacher are partners in process. Learning is a holistic process. It will not be easy to change conceptions. Therefore, investing in longitudinal staff development programmes is important. Developing and refining knowledge and skills, as well as transferring these new insights into the teachers' teaching practice remains important. On-the-job training is seen as a very successful method. The teacher is in a continuous learning process. The characteristics of this category can be illustrated with the following quotations:

An effective approach within staff development is putting teachers on the wrong track. As a staff developer, I constantly confront people with their own expressions and with the incompleteness of their expressions in such a way that they pick it up themselves. Staff development is changing attitudes. The goal is that participants really want to do things differently. As a staff developer, you have to know the teachers previous experiences in order to adjust the 
programme. That is why tailor-made packages are important. Continuity is important for staff development: it helps teachers to reflect and to improve themselves over time. One goal of staff development is to gain expertise and knowledge, to develop skills, motivation, attitude and reflection and to translate this into educational practice. The ultimate aim is to become a better teacher and to form a personal identity.

\section{Relationships between the different ways of experiencing staff development}

These four categories differ from each other in a range of areas (distinctive features): knowledge and skills; educational conceptions; learner focus; competences; transfer; prior knowledge; the importance of longitudinal learning and approach. Table 1 provides an overview of these areas. While each additional category has features in common with the previous categories, it also presents a new element in the experience of the staff developer. The composition of these four categories contains a process of gradual change from teacher-centred to learner-centred, from involving small amounts of reflection to purposeful reflection, from limited self-directed learning to substantial self-directed learning, from unequal to equal levels, from no attention to a lot of attention being paid to learning transfer, from implicit beliefs and conceptions to explicit ones, from implicit prior knowledge and previously acquired competences to personal prior knowledge and previously acquired competences as the starting point for further learning, and from brief and solitary staff development interventions to longitudinal ones.

\section{Conclusion and discussion}

This study has shown that staff developers' understanding of staff development may be described in terms of four qualitatively different ways. This study provides us with insight into staff developers' understanding of staff development, and therefore increases conceptual clarity.

The non dualistic perspective advocated to phenomenography is unique. However, it is emphasised by Biggs (2003) that both constructivism and phenomenography typify the learner as the knowledge creator. The learner is constructing knowledge or constituting knowledge. This is in opposite to the idea of transmitting knowledge by direct instruction.

Following Biggs (2003) we selected other phenomenographic studies but also constructivist studies for the discussion part of the current study. 


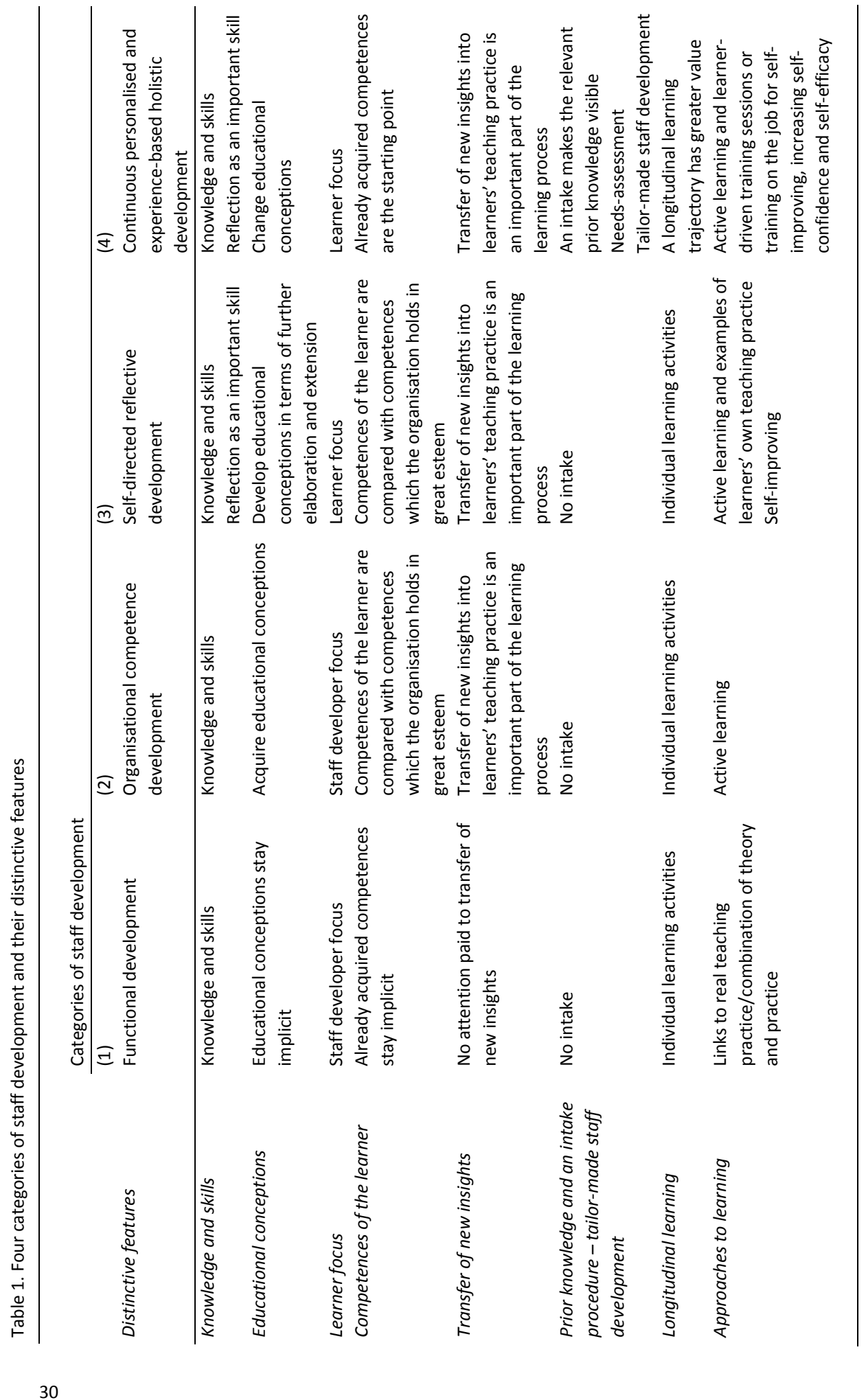


In the present study, all four distinct categories of staff development are focussed on improving teachers' educational knowledge and skills. With regard to conceptions, we found a gradual change. This could be associated with the three broad stages of development of university teachers found by Nyquist and Wulff (1996). Novice teachers are the most likely to participate in staff development programmes. As these teachers are in the first stages of their own development, their conceptions are not evolving, because they are focussed on surviving and skill development. When teachers are already more experienced, their focus shifts to the learner and the learning process and they will shift into the third stage and begin to develop conceptions. The teaching of novice teachers will improve through their first and second stages of development, during which a focus on knowledge and skills is important.

Three of our four categories are focussed on conceptions. In previous research, the impact of staff development on the conceptions of teachers has been proven (DeWitt et al., 1998; Gibbs \& Coffey, 2004; Huball, Collins \& Pratt, 2005; Medsker, 1992; Nasmith, Saroyan, Steinert, Lawn, \& Franco, 1995; Pololi et al., 2001; Postareff, Lindblom-Ylänne, \& Nevgi, 2007; Slavit, Sawyer, \& Curley, 2003).

Whether changes in beliefs and conceptions occur after knowledge and skills are improved or vice versa can be questioned. Hereabout the literature reveals the following two perspectives. Fitch and Kopp (1990) see improved instruction as the primary purpose of staff development. Effective staff development should therefore constantly focus on this goal. Therefore, it should build up common knowledge and concepts and contain clear objectives which are linked to what should be learned in classroom practice. Furthermore, the desired changes must be turned into beliefs and, in turn, these must be translated into specific behaviours. This can be seen in contrast to the work of Guskey (1986) and Eley (2006), who found changes in teachers' beliefs only after the implementation of new methods, new skills and new knowledge.

How the learner perceives a learning environment affects how he or she copes with it, rather than the set-up of the factual learning environment itself (Entwistle \& Tait, 1990). As a consequence, staff development activities will remain ineffective unless staff developers modify learners' perceptions of the learning environment in the intended way. Modifying the perceptions of the learner will be easier when their prior knowledge - including beliefs and conceptions - are made explicit. Furthermore, beliefs which remain unacknowledged or unarticulated do not assist but subvert transformations in practice (Smyth, 2003). This means that exploring the beliefs of the learner must be a part of the staff development process. This view matches the fourth category in this study.

Trowler and Cooper (2002) point to the importance of making conceptual frameworks of teaching and learning, which participants bring to staff development programmes and those which underpin the programmes themselves, explicit. 
Furthermore, these authors emphasise that staff developers themselves should develop a process for diagnosing conceptual frameworks and revealing them to participants. Recognising and surfacing those frameworks is a key factor in enhancing the effectiveness of staff development (Trowler \& Cooper, 2002). Trigwell (2003) studied staff developers' conceptions with regard to good staff development. The results also show the importance of an awareness of conceptions and perceptions of learning, teaching and development.

Ensuring that the training content is consistent with the job requirements (Bates, Holton, \& Seyler, 1998) is a design factor (Baldwin \& Ford, 1988) that may influence the transfer of what is learned to teaching practice. This means that a good intake and attention paid to teachers' prior knowledge is a requirement for transfer. Holton, Bates and Ruona (2000) embrace prior experiences and beliefs regarding efficacy as the key characteristics influencing transfer. Saks and Belcourt (2006) emphasise the importance of pre-training activities, such as trainee input and involvement, in stimulating transfer. Cheng and Hampson (2008) see the decision-making role of trainees as the most important factor in the transfer process. For Holton (1996) intervention readiness has an influence on the motivation to learn, which has an effect on transfer. An example of Holtons' intervention readiness is the degree of employee involvement with regard to needs assessment or planning of the training. In our study, a good intake in order to make prior knowledge, learning needs and involvement of the teacher explicit was only seen as important in the fourth category: "continuous personalised and experiencebased holistic development". Nevertheless, the categories of: "organisational competence development" (2); "self-directed reflective development"; (3) and "continuous personalised and experience-based holistic development" (4) stress the importance of the transfer of new insights to learners' teaching practice as part of the learning process. A learner focus is emphasised in our third and fourth category and can also be seen as the decision-making role of trainees in promoting transfer.

The outcomes of our study are similar to the concept of single loop and double loop learning developed by Argyris and Schön (1978). In this respect, we can see a gradual change in our four categories, from acquiring information and change to learning to learn and learning to change. Following on from the work of Argyris and Schön (1978), we found alternative terms with which to identify our four categories: informing oneself (1); learning to inform oneself (2); changing oneself (3); learning to change oneself (4).

Our fourth category is called "staff development as continuous personalised and experience-based holistic development". Based on the work of Andresen, Boud and Cohen (2000), we could simplify the title of this category because experiencebased learning implies continuous, personalised and holistic learning. However, in order to make our categorisation more transparent and easier to understand, we opted to mention all of the terms. This decision was based on the feedback we 
received from other educational researchers and educational practitioners during the process in order to ensure inter-audience communicability.

This study has - as a response to Åkerlinds' (2008) call for practical guidance significant value for training practices. Åkerlind (2008) uses the four steps to achieve conceptual change which are recommended by Marton and Tsui (2004) - contrast, generalisation, separation and fusion - in the design of her course in order to encourage an increase in the awareness of the nature of teaching. As conceptual development can be achieved by studying variation in the characteristics of the phenomenon of staff development that are currently taken for granted, a categorisation of staff developers' views on staff development and also particular quotations from staff developers from this study could be used in a developmental situation following the four steps recommended by Marton and Tsui (2004).

The results of our study show similarities with the study of Åkerlind (2003) on teachers' perceptions of their own growth and development. Also, in our study we discovered a change from focus on the staff developer himself (teacher in the staff development setting) towards a focus on the teacher (learner in the staff development setting). It would be interesting to compare, in one study, the different ways in which both stakeholders experience the phenomenon staff development. Or, it would be useful to investigate whether teachers, who are in fact the learners in this context, recognise the four categories mentioned in the present study. It would also be interesting to explore and compare the conceptions held by other stakeholders of staff development, such as management or students.

Furthermore, the empirical results of this study could be further examined using another research approach. Next to this, the conceptions of staff development which have been discovered as a result of this study could affect the approach of staff developers. It would be useful to evaluate those different approaches. This further study could combine data sources such as learning outcomes from teachers, observations of teacher practices, interviews with teachers and the learning outcomes of students. Finally, it would be interesting to have more insight into the beliefs of our respondents with regard to transfer of learning to the workplace within the area of staff development. A follow-up focus interview could focus on the multiple factors and influences that could affect transfer. In addition, a phenomenographic study aiming to define transfer of learning to the workplace within the area of staff development could provide further insight.

\section{References}

Åkerlind, G.S. (2003). Growing and developing as a university teacher - variation in meaning. Studies in Higher Education, 28(4), 375-390. 
Åkerlind, G.S. (2005). Variation and commonality in phenomenographic research methods. Higher Education Research and Development, 24(4), 321-334.

Åkerlind, G. S. (2007). Constraints on academics' potential for developing as a teacher. Studies in Higher Education, 32(1), 21-37.

Åkerlind, G. S. (2008). A phenomenographic approach to developing academics' understanding of the nature of teaching and learning. Teaching in Higher Education, 13(6), 633-44.

Andresen, L., Boud, D., \& Cohen, R. (2000). Experience-based learning. In G. Foley (Ed.), Understanding Adult Education \& Training (pp. 225-39). Sydney: Allen \& Unwin.

Argyris, C., \& Schön, D. (1978). Organizational learning: A theory of action perspective. Reading, MA: Addison Wesley.

Ashworth, P. (1999). "Bracketing" in phenomenology: Renouncing assumptions in hearing about student cheating. International Journal of Qualitative Studies in Education, 12(6), 707-721.

Baldwin, T. T., \& Ford, J. K. (1988). Transfer of training: A review and directions for future research. Personnel Psychology, 41, 63-105.

Bates, R. A., Holton, E. F. III, \& Seyler, D. L. (1998). Factors affecting transfer of training in an industrial setting. In R. L. Dilworth, \& V. J. Willis (Eds.), The cutting edge in HRD-1997 (pp. 5-13). Baton Rouge, LA: International Society for Performance Improvement and the Academy of Human Resource Development.

Bowden, J. (2000a). Experience of phenomenographic research: A personal account. In J. Bowden \& E. Walsh (Eds.), Phenomenography (pp. 47-61). Melbourne: RMIT Publishing.

Bowden, J. (2000b). The nature of phenomenographic research. In J. Bowden \& E. Walsh (Eds.), Phenomenography (pp. 1-18). Melbourne: RMIT Publishing.

Bruce, C. \& Gerber, R. (1995). Towards university lecturers' conceptions of student learning. Higher Education, 29, 443-458.

Cheng, E. W. L., \& Hampson, I. (2008). Transfer of training: A review and insights. International Journal of Management Reviews, 10, 327-341.

Cope, C. J. (2004). Ensuring validity and reliability in phenomenographic research using the analytical framework of a structure of awareness. Qualitative Research Journal, 4(2), 5-18.

De Rijdt, C., Stes, A., van der Vleuten, C., \& Dochy, F. (submitted). Predictors and moderators of transfer of learning to the workplace within the area of staff development: research review and critique.

Devlin, M. (2006). Challenging accepted wisdom about the place of conceptions of teaching in university teaching improvement. International Journal of Teaching and Learning in Higher Education, 18(2), 112-119.

Dewitt, P., Birrell, J. R., Egan, M. W., Cook, P. F., Oslund, M. F., \& Young, J. R. (1998). Professional development schools and teacher educators beliefs: Challenges and change. Teacher Education Quarterly, 25(2), 63-80.

Dall'alba, G. (2000). Reflections on some faces of phenomenography. In J. Bowden \& E. Walsh (Eds.), Phenomenography (pp. 47-61). Melbourne: RMIT Publishing.

Eley, M. G. (2006). Teachers' conceptions of teaching and the making of specific decisions in planning to teach. Higher Education, 51(2), 191-214. 
Entwistle, N. J., \& Tait, H. (1990). Approaches to learning, evaluations of teaching, and preferences for contrasting academic environments. Higher Education, 19, 169-194.

Fitch, M. E., \& Kopp, O. W. (1990). Staff development for the practitioner. Springfield: Charles C. Thomas.

Fraser, K. (2001). Australasian academic developers' conceptions of the profession. International Journal for Academic Development, 6, 54-64.

Gardner, K.D. (2008). Investigating Secondary School Students' Experience of Learning Statistics. MiddleSecondary Education and Instructional Technology Dissertations (Paper 30). Retrieved from http://digitalarchive.gsu.edu/msit_diss/30

Gibbs, G., \& Coffey, M. (2004). The impact of training of university teachers on their teaching skills, their approach to teaching and the approach to learning of their students. Active Learning in Higher Education, 5(1), 87-100.

Green, P., \& Bowden, J. (2009). Principles of developmental phenomenography. Malaysian Journal of Qualitative Research, 2(2), 55-74.

Guba, E., \&Lincoln, Y. (1981). Effective evaluation: Improving the usefulness of evaluation results through responsive and naturalistic approaches. San Francisco: Jossey-Bass Higher Education \& Social and Behavioral Science Series.

Guskey, T. (1995). Results-oriented professional development: In search of an optimal mix of effective practices. North Central Regional Educational Laboratory. Retrieved from http://web.archive.org/web/20060405093712/http://www.ncrel.org/sdrs/areas/rpl_esys/pdlitrev.h $\mathrm{tm}$

Guskey, T. R. (1986). Staff development and the process of teacher change. Educational Researcher, 15(5), 5-12.

Harris, L.R. (2011). Phenomenographic perspectives on the structure of conceptions: The origins, purposes, strengths, and limitations of the what/how and referential/structural frameworks. Educational Research Review, 6, 109-124.

Hattie, J. (2009). Visible learning: A synthesis of over 800 meta-analyses relating to achievement. London: Routledge.

Hattie, J. A. (1987). Identifying the salient facets of a model of student learning: A synthesis of metaanalyses. International Journal of Educational Research, 11, 187-212.

Holton, E. F. (1996). The flawed four-level evaluation model. Human Resource Development Quarterly, $7(1), 5-21$.

Holton, E. F., Bates, R. A., \& Ruona W. E. (2000). Development of a generalized learning transfer system inventory. Human Resource Development Quarterly, 11(4), 333-360.

Huball, H., Collins, J., \& Pratt, D. (2005). Enhancing reflective teaching practices: Implications for faculty development programs. The Canadian Journal of Higher Education, 35, 57-81.

Jones, A. (2010) Examining the public face of academic development. International Journal for Academic Development, 15(3), 241-251.

Kvale, S. (1995). The social construction of validity. Qualitative Inquiry, 1(1), 19-40.

Marton, F. (1981). Phenomenography: Describing conceptions of the world around us. Instructional Science, 10, 177-200. 
Marton, F. (1997). Phenomenography. In J.P. Keeves (Ed.), Educational research, methodology, and measurement: an international handbook ( $2^{\text {nd }}$ ed., pp. 95-101). Oxford: Pergamon.

Marton, F., \& Booth, S. (1997). Learning and awareness. Hillsdale, NJ: Lawrence Erlbaum.

Marton, F., \& Tsui, A. (2004). Classroom discourse and the space of learning. Hillsdale, NJ: Lawrence Erlbaum.

Medsker, K. L. (1992). NETwork for excellent teaching: A case study in university instructional development. Performance Improvement Quarterly, 5, 35-48.

Morse, J.M., Barrett, M., Mayan, M., Olson, K., \& Spiers, J. (2002). Verification strategies for establishing reliability and valididty in qualitative research. International Journal of Qualitative Methods, 1(2), 19.

Nasmith, L., Saroyan, A., Steinert, Y., Lawn, N., \& Franco, E. D. (1995). Long-term impact of faculty development workshops. Report by the McGill University, Canada.

Nyquist, J. D., \& Wulff, D. H. (1996). Working effectively with graduate assistants. Thousand Oaks, CA: Sage.

Postareff, L., Lindblom-Ylänne, S., \& Nevgi, A. (2007). The effect of pedagogical training on teaching in higher education. Teaching and Teacher Education, 23, 557-571.

Prosser, M., Trigwell, K., \& Taylor, P. (1994). A Phenomenographic Study of Academics' Conceptions of Science Teaching and Learning. Learning and Instruction, 4, 217-231.

Runesson, U. \& Mok, A.C. (2004). Discernment and the question, "What can be learned?" In F. Marton \& A.B.M. Tsui (Eds.), Classroom discourse and the space of learning (pp. 55-76). Mahwah, NJ: Lawrence Erlbaum Associates.

Saks, A. M., \& Belcourt, M. (2006). An investigation of training activities and transfer of training in organizations. Human Resource Management, 45, 629-648.

Säljo, R. (1996). Minding action: Conceiving of the world versus participating in cultural practices. In G. Dall' Alba \& B. Hasselgren (Eds.), Reflections on phenomenography: Towards a methology? (pp. 1934). Goteborg: ACTA Universitatis Gothoburgensis.

Sandberg, J. (1997). Are phenomenographic results reliable? Higher Education Research and Development, 16(2), 203-212.

Sin, S. (2010). Considerations of quality in phenomenographic research. International Journal of Qualitative Methods, 9(4), 306-319.

Sjöström, B. \& Dahlgren, L.O. (2002). Nursing theory and concept development or analysis. Applying phenomenography in nursing research. Journal of Advanced Nursing, 40(3), 339-345.

Slavit, D., Sawyer, R., \& Curley, J. (2003). Filling your plate: A professional development model for teaching with technology. TechTrends, 47, 35-38.

Smyth, R. (2003). Concepts of change: Enhancing the practice of academic staff development in higher education. The International Journal of Academic Development, 8, 51-60.

Stefani, L. (2003), What is staff and educational development? In P. Kahn and D. Baume (Eds.), A Guide to Staff and Educational Development (9-23). London: Kogan Page.

Trigwell, K. (2000). A phenomenographic interview on phenomenography. In J. Bowden \& E. Walsh (Eds.), Phenomenography (pp. 62-82). Melbourne: RMIT University Press. 
Trigwell, K. (2003). A relational approach model for academic development. In H. Eggins \& R. Macdonald (Eds.), The Scholarship of Academic Development (pp. 23-33). Buckingham UK: SRHE and Open University Press.

Trowler, P. \& Cooper, A. (2002). Teaching and Learning Regimes: implicit theories and recurrent practices in the enhancement of teaching and learning through educational development programmes. Higher Education Research and Development, 21(3), 221-240. 

Chapter 3

Classification of staff development programmes and effects perceived by teachers 


\section{Introduction and theoretical background}

\section{The concept of staff development}

In this study staff development is defined as the coherent sum of activities targeted at strengthening and extending the knowledge, skills and beliefs of teachers in a way that will lead to changes in their way of thinking and in educational behaviour (Fenstermacher \& Berliner, 1985) and to the maximisation of the learning process of students (Sparks \& Loucks-Horsley, 1990). These changes continuously take place within the context of schools for higher education as organisations, and are aimed at the school team as an organised group (Guskey, 1996). The focus is on the needs of the individual teacher and the school team. The teacher is viewed as an active and reflective person who explores his/her own knowledge skills and beliefs. Staff development then becomes the sum of the formal (e.g. workshops) and the informal (e.g. exchange of ideas among teachers) learning experiences (Fullan, 1990).

\section{Classification of staff development programmes}

Staff development is operationalised in different forms. Smith (1992a, 1992b) distinguishes three macro models on the basis of who takes responsibility for implementing staff development activities: the management model (MM), the shop-floor model (SM) and the partnership model (PM). These three macro models may be used - simultaneously or otherwise - within institutions. In the management model, initiatives are taken at the top and imposed on lower layers of the organisation. The shop-floor model is characterised by initiatives taken on the floor and carried out at the top. Finally, in the partnership model, initiatives are taken by intermediaries such as staff developers who organise several activities considered useful by both management and staff. With this model, the divergence of interests between the individual and the educational institution is taken into account.

Smith (1992a, 1992b) sees advantages and disadvantages in each model. The management model has the weakness of ignoring the views and needs of staff. The shop-floor model's weakness is the limited expertise of teachers. This model assumes that staff are capable of identifying their own needs and suggesting actions to meet these needs. The partnership model unites both the needs of staff and the wishes of management. Achieving this unity is a difficult task. This weakness can be addressed by the involvement of local staff developers (decentralised) alongside central staff developers (Main, 1985). The local staff developer is better able to examine the training needs of the staff and to discuss them with the central staff developer, who has a better picture of the wishes of the management. Smith 
(1992a, 1992b) and Main (1985) recognise this extension of the partnership model, also called the decentralised partnership model.

\section{Levels of impact}

Kirkpatrick (1998) formulated four levels for evaluating training programmes: reaction, learning, behaviour and results. Each level is important and has an impact on the next level. Levels 3 and 4 seem hard to achieve. Kirkpatrick (1998) illuminates four necessary conditions to make change in behaviour (level 3) possible. First, the person must have a desire to change. Second, the person must know what to do and how to do it. Third, the person must work in the right climate. Fourth, the person must be rewarded for changing.

Kirkpatrick's four-level evaluation model (1998) has been criticised, but it is still used because of its simplicity. Recent reviews on effective staff development make use of a slightly adapted version of Kirkpatrick's model (Stes, Min-Leliveld, Gijbels, \& Van Petegem, 2010; Steinert et al., 2006).

Holton (1996) emphasises the lack of detail in Kirkpatrick's model: major intervening variables affecting learning are not specified. Motivation to learn is an important variable in Holton's alternative evaluation model. Holton refines Kirkpatrick's model and stresses the importance of variables leading to a more effective learning process and better transfer to the workplace. Knowles, Holton and Swanson (1998) acknowledge that to create adult learning experiences adult learners must have an internal rather than an external motivation. Research on adult learning also reveals that learning processes in work-related learning have an unconscious character. In other words, most adult learners are not aware of the learning process (Candy, 1991; Eraut, 2000; Eraut, Alderton, Cole \& Senker, 1998). Next to the implicit form of learning with no intention to learn and no awareness of the learning, Van Eekelen, Vermunt and Boshuizen (2006) distinguish two other forms of workplace learning. Reactive learning is almost spontaneous and largely unplanned. Spontaneous reflection or the incidental notation of facts are examples of reactive learning. Deliberative learning is the third form which involves explicitly setting time aside.

\section{Aim and research question}

Quality education cannot exist without quality teachers (Grant \& Murray, 1999). Moreover, as regards key factors that contribute to effective learning, next to variables of the learner like intelligence and motivation the only variable that really makes a difference is the teacher (Hattie, 1987, 2009). Effective educational improvements begin with teachers (Grant \& Murray, 1999). Therefore, innovative views on teaching must reach teachers. The importance of staff development with 
the teacher as an important stakeholder cannot be denied. A collaborative vision or shared language on teaching, learning, and teacher education among different stakeholders is an important prior condition to make staff development work (Dewitt et al., 1998). This shared language of different stakeholders in staff development seems however hard to achieve. As teachers construct a meaningful personal reaction to staff development, this subjective perception is an important source of knowledge. Grasping those perceptions of teachers is a step towards a collaborative vision and shared language. By understanding perceptions of teachers affecting teacher professionalisation, we can support and encourage the continuous professionalisation of teachers.

As Smith's (1992a, 1992b) three staff development models are still recognised in practice, it is interesting in terms of shared language to know what effects a management model, a shop-floor model and a partnership model (Smith, 1992a, 1992b) have on teachers. To take a closer look at the necessary desire to change as formulated by Kirkpatrick (1998), and the important intervening variable emphasised by Holton (1996) it is intriguing to investigate with what kind of motivation teachers enrol on a staff development programme.

Therefore this study focused on the following research questions:

1. Does the teacher perceive staff development as a management model, a shop-floor model or a partnership model (Smith, 1992a, 1992b)?

2. Which effects of staff development as a management model, a shop-floor model and a partnership model (1992a, 1992b) are perceived by teachers in higher education?

3. What kind of motivation is apparent when teachers decide to participate in a staff development activity?

4. Is there a significant difference between types of motivation regarding the effects perceived by teachers?

\section{Methods}

\section{Instruments}

This study opted for a survey and semi-structured interviews. For reasons of complementarity we opted for a mixed method design (Greene, Caracelli, \& Graham, 1989). The results of the semi-structured interviews were used to clarify and illustrate results from the survey.

The questionnaire evaluated the number of sessions followed by the respondents and the content of those staff development sessions. Then the three macro models of Smith (1992a, 1992b) were introduced. Respondents were asked 
to categorise the staff development activities they followed according to the three models.

For each macro model the respondents were also asked what kind of motivation they had, i.e. intrinsic (from within), extrinsic (from without) or a combination of both, when they decided to participate in staff development.

For each model, the effects were measured with regard to five levels of impact: satisfaction after following a staff development session; consciousness of the learning process; changes in conceptions of teaching; application of newly acquired knowledge and skills; and changes for students. These five levels of impact can be associated with Kirkpatrick's (1998) four levels for evaluating training programmes, i.e. reaction, learning, behaviour and results.

Respondents were asked to answer 'yes', 'more or less', or 'no'. After this, respondents could add remarks. They were also asked to clarify their reasons for satisfaction or dissatisfaction. If changes in conceptions were noticed they were asked to specify these. When the application of newly acquired knowledge was queried, respondents were asked which areas of knowledge and skills (ICT, didactic, subject-related or educational organisation) were applied the most. Finally, they could specify the exact impact they observed on students.

Semi-structured interviews were held after the questionnaires had been completed. During the interviews background information about the organisation of the staff development sessions was gathered. Furthermore, questions from the questionnaire were repeated to provide better understanding of the data from the questionnaire.

\section{Participants and setting}

The participants were 97 teachers from seven departments of two schools for higher education. In total 205 questionnaires were handed out. The total response was $47 \%$. We searched for two schools of higher education with a similar profile. This profile was characterised by the following three elements. (1) The staff development policy is highly developed. (2) A centre or workgroup for staff development is active in the school. (3) Furthermore, staff members are working with teaching portfolios.

\section{Data analysis}

We used SAS for the quantitative analyses. An ANOVA was conducted to identify significant differences between types of motivation regarding the effects perceived by teachers. When the assumption of homogeneity of variance was not fulfilled, a Kruskal-Wallis test was performed. A Fisher's exact test was used to examine the significance of the association between two kinds of classification where sample 
sizes were small. Statistical differences in this study were measured at the $5 \%$ significance level. The Bonferroni method was used to address the problem of multiple comparisons.

The answers to open questions were analysed in a qualitative way. Two researchers, one of whom had no involvement in the actual interviews, interpreted the data separately. Through reflection and discussion they came to a consensus. Data reduction and development of descriptive categories were performed. The information gathered from the semi-structured interviews was used to support the results of the questionnaire.

\section{Validity and reliability}

Internal validity and internal reliability were increased through the triangulation of the different data sources. During the interviews a recapitulation of the answers from the participants was presented to them in order to let them reconsider their answer. Subsequently, the participants had the opportunity to reformulate or to enrich their answer. The results were illustrated by quotations that were consistently expressed during the interviews. Four other researchers and experts in the field provided feedback on our findings. Taking into account those comments on our findings strengthened the credibility of the study.

\section{Results}

The results are presented below according to the four research questions.

\section{Does the teacher perceive staff development as a management model, a shop-} floor model or a partnership model (Smith, 1992a, 1992b)?

Staff development according to the management model occurs most frequently (42\%). The shop-floor model and the partnership model share second place (29\%). In school A we see almost no difference in perception ( $\mathrm{MM}=33 \%, \mathrm{SM}=33.5 \%$ and $\mathrm{PM}=31.5 \%)$. In school B staff development is perceived mostly as a management model (47\%). The shop-floor model (26\%) and the partnership model $(27 \%)$ share second place. Table 1 gives an overview. 
Table 1. The occurrence of training courses according to the management model, shop-floor model and partnership model in \%

\begin{tabular}{llccc}
\hline $\begin{array}{l}\text { Characteristics } \\
\text { respondents }\end{array}$ & Management Model & Shop-floor Model & Partnership Model \\
\hline Total & & 42 & 29 & 29 \\
\multirow{5}{*}{ Institution } & School A & 34 & 34 & 32 \\
& School B & 47 & 26 & 27 \\
Gender & Male & 43 & 27 & 30 \\
\multirow{5}{*}{ Age } & Female & 42 & 30 & 28 \\
& $18-29 y$ & 38 & 35 & 27 \\
& $30-39 y$ & 48 & 19 & 33 \\
& $40-49 y$ & 40 & 30 & 30 \\
\multirow{5}{*}{ Sessions } & 0 & 43 & 36 & 21 \\
& $50+y$ & 100 & 0 & 0 \\
& $1-5$ & 51 & 17 & 32 \\
& $5-10$ & 39 & 42 & 19 \\
& $10+$ & 37 & 25 & 38 \\
\hline
\end{tabular}

During the interviews respondents from School A pointed out that the three organisational models were equally present. An example of staff development sessions that are organised top-down (management model) are the electronic learning environment training sessions. Working with an electronic learning environment is a policy decision. Sometimes the needs of the teachers are questioned (shop-floor model). Staff development according to the partnership model is organised by a workgroup responsible for the development and organisation of these sessions. This workgroup is located at a central level, but every department is represented. The workgroup has the characteristics of a 'decentralised partnership model', which is an extension of the partnership model. There is a central staff developer, but there are also decentralised staff developers, who work in every department.

Respondents indicated that in School B a hybrid of the three models exists. Training courses which are given for educational reforms belong to the management model. On the other hand, an investigation into the teachers' needs is also done. Furthermore, teachers can put questions to a centre which is responsible for staff development. This centre cooperates with an agent from every department, who indicates the needs of his/her department.

\section{What effects of staff development as a management model, a shop-floor model and a partnership model (Smith, 1992a, 1992b) are perceived by teachers in higher education?}

Effects are measured with regard to five levels of impact: satisfaction after following a staff development session; consciousness of the learning process; changes in 
conceptions of teaching; application of newly acquired knowledge and skills; and changes for students.

The different effects are discussed in the following section.

\section{Satisfaction after following staff development sessions}

An average of $99 \%$ of all the respondents was completely satisfied or, more or less satisfied, after following a staff development session. For the shop-floor model, not one respondent was dissatisfied after following a staff development session. Given the number of totally satisfied participants, however, the partnership model is the most effective. Table 2 gives an overview.

Table 2. Satisfaction according to the management model, shop-floor model, and partnership model in \%

\begin{tabular}{lccc}
\hline Satisfied & Management Model & Shop-floor Model & Partnership Model \\
\hline Yes & 41 & 51 & 62 \\
More or less & 58 & 49 & 36 \\
No & 1 & 0 & 2 \\
\hline
\end{tabular}

Respondents indicate the same reasons for satisfaction and dissatisfaction after following a staff development programme within each of the three different models.

Six reasons for satisfaction are mentioned. First and most often named is easy application to teaching practices. Tutors appreciate it when helpful tips and useful information are offered. Moreover, it is important that the training course is practical and focused, connects to the field of knowledge and is conducted as expected. Second, teachers are satisfied when personal needs and interests are taken into account. Third, experience exchange is a reason for satisfaction. Tutors experience contact with others as a source of stimulation, which increases their motivation. Furthermore (fourth) the presence of an expert is important. The fifth reason for satisfaction is the way in which the sessions are set up. People have positive perceptions of working in small groups and like a good balance between explanation and interaction. Finally, (sixth) respondents agree that a broad range of staff development sessions on offer is a reason for satisfaction.

Respondents give five reasons for dissatisfaction. The first reason is the level of the training. Teachers are sometimes dissatisfied when their own knowledge is not taken into account and when the pace of the training is not appropriate. A second reason for dissatisfaction is the absence of concrete and useful information. Teachers find it important that the content of a training session is well described. Practical problems are the third reason for dissatisfaction. Examples cited by the respondents are not providing them with a manual and technical problems with ICT. Fourth, teachers are not satisfied when they do not receive feedback during the 
staff development session. Finally, obligation or lack of interest leads to a feeling of wasted time and dissatisfaction.

Consciousness of the learning process during the staff development sessions

For the three models, on average, $5 \%$ of the tutors indicate being unaware of a learning process during staff development sessions. Furthermore, 30\% of the respondents are sometimes aware of a learning process. An average of $65 \%$ respondents is aware of a learning process.

During the staff development sessions, according to the management model $60 \%$ of the respondents are aware of a learning process, whereas for the shop-floor model this is $67 \%$ and for the partnership model $69 \%$.

\section{Changes in conceptions of teaching}

With regard to the three models, $72 \%$ of the respondents have changed their teaching conceptions after following staff development programmes. The percentage of respondents indicating that their conceptions about teaching have changed is the largest for the shop-floor model (77\%). For the partnership model this is $75 \%$ and for the management model $64 \%$.

During the interview respondents notice that a lot of teachers consider the change in conceptions of teaching as something obvious. Moreover, there are teachers who specifically follow staff development sessions in order to develop new ways of thinking to which they may adapt their methods.

Respondents notice the changes in conceptions in different ways. First, as a result of the change in conceptions, teachers see more possibilities for the application of technology. For example, respondents mention that they make more use of ICT in teaching practices. A second category of noticed changes in conceptions is a more student-centred approach. Respondents mention that they adapt their teaching style to the students and that they are better able to guide them since they have gained different insights. Their role has evolved from that of teacher to coach. Respondents indicate that they use methods such as problembased learning and competence-based learning. The third category of noticed changes in conceptions is a more reflective practitioner attitude. Respondents state that by attending staff development activities they improve their insights into their own teaching styles and they are better able to reflect upon them. They start questioning their own teaching styles. Respondents notice a progression from good teaching to creating conditions in which the students can learn well.

\section{Applying what is learned in practice}

On average, $89 \%$ of the respondents indicated that they apply what they have learned during staff development sessions in their own teaching practice. For the management model $90 \%$ of the respondents apply the knowledge and skills gained. 
For the shop-floor model and the partnership model these are $89 \%$ and $89 \%$ respectively. ICT topics in particular are applied by teachers (Table 3).

Table 3. Area of knowledge and skills applied by the management model, shop-floor model and partnership model in \%

\begin{tabular}{lccc}
\hline $\begin{array}{l}\text { Applied knowledge } \\
\text { and skills area }\end{array}$ & Management Model & Shop-floor Model & Partnership Model \\
\hline ICT & 64 & 64 & 63 \\
Didactic & 25 & 22 & 21 \\
Subject substantive & 6 & 8 & 11 \\
$\begin{array}{l}\text { Educational } \\
\text { organisation }\end{array}$ & 5 & 6 & 5 \\
\hline
\end{tabular}

\section{Effects on students}

On average, $83 \%$ of the respondents observed an impact on the students after they applied what they had learned during staff development sessions. For the shopfloor model $92 \%$ of the respondents mentioned an impact on students. For the partnership model $85 \%$ of the respondents and for the management model $71 \%$ of the respondents observed an impact on students.

Teachers mention different effects on students. First, respondents see students perform better. Respondents experience a better insight, a deeper study approach and a more analytical approach by students. Students increasingly ask better topicrelated questions and they require less additional explanation. Furthermore, respondents notice better test results and an increased number of students passing courses. Second, respondents experience better contact with their students, in both formal and informal situations. A third change concerns greater self-directing activities and better collaborative work of students. Students show a more active approach to learning. For example, respondents noticed a greater input from students during lessons. Students have higher motivation. They show greater interest and are more inquisitive. Teachers sensed this by students' greater involvement and their more critical attitude. They noticed a change in evaluations of teachers, and finally they perceived the increased satisfaction of students during internships. These changes are mentioned for all three models.

\section{What kind of motivation (intrinsic, extrinsic or a combination of both) is apparent when teachers decide to participate in a staff development activity?}

Extrinsic motivation only occurs within the management model. Table 4 gives an overview of the kinds of motivation per staff development model. 
The interviews indicate that an indirect form of obligation is present in School A and in School B. In both schools teachers are working with a personal teaching portfolio. In this portfolio tutors must indicate what efforts are made within the framework of professionalisation. Staff development sessions following the management model have generally been aimed at educational innovation processes.

Table 4. Type of motivation by the management model, shop-floor model and partnership model in \%

\begin{tabular}{lccc}
\hline Type of motivation & Management Model & Shop-floor Model & Partnership Model \\
\hline Intrinsic & 61 & 80 & 71 \\
Extrinsic & 5 & 0 & 0 \\
Both & 34 & 20 & 29 \\
\hline
\end{tabular}

\section{Is there a significant difference in perceived effects by teachers between types of motivation?}

The search for significant differences considered the five levels of impact: satisfaction after following a staff development session; consciousness of the learning process; changes in conceptions of teaching; application of newly acquired knowledge and skills; and changes for students.

There are significant differences between type of motivation and the satisfaction of teachers. In the management model $(F=4.82, p=0.01)$ we see that tutors with an intrinsic motivation differ significantly from tutors with an extrinsic motivation. Here, intrinsically motivated tutors indicate that on average they are more satisfied (50\%) than extrinsically motivated tutors (0\%). With the shop-floor model $\left(x^{2}=5.63, p=0.02\right)$ significant differences are noticeable between respondents with an intrinsic motivation and those with both motivations. Intrinsically-motivated tutors are on average more satisfied than tutors who are motivated both intrinsically and extrinsically (58\% compared with $18 \%$ ). With regard to the partnership model there is also a significant difference between tutors with an intrinsic motivation and those who participate in staff development activities with an intrinsic motivation and an extrinsic motivation ( $F=5.98, p=0.02)$. Here, $75 \%$ of the intrinsically motivated tutors indicate that they are satisfied, compared with $30.77 \%$ of the tutors who are motivated intrinsically as well as extrinsically.

Significant differences are also found for type of motivation and consciousness of the learning process. For the partnership model, there is a statistical difference between the teachers who followed staff development sessions from intrinsic motivation and tutors who have both intrinsic and extrinsic motivation $(F=9.39, p=$ 0.0039). Here, $83 \%$ of the intrinsically-motivated teachers are aware of a learning 
process, compared with $33 \%$ of teachers who are motivated intrinsically as well as extrinsically.

There are no significant differences between the different motivations and the changes in conceptions of teaching according to the three models. Also, no significant differences are found between different motivations and applying what is learned. Finally, no significant differences are found between different motivations and effects on students.

\section{Conclusion and discussion}

Understanding underlying characteristics affecting staff development means better support and facilitation for teachers who are striving towards continuous professionalisation. This study provides increased understanding of the conceptions of teachers and the barriers/opportunities perceived by teachers. The current study investigates by means of a survey and semi-structured interviews whether the teacher perceives staff development as a management model, a shop-floor model or a partnership model (Smith, 1992a, 1992b); what effects are perceived by teachers in higher education; what kind of motivation is apparent when teachers decide to participate in a staff development activity; and significant differences between types of motivation regarding the effects perceived by teachers.

We can conclude that the different staff development models bring limited differences in terms of effects. The three models (Smith, 1992a, 1992b) are used in higher education. In our study the difference between the three staff development models is visible in the level of satisfaction. This difference in satisfaction seems to have no effect on the application of newly gained knowledge, skills or conceptions in practice.

Most of our respondents are aware of their own learning process during staff development sessions and respondents indicated that their conceptions changed after following staff development programmes. Moreover, it seems that teachers consider the change in conceptions of teaching as something obvious. Respondents notice a shift in conceptions to a more student-centred approach. Postareff, Lindblom-Ylänne and Nevgi (2007) and Gibbs and Coffey (2004) both used the Approaches to Teaching Inventory (Prosser \& Trigwell, 1999) to study the impact of staff development on teachers' behaviour. Both studies concluded that the teaching of teachers who participated in staff development programmes had more studentfocused features.

With a reform minded teacher certificate program Addy and Blanchard (2010) attempt to reach more student centered teaching. A conclusion of the study of Addy and Blanchard (2010) is that bottom up reform is problematic if curriculum redesign is not taken into account. The participants of the study were limited by the 
structure of the course they were teaching. The authors conclude that teacher perceptions of environmental constraints can weaken the alignment of practices and beliefs (Addy \& Blanchard, 2010, p. 1068).

In contrast to the findings of Addy and Blanchard (2010), Showers and Joyce (1996) and Nasmith, Saroyan, Steinert, Lawn and Franco (1995) the majority of respondents in this study indicate that they apply their newly gained knowledge and skills in practice. This particularly refers to ICT topics. Looking for an explanation for this we note that the schools participating in the current study have implemented several ICT innovations. As a result of this, many staff development sessions are organised to address ICT. Another explanation is that it may be easier to apply the subject matter of the ICT sessions than the subject matter of other sessions. If the use of ICT could be defined as producing the new skills in a transfer environment almost identical to the learning environment we can label it as closed skills (Yelon \& Ford, 1999). The opposite is open skills. Blume, Ford, Baldwin and Huang (2010) note that with closed skills the learner often has the opportunity to apply the new skills immediately on the job. Additionally, social pressure on teachers to develop ICT skills can play a role. A final possible explanation could be that applications of ICT are easier to verify than, for example, a different perception of education. Teachers mention different effects on students. Nurrenbern, Mickiewicz and Francisco (1999) also found that students of teachers participating in staff development programmes were working together more. Brauchle and Jerich (1998), McShannon and Hynes (2005) and Sydow (1998) found, exactly as mentioned by our respondents, that students of teachers participating in staff development programmes have better learning outcomes than other students. Furthermore, we can conclude that intrinsic motivation gives more satisfaction after a staff development activity.

The result section about reasons for satisfaction specified by our respondents has practical implications. Staff developers must pay attention to transfer of learning. Transfer of training seems to be a complex item. Saks and Belcourt (2006) reported less than $50 \%$ transfer of knowledge and skills learnt at training activities. Other studies mention that only $10 \%$ of learning actually transfers to job performance (Fitzpatrick, 2001; Holton \& Baldwin, 2000; Kupritz, 2002). Cheng and Hampson (2008) see the decision role of trainees as the most important factor in the transfer process. From this viewpoint the shop-floor model has an advantage in stimulating transfer of learning to the workplace. This is an interesting hypothesis for further research.

More practical implications could be inferred from the reasons for satisfaction mentioned by the respondents of this study. The constructivism approach within staff development is a definite pro. Furthermore, information about the staff development activity must be transparent. Collaborative learning - especially in 
small groups - works well. Taking prior knowledge into account and feedback during the learning process are a must.

Respondents in our study are more satisfied when the staff developer gives away some tips, but it is debatable whether these tips contribute to teachers' conceptual change.

Previous research confirms that teachers appreciate staff development sessions more when they are practical and concrete (Joyce \& Showers, 1980; Butler, 1992), connected to their field of knowledge (Stes, Clement \& van Petegem, 2005) and finally work out as expected (Orlich, 1988). A connection to the needs and interests of participants is also mentioned by Wood, Thompson and Russel (1981) as a reason for satisfaction. Previous research also reveals the importance of exchanging experiences as an element in raising the satisfaction level (Hamilton \& Richardson, 1995; Fullan, Bennett \& Rolheiser-Bennett, 1990). In our study, change in conceptions is lowest within the management model and highest within the shopfloor model. In this process the decision role of trainees also seems to be an important factor.

The results indicate that the management model is used most often in higher education. In the study by Smith $(1992 a, 1992 b)$ it is indicated that little attention to personal interests is a reason for dissatisfaction with staff development activities based on the management model. In our study, almost all respondents are at least more or less satisfied after following activities based on the management model. The lack of ownership (Fullan, 2003) in the management model does not seem to be a disturbing factor in our study. Extrinsic motivation, however, is only reported when the management model is used. The (indirect) obligation to participate in staff development activities could explain extrinsic motivation.

Our study leads us to believe, contrary to Smith (1992a, 1992b), that teachers can handle the responsibility for identifying their own needs and suggesting actions to meet these needs. No respondents were dissatisfied after following a shop-floor model staff development session and the percentage of intrinsic motivation is highest within the shop-floor model. When teachers are responsible for staff development initiatives (shop-floor model) conceptions of teaching have changed the most. Perhaps the initiative starts with the personal question 'How must I teach, and why?'. The personal answer to this question has consequences for subjective educational theory (Kelchtermans \& Ballet, 2002).

Especially when teachers are taking initiatives (shop-floor model) an impact could be observed on the students. From a constructivist point of view we can assume that shop-floor model staff development activities result in the most effective learning by the teacher. The will to know is surely an important characteristic of a constructivist vision on learning.

Whether changes in conceptions occur after improvement of knowledge and skills or vice versa can be questioned. The literature reveals the following two 
perspectives. Fitch and Kopp (1990) see improved instruction as the primary purpose of staff development. Effective staff development should thus constantly focus on this goal. Therefore it should build common knowledge and concepts and contain clear objectives which are linked to what should be learned in classroom practice. Furthermore, the desired changes must be turned into conceptions and in turn these must be translated into specific behaviours. This can be seen in contrast to Guskey (1986) and Eley (2006) who see changes in teachers' conceptions only after the implementation of new methods, new skills and knowledge. Kirkpatrick's model is a taxonomy characterised by the hierarchical composition of the four levels. Effects on higher levels are preceded by effects on lower levels. For Kirkpatrick, change in attitude is level two and change in behaviour is level three. On the hierarchical construction of Kirkpatrick's model is critique (Holton, 1996). Positive effects on higher levels do not always accompany effects on lower levels. The effects on lower levels are not a necessary condition for effects on higher levels. In our study, more respondents apply newly acquired knowledge and skills than changes in conceptions are mentioned. The theory of Guskey (1986) and Eley (2006) could give an explanation. Perhaps change in conceptions comes after implementation of new skills and knowledge. This brings us to an interesting idea for further research. Interviews or focus groups with the respondents could elucidate this recurring question.

In our study, we do not differentiate between on-the- job and off-the-job staff development initiatives. Further research on perceptions regarding the three staff development models could integrate this difference in intervention design.

In these two schools for higher education the staff development policy was highly developed. We can ask ourselves what effects we could measure in institutions where staff development is not as developed. In our study, no statement can be made about causal links, and it would be interesting to research the causal connections between these perceived effects. Studies to optimise staff development and to explore opportunities for teachers to develop themselves are still needed.

Several limitations of the current study should be mentioned. This study sought the perceptions of the teacher. Therefore we relied on the self-report of the teachers. Further research using observation methods, portfolios of teachers and student focus groups linking to the current findings could give additional interesting information on staff development. Knowledge, skills and conceptions were not evaluated before the staff development activities took place. This is because the goal of this study was not to evaluate a particular staff development programme. With this study we wanted to understand perceptions of teachers affecting the three different types of staff development defined by Smith. With this expanded view on perceptions on staff development we want to support and encourage the continuous professionalisation of teachers. 


\section{References}

Addy, T. M., \& Blanchard, M. R. (2010). The problem with reform from the bottom up: instructional practices and teacher beliefs of graduate teaching assistants following a reform-minded university teacher certificate program. International Journal of Science Education, 32(8), 1045-1071.

Blume, B.D., Ford, J.K., Baldwin, T.T., \& Huang, J.L. (2010). Transfer of training: A meta-analytic review..Journal of Management, 36(4), 1065-1105.

Brauchle, P.E., \& Jerich, K.F. (1998). Improving instructional development of industrial technology graduate teaching assistants. Journal of Industrial Teacher Education, 35, 67-92.

Butler, J. A. (1992). Staff development [Online]. Retrieved from http://www.nwrel.org/scpd/sirs/6/cu12.html [2006]

Candy, P.C. (1991). Self-direction for lifelong learning. A comprehension guide to theory and practice. San Francisco, CA: Jossey-Bass.

Cheng, E.W.L., \& Hampson, I. (2008) Transfer of training: a review and insights. International Journal of Management Reviews, 10, 327-341.

Dewitt, P., Birrell, J. R., Egan, M. W., Cook, P. F., Oslund, M. F., \& Young, J. R. (1998). Professional development schools and teacher educators' beliefs: Challenges and change. Teacher Education Quarterly, 25(2), 63-80.

Eley, M.G. (2006). Teachers' conceptions of teaching and the making of specific decisions in planning to teach. Higher Education, 51(2), 191-214.

Eraut, M. (2000). Non-formal learning and tacit knowledge in professional work. British Journal of Educational Psychology, 70, 113-136.

Eraut, M., Alderton, J., Cole, G., \& Senker, P. (1998). Development of knowledge and skills in employment. Brighton: University of Sussex.

Fenstermacher, G. D., \& Berliner, D. C. (1985). Determining the value of staff development. The Elementary School Journal, 85(3), 281-314.

Fitch, M. E., \& Kopp, O. W. (1990). Staff development for the practitioner. Springfield, Illinois: Charles C. Thomas Publisher.

Fitzpatrick, R. (2001). The strange case of the transfer of training estimate. Industrial-Organizational Psychologist, 39(2), 18-19.

Fullan, M. (1990). Staff development, innovation and institutional development. In B. Joyce (Ed.), Changing school culture through staff development (pp. 3-25). Virginia: Association for Supervision and Curriculum Development.

Fullan, M. (2003). The moral imperative of school leadership. California: Corwin Press.

Fullan, M., Bennett, B., \& Rolheiser-Bennett, C. (1990). Linking classroom and school improvement. Educational Leadership, 47(8), 13-19.

Gibbs, G., \& Coffey, M. (2004). The impact of training of university teachers on their teaching skills, their approach to teaching and the approach to learning of their students. Active Learning in Higher Education, 5(1), 87-100.

Grant, G., \& Murray, C. (1999). Teaching in America: The slow revolution. Cambridge, MA: Harvard University Press. 
Greene, J.C., Caracelli, V.J., \& Graham, W.F. (1989). Toward a conceptual framework for mixed-method evaluation design. Educational Evaluation and Policy Analysis, 11(3), 255-274.

Guskey, T. R. (1986). Staff development and the process of teacher change. Educational Researcher, 15(5), 5-12.

Guskey, T.R. (1996). Exploring the relationship between staff development and improving student learning. Journal of Staff Development, 17(4), 34-38.

Hamilton, M. L., \& Richardson, V. (1995). Effects of the culture in two schools on the process and outcomes of staff development. The Elementary School Journal, 95, 367-385.

Hattie, J. (1987). Identifying the salient facets of a model of student learning: A synthesis of metaanalyses. International Journal of Educational Research, 11, 187-212.

Hattie, J. (2009). Visible learning : a synthesis of over 800 meta-analyses relating to achievement. London \& New York: Routledge, Taylor\& Francis Group.

Holton, E.F. III (1996). The flawed four-level evaluation model. Human Resource Development Quarterly, $1,5-21$.

Holton, E.F.III, \& Baldwin, T.T. (2000). Making transfer happen: An action perspective on learning transfer systems. Advances in Developing Human Resources, 2(4), 1-6.

Joyce, B., \& Showers, B. (1980). Improving in-service training: The messages of research. Educational Leadership, 37(5), 379-385.

Kelchtermans, G., \& Ballet, K. (2002). The micropolitics of teacher induction. A narrative-biographical study on teacher socialisation. Teaching and Teacher Education, 18, 105-120.

Kirkpatrick, D.L. (1998). Evaluating training programs: the four levels. San Francisco, CA: Benett-Koehler.

Knowles, M., Holton, E., \& Swanson, R. (1998). The adult learner (5th ed.). Houston, TX: Gulf Publishing.

Kupritz, V.W. (2002). The relative impact of workplace design on transfer. Human Resource Development Quarterly, 13, 427-447.

Lieberman, A. (1996). Practices that support teacher development: Transforming conceptions of professional learning. In M. W. Mc Laughlin \& I. Oberman (Eds.), Teacher learning. New policies, new practices (pp. 185-201). New York, NY: Teachers College.

Main, A. (1985). Educational staff development. London: Croom Helm.

McShannon, J., \& Hynes, P. (2005). Student achievement and retention: Can professional development programs help faculty GRASP it? Journal of Faculty Development, 20(2), 87-94.

Nasmith, L., Saroyan, A., Steinert, Y., Lawn, N., \& Franco, E. D. (1995). Long-term impact of faculty development workshops. Report of McGill University, Canada.

Nurrenbern S. C., Mickiewicz, J. A., \& Francisco, J. S. (1999). The impact of continuous instructional development on graduate and undergraduate students. Journal of Chemical Education, 76(1), 114119.

Orlich, D.C. (1988). A handbook for staff development. lowa: Kendall.

Postareff, L., Lindblom-Ylänne, S., \& Nevgi, A. (2007). The effect of pedagogical training on teaching in higher education. Teaching and Teacher Education, 23, 557-571.

Prosser, M., \& Trigwell, K. (1999). Understanding learning and teaching. The experience in higher education. Suffolk: Society for Research into Higher Education \& Open University Press. 


\section{CHAPTER 3}

Richardson, V. (1990). Significant and worthwhile change in teaching practice. Educational Researcher, 19(7), 10-18.

Roelofs, E. (1992). Teamgerichte nascholing en coaching. Een experimentele studie in scholen met combinatieklassen. [Team-focused refresher courses and coaching. An experimental study in colleges with combination classes]. Nijmegen: Universiteitsdrukkerij.

Saks, A. M., \& Belcourt, M. (2006). An investigation of training activities and transfer of training in organizations. Human Resource Management, 45, 629-648.

Showers, B., \& Joyce, B. (1996) The evolution of peer coaching. Educational Leadership, 53, 12-16.

Smith, G. (1992a). A categorisation of models of staff development in higher education. British Journal of Educational Technology, 23(1), 39-47.

Smith, G. (1992b). Responsibility for staff development. Studies in Higher Education, 17(1), 27-41.

Sparks, D., \& Loucks-Horsley, S. (1990). Models of staff development. In W. R. Houston (Ed.), Handbook of research on teacher education (pp. 234-250). New York, NY-London: MacMillan.

Steinert, Y., Mann, K., Centeno, A., Dolmans, D. H. J. M., Spencer, J., Gelula, M., \& Prideaux, D. (2006). A systematic review of faculty development initiatives designed to improve teaching effectiveness in medical education: BEME Guide No.8. Medical Teacher, 28, 497-526.

Stes, A., Clement, M., \& van Petegem, P. (2005). Langetermijneffecten van een onderwijskundig professionaliseringstraject. [Long-term effects of educational professionalization courses]. Tijdschrift voor Hoger Onderwijs, 4, 254-263.

Stes, A., Min-Leliveld, M., Gijbels, D., \& Van Petegem, P. (2010). The impact of instructional development in higher education: The state-of-the-art of the research. Educational Research Review, 5(1), 25-49.

Sydow, D. L. (1998). Outcomes of the VCCS professional development initiative: 1993-1998. Big Stone Gap, VA: Mountain Empire Community College.

Van Eekelen, I.M., Vermunt, J.D., \& Boshuizen, H.P.A. (2006). Exploring teachers' will to learn. Teaching and Teacher Education, 22, 408-423.

Wood, F., Thompson, S., \& Russel, F. (1981). Designing effective staff development programs. In B. DillonPeterson (Ed.), Staff development / Organizational development (pp.54-76). Washington, DC: ASCD.

Yelon, S.L., \& Ford,, J.K. (1999). Pursuing a multidimensional view of transfer. Performance Improvement Quarterly, 12, 58-78. 
Chapter 4

Teachers' perceptions of teaching portfolios in higher education: Content, conceptions and attitudes 


\section{Introduction}

Teaching that responds to human diversity requires a wide range of teaching strategies. These strategies are activated by sophisticated judgements which are grounded in disciplined experimentation, insightful interpretation of often ambiguous events and continuous reflection. Teaching aims to diagnose and make use of variability, rather than implement uniform techniques or routines (DarlingHammond \& Snyder, 2000).

Therefore, learning from everyday practice has become increasingly important in the evolution of teaching (Stokking, Leenders, de Jong, \& Van Tartwijk, 2003). Reflecting on everyday practice gives teachers the capacity to steer their own development (Korthagen, 2001; Mansvelder-Longayroux, Beijaard, \& Verloop, 2007; Schön, 1983). In order to learn, teachers need guided and sustained opportunities to reflect on their practice and to consider and try out alternatives (Van Eekelen, Boshuizen, \& Vermunt, 2005). A teaching portfolio is an instrument with which to scaffold this guidance (Borko, Michalec, Timmons, \& Siddle, 1997). It seems to be a good tool with which to comprehend the complexity of teaching practices. Formative assessment seems to be a logical purpose of a teaching portfolio. On the other hand, portfolios could be a tool for summative assessment as well (Smith \& Tillema, 2007; Tillema \& Smith, 2007). If portfolios are used for summative purposes, it is important that teachers know in advance which aspects of their portfolio will be evaluated (De Rijdt, Tiquet, Dochy, \& De Volder, 2006). The form of assessment should be chosen according to the objectives the teaching portfolios are intended to achieve (Meeus, Van Looy \& Van Petegem, 2006).

In order to create a shared vision, we present a definition of a teaching portfolio:

A teaching portfolio is a purposeful collection of evidence, consisting of descriptions, documents and examples of what is good teaching for the teacher. Moreover, it contains reflections upon one's educational practice (including illustrations of its complexity). Such a teaching portfolio can be managed by the teacher himself or by a central internal authority. Using a teaching portfolio, the teacher passes through a learning process aiming at improving the individual and institutional quality (De Rijdt et al., 2006).

Putting together a teaching portfolio costs time and energy. Therefore, a feeling of ownership is important in order to make a teaching portfolio work. Participants' feeling of ownership of the programme is an important component of successful professional development (O'Hara \& Pritchard, 2008). Freedom in deciding what information to put in a teaching portfolio and how to do so contributes to this 
feeling of ownership (Borko et al., 1997). In addition, insight into teachers' conceptions of teaching portfolios can contribute to this feeling of ownership.

With the purpose of contributing to this feeling of ownership, it is interesting to study teachers' perceptions of the content of a teaching portfolio. In the educational literature, two content components of a teaching portfolio are distinguished: artefacts of evidence and reflective analysis.

\section{Content of a teaching portfolio}

\section{Artefacts of evidence}

Wray (2008) concludes that the selection of artefacts and the process of turning these artefacts into warranted evidence is a useful tool for helping novice teachers to find their identity as a teacher. Artefacts provide information about educational practice and document the substance of reflective analyses. If a teaching portfolio is used for summative evaluation, the contents are often a standard requirement of the educational institution, the aim of which is to create a common standard in order to facilitate the evaluation of teachers' performance. Using a teaching portfolio as an instrument of formative evaluation offers more flexibility in the choice of artefacts (Powell, 2000).

When putting together a teaching portfolio, teachers should avoid the pitfall of creating a portfolio that is nothing more than a hodgepodge of artefacts. After all, a teaching portfolio is not an archive of all possible documentation. It should be representative and selective. Teachers could decide to use only the best examples of applied class preparations, learning methods, chosen learning topics, etc. in order to show that they are competent professionals. However, they may also choose to incorporate an artefact which - at first sight - seems negative, but which could be really interesting as it illustrates a critical incident that has contributed to an improvement in educational quality. Reflective analysis on this critical incident is a learning process.

\section{Reflective analysis}

It is not sufficient for teachers to include artefacts in their teaching portfolios: a portfolio should also include their reflections on educational practice. Reflection within portfolios gives teachers the opportunity to learn about their own learning process. Such a process promotes teachers' awareness of their knowledge of practice (Wray, 2008). Reflective analyses are used to present a teacher's philosophy of teaching and education. This philosophy of teaching and education demonstrates the teacher's vision of his or her own educational practice and education in general. This philosophy of teaching can be compared to concepts such as subjective educational theory (Kelchtermans, 2009), teacher identity (Lasky, 2005), professional identity (Korthagen, 2003), implicit theory (Clark \& Peterson, 
1986) and the understanding of the professional self (Kelchtermans, 2005). It is important that teachers explicate their philosophy of teaching and education, because a teacher's thinking will determine his or her actions. When teachers articulate their subjective theory of education for themselves, they often become aware of possible causes that determine their own methods of teaching. This awareness grows as a teacher regularly reflects on his or her educational practice. Ouellett (2007) has appointed teachers' teaching philosophy as the key element of the portfolio.

\section{Conceptions of a teaching portfolio}

Conceptions play an unequivocal role in contributing to teachers' feeling of ownership. Conceptions are described as the relationship between an individual and a particular task and context. They are not stable entities within cognitive structures. They are dynamic and depend on the particular task and context in which they are being studied. They can nevertheless be identified within a context and then de-contextualised. One can then expect to find them again in a broadly similar context (Prosser, Trigwell, \& Taylor, 1994). An association between teachers' conceptions and their teaching practices has been confirmed (Ho, Watkins, \& Kelly, 2001; Kember \& Kwan, 2000; Prosser, Martin, Trigwell, Ramsden, \& Lueckenhausen, 2005; Trigwell, Prosser, \& Waterhouse, 1999). Moreover, teachers' conceptions affect the way in which they respond to staff development. In order to be successful, staff development must also assess and address teachers' conceptions (Lotter, Harwood, \& Bonner, 2007). Therefore, conceptions may influence a teacher's willingness to integrate a teaching portfolio into his or her teaching practices. Furthermore, research has shown that the impact of portfolios varies depending on individual conceptions of technology, learning and teaching (Hauge, 2006). Hence, identifying teachers' conceptions of portfolios is useful with regard to ensuring well-planned portfolio implementation.

\section{Aim and research questions}

Making teachers' perceptions of teaching portfolios explicit can contribute to wellplanned portfolio implementation, which is a vital pre-condition for obtaining optimal results (Strijbos, Meeus, \& Libotton, 2007). In the process of educational change, meaning must be accomplished at every level of the system (Fullan, 2007). Therefore, teachers' perceptions and conceptions are indispensable if we want to understand the working of teaching portfolios. As conceptions determine one's actions, the teaching portfolio implementation process will have a better chance of success if the organisation can respond to the actual conceptions of the teacher. In other words, in order to successfully implement teaching portfolios and to minimise 
the resistance to the portfolio within the organisation, it is interesting to gain information about teachers' perceptions and conceptions of teaching portfolios.

Although extensive research has documented the different forms and uses of portfolios in teacher education, research has not provided much insight into teachers' perceptions and conceptions of portfolios. Therefore, this study explores what teachers in higher education consider to be the relevant content of a teaching portfolio (perceptions) and looks into teachers' conceptions of teaching portfolios. In addition, this study explores whether teachers are for or against the use of teaching portfolios. In other words, we also studied the attitudes (pro or con) of teachers towards teaching portfolios.

We specifically addressed five detailed research questions:

1. What do teachers view as being relevant information for inclusion in a teaching portfolio?

2. What are teachers' conceptions of teaching portfolios?

3. Are teachers' conceptions of teaching portfolios related to background variables, including educational institution, gender, age, years of experience, whether or not they are using a teaching portfolio, educational degree and whether they are currently working at a university or school for higher education?

4. What are teachers' attitudes (pro or con) towards teaching portfolios?

5. Do teachers' conceptions of teaching portfolios influence their attitude (pro or con) towards teaching portfolios?

\section{Methods}

\section{Subjects}

The study was conducted in four institutions of higher education. In order to answer the research questions listed above, we administered a questionnaire in order to gain data from 132 teachers.

Descriptive statistics of the 132 teachers who participated in this study are portrayed in Table 1 . These 132 participants represented a total response rate of $36 \%$. 
Table 1. Descriptive statistics of the research population

\begin{tabular}{lrr}
\hline & Characteristics of the research population & Number \\
\hline Total & A & 54 \\
Educational & B & 29 \\
institution (1) & C & 38 \\
& D & 11 \\
Educational & University & 38 \\
institution (2) & School for higher vocational education & 94 \\
Gender & Male & 59 \\
& Female & 73 \\
Age & $18-29$ & 13 \\
& $30-39$ & 20 \\
& $40-49$ & 53 \\
Years of experience & $50+$ & 46 \\
& S-5 years & 43 \\
Teaching portfolio & $>5$ years & 89 \\
user & No & 102 \\
Educational degree & Yes & 27 \\
(1) & School for higher vocational education & 28 \\
Educational degree & University & 49 \\
(2) & In non-educational subject matter (e.g. law) & 33 \\
\hline
\end{tabular}

\section{Questionnaire}

As we were interested in teachers' self-reports due to the explorative character of the study and because we wanted to reach a considerable number of teachers, data were collected by means of a questionnaire. One contact person per institution ensured that informed consent was acquired. The purpose of the questionnaire was also explained to the respondents in a letter they received together with the questionnaire.

The questionnaire consisted of five parts. The first part consisted of background questions. In the second part, our definition of a teaching portfolio was presented. The third part of the questionnaire presented a variety of artefacts and reflective documents that could be incorporated into a teaching portfolio. This potential content was derived from the literature (Berk, 1999; Burns, 1999; Hurst, Wilson, \& Kramer, 1998; Imhof \& Picard, 2009; Mansvelder-Longayroux et al., 2007; Murray, 1995; Tillema \& Smith, 2007; Van Wagenen \& Hibbard, 1998; Wolf, 1991; Wolf, 1996; Wray, 2007). The teachers were asked to indicate their level of agreement with the inclusion of specific components in a teaching portfolio on a five-point scale ranging from 'totally disagree' to 'totally agree' (perceptions). In addition to these artefacts and reflective documents, the respondents were asked to propose any additional elements which they thought should be part of a teaching portfolio. 
In the fourth part of the questionnaire, we investigated the conceptions of teachers. Therefore, teachers were asked to indicate, on a five-point scale ranging from 'totally disagree' to 'totally agree,' their level of agreement with propositions concerning teaching portfolios. These propositions were derived from the crucial literature (Berrill \& Addisson, 2010; Buckbridge, 2008; Centra, 1994; Fitzpatrick \& Spiller, 2010; Imhof \& Picard, 2009; Meyer \& Tusin, 1999; Mansvelder-Longayroux et al., 2007; Murray, 1995; Seldin, 1997; Tellez, 1996; Tillema \& Smith, 2007; Wolf, 1991; Zeichner \& Wray, 2001). Part five of the questionnaire was an open-ended question. The teachers were invited to provide their own comments on the use of teaching portfolios in higher education.

With the aim of improving the instrument, the questionnaire was first discussed with and administered to 35 students on the Master's of Educational Studies course. Based on their suggestions, one item was removed from part four (propositions) of the questionnaire.

After removing this item, part four of the questionnaire (propositions) consisted of 25 items. In order to establish relationship patterns between the dependent variables - and to explore the nature of the independent variables affecting them an explorative factor analysis using principal component analysis followed by a varimax rotation was performed on those 25 items. Based on the 5:1 ratio of participants to items, as recommended by Tabachnick and Fidell (2007), the dataset (with 132 participants to 25 items) was deemed to be suitable for factor analysis. The strength of the intercorrelations between the items was checked. The result of Bartlett's test of sphericity was significant $(p<.05)$ and the KMO index was .9. As a result of this assessment of the suitability of the data, we concluded that factor analysis could be performed.

The number of factors to be extracted was determined by eigenvalues above 1.0 and an inspection of the scree plot (Cattell, 1966). Based on these criteria, it was possible to extract three factors. Due to the cut-off criterion of factor loadings above .35 and the discrepancy of cross-loadings of .20, we removed 10 items (Nunally \& Bernstein, 1994).

Based on the factor analysis, the remaining items of part four of the questionnaire were reduced to three factors: support-oriented conceptions ( $\alpha=$ .94), career-oriented conceptions $(\alpha=.77)$ and anxiety-oriented conceptions ( $\alpha=$ 0.79). The rotated component matrix with the propositions of the three factors is presented in Table 2. All of the items had a loading of at least .67 and the three factors together explained $67 \%$ of the variance.

Five educational researchers and educational practitioners searched independently for a term that identified each factor. We reached consensus by blending these different terms that identified each factor. Subsequently, two other researchers were asked whether or not the terms were applicable. Feedback from these researchers was taken into account. 
Table 2. Rotated component matrix (Part D of the questionnaire)

\begin{tabular}{|c|c|c|c|c|}
\hline \multicolumn{2}{|c|}{ Proposition } & \multicolumn{3}{|c|}{ Component } \\
\hline & & 1 & 2 & 3 \\
\hline P17 & $\begin{array}{l}\text { Teaching portfolios have the potential to influence the quality of } \\
\text { education within the educational institution in a positive way. }\end{array}$ & .819 & & \\
\hline P19 & Teaching portfolios contribute to the quality of education. & .816 & & \\
\hline P10 & $\begin{array}{l}\text { By introducing teaching portfolios, the quality of education improves in } \\
\text { the entire faculty/institution. }\end{array}$ & .813 & & \\
\hline P24 & $\begin{array}{l}\text { A teaching portfolio stimulates reflection on the effectiveness of my } \\
\text { teaching. }\end{array}$ & .810 & & \\
\hline P5 & A teaching portfolio justifies my teaching efforts. & .806 & & \\
\hline P15 & $\begin{array}{l}\text { One effect of working with a teaching portfolio is that I receive more } \\
\text { feedback on my teaching practices. }\end{array}$ & .800 & & \\
\hline P25 & My teaching portfolio is concrete proof of my teaching qualities. & .724 & & \\
\hline P7 & A teaching portfolio is good support for performance interviews. & .713 & & \\
\hline P8 & A teaching portfolio is good support for assessment interviews. & 699 & & \\
\hline P6 & A teaching portfolio gives me a feeling of insecurity. & & .839 & \\
\hline P12 & $\begin{array}{l}\text { I am worried that a teaching portfolio will have negative consequences for } \\
\text { my teaching career. }\end{array}$ & & .784 & \\
\hline P4 & $\begin{array}{l}\text { I am worried that too many people will have access to my teaching } \\
\text { portfolio. }\end{array}$ & & .691 & \\
\hline P9 & Teaching portfolios increase competition and rivalry between colleagues. & & .667 & \\
\hline P22 & $\begin{array}{l}\text { A teaching portfolio could be a valuable instrument regarding the mobility } \\
\text { of teachers between faculties/institutions. }\end{array}$ & & & .886 \\
\hline P21 & $\begin{array}{l}\text { A teaching portfolio gives me an opportunity to express my ideas and } \\
\text { career goals. }\end{array}$ & .416 & & .766 \\
\hline
\end{tabular}

Note: Extraction method: Principal component analysis.

Rotation method: Varimax with Kaiser normalization.

Rotation converged in five iterations.

$P$ followed by a number refers to the number of the proposition on the original list.

Values marked in grey represent the highest factor loadings.

\section{Data analysis}

This study is characterised by a mixed-methods approach. Quantitative and qualitative data were obtained. Quantitative data were coded and analysed using SPSS. Descriptive statistics were used to answer research questions 1, 2 and 4 . In order to explore significant relationships between the independent and dependent variables (research questions 3 and 5 ), we used regression analysis and $t$-tests.

The qualitative data were retrieved from the voluntary parts of the questionnaire. The participants did not mention additional content (part three of the questionnaire). The qualitative data from part five of the questionnaire were used to gain a better understanding of the conceptions of the teachers. We analysed the content of the free comments from part five of the questionnaire and deduced some categories. After this, the answers and categories were studied once 
again and were classified according to the three different conceptions, as in part four of the questionnaire. Horizontal and vertical analyses were performed. Two researchers interpreted the data separately. Through reflection and discussion, they came to a consensus. Some quotations (free comments from part five of the questionnaire) will be presented as an answer to research question 2 .

\section{Results}

First, we will present the teachers' perceptions of portfolio content. This section deals with research question 1 . Then, the results concerning conceptions of teaching portfolios are presented. Research questions 2 and 3 are incorporated into this section. The final section is a report on the teachers' attitudes (pro or con) towards teaching portfolios. This part provides an answer to research questions 4 and 5.

\section{Portfolio content}

The results concerning the teachers' views on portfolio content are presented in Table 3. An overview of the goals that students must reach is the best-valued content element. Up to $92 \%$ of the respondents agreed that these goals constitute important portfolio content. Furthermore, teachers see a teaching portfolio as a good place to record the number of teaching hours and the amount of additional activities performed. Respectively, $87 \%$ and $85 \%$ of the respondents agreed with these content elements. The reports of colleagues are not really appreciated as a content element. Up to $46 \%$ of the respondents were not in favour of "reports on teachers' educational practices from a colleague" as portfolio content. In addition, the reflections of colleagues were not appreciated (52\% disagree). Furthermore, the majority of the respondents saw reports made by an external person as unnecessary when putting together a portfolio. However, our respondents did see the merit of putting into their portfolios a self-report on their teaching practices (61\% agree). In addition, $48 \%$ of the respondents thought that a self-reflection report is important when putting together a teaching portfolio. Furthermore, $76 \%$ of the respondents thought that it was important to communicate their own vision of good educational practice through their portfolio.

A lot of educational organisations are using teaching portfolios to counteract the research-minded appraisals in higher education; however, our findings concerning this area are striking. Only $14 \%$ of the respondents did not see the advantage of taking research activities into account. Only $22 \%$ of the respondents did not agree with adopting research output as a content element. Information about research activities seems to be an important element of teaching portfolios. 
Table 3. Content of the teaching portfolio

\begin{tabular}{|c|c|c|c|c|c|c|c|}
\hline \multicolumn{3}{|c|}{$\begin{array}{l}\text { What should and should not be included in a } \\
\text { teaching portfolio? }\end{array}$} & \multirow{2}{*}{$\begin{array}{r}\text { Disagree } \\
\% \\
1.5\end{array}$} & \multirow{2}{*}{$\begin{array}{r}\text { Rather } \\
\text { disagree } \\
\% \\
6.1\end{array}$} & \multirow{2}{*}{$\begin{array}{r}\text { No } \\
\text { opinion } \\
\% \\
5.3\end{array}$} & \multirow{2}{*}{$\begin{array}{r}\text { Rather } \\
\text { agree } \\
\% \\
17.6\end{array}$} & \multirow{2}{*}{$\begin{array}{r}\text { Totally } \\
\text { agree } \\
\% \\
69.5\end{array}$} \\
\hline 1. & Number & f teaching hours & & & & & \\
\hline \multirow[t]{4}{*}{2.} & Addition & activities: & 1.9 & 2.9 & 10.5 & 30.5 & 54.3 \\
\hline & a) & Meetings & 7.1 & 6.3 & 13.4 & 26 & 47.2 \\
\hline & b) & Supervising practical training & 4.0 & 3.2 & 9.6 & 24.8 & 58.4 \\
\hline & c) & $\begin{array}{l}\text { Attending training sessions } \\
\text { (internal or external) }\end{array}$ & 3.1 & 3.9 & 13.4 & 29.9 & 49.6 \\
\hline 3. & \multicolumn{2}{|c|}{ Content of courses } & 7.0 & 9.4 & 6.3 & 36.7 & 40.6 \\
\hline 4. & \multicolumn{2}{|c|}{$\begin{array}{l}\text { Didactical materials used during courses } \\
\text { (illustrations, presentation materials, video, } \\
\text { etc.) }\end{array}$} & 16.2 & 13.1 & 12.3 & 28.5 & 30.0 \\
\hline 5. & \multicolumn{2}{|c|}{$\begin{array}{l}\text { The teacher's own vision of good educational } \\
\text { practice }\end{array}$} & 9.2 & 2.3 & 13.0 & 35.9 & 39.7 \\
\hline 6. & \multicolumn{2}{|c|}{$\begin{array}{l}\text { Goals that students should achieve through } \\
\text { the teacher's educational practice }\end{array}$} & 2.3 & 4.7 & 0.8 & 29.5 & 62.8 \\
\hline \multirow[t]{5}{*}{7.} & \multicolumn{2}{|c|}{$\begin{array}{l}\text { A report on the teacher's educational practice } \\
\text { over a period of one semester } \\
\text { from: }\end{array}$} & 19.4 & 15.3 & 20.8 & 16.7 & 27.8 \\
\hline & a) & The teacher & 10.7 & 5.7 & 23.0 & 31.1 & 29.5 \\
\hline & b) & Students & 8.2 & 7.4 & 16.4 & 32.8 & 35.2 \\
\hline & c) & Colleagues & 23.3 & 22.4 & 33.6 & 17.7 & 6.0 \\
\hline & d) & External sources & 23.3 & 19.0 & 34.5 & 16.4 & 6.9 \\
\hline 8. & \multicolumn{2}{|c|}{ Curriculum vitae } & 15.2 & 15.9 & 22.0 & 19.7 & 27.3 \\
\hline \multirow[t]{5}{*}{9.} & \multicolumn{2}{|c|}{$\begin{array}{l}\text { Reflection report (formal and/or informal) on } \\
\text { a lesson }\end{array}$} & 21.8 & 17.9 & 21.8 & 24.4 & 14.1 \\
\hline & a) & The teacher & 16.5 & 14.9 & 20.7 & 29.8 & 18.2 \\
\hline & b) & Students & 20.2 & 12.6 & 21.8 & 26.1 & 19.3 \\
\hline & c) & Colleagues & 31.3 & 20.9 & 32.2 & 11.3 & 4.3 \\
\hline & d) & External sources & 29.3 & 21.6 & 33.6 & 11.2 & 4.3 \\
\hline \multicolumn{3}{|c|}{ 10. A few assignments done by students } & 21.5 & 12.3 & 13.1 & 38.5 & 14.6 \\
\hline \multicolumn{3}{|c|}{ 11. A few exams taken by students } & 17.7 & 12.3 & 13.8 & 36.2 & 20.0 \\
\hline \multicolumn{3}{|c|}{ 12. Resear } & 6.2 & 7.7 & 23.1 & 36.9 & 26.2 \\
\hline \multicolumn{3}{|c|}{ 13. Research output, e.g., publications } & 10.9 & 10.9 & 26.4 & 27.1 & 24.8 \\
\hline
\end{tabular}

\section{Conceptions of teaching portfolios}

Most of our respondents benefitted from the support of a teaching portfolio; support-oriented conceptions attained the highest scores (mean $=3.5$; $\mathrm{SD}=.9$ ). Teachers with support-oriented conceptions realize that a teaching portfolio contributes to development. The following quotations illustrate the supportoriented conceptions of the respondents: 
A teaching portfolio can contribute to the quality of our education (T90, T91). A teaching portfolio really has a value in education, but only if it is wellimplemented (T126, T74).

The opinion of the students as a part of the teaching portfolio really contributes to developing good teaching (T8). A self-evaluation is an important part of the teaching portfolio. Together with a good survey of the students, this can really lead to better educational quality (T11).

Reflection is important for a teacher (T19, T26, T46).

A teaching portfolio can contribute to the quality of our education. Therefore, it is important that, as well as individual goals, a teaching portfolio must serve organisational goals (T7).

A teaching portfolio is a good instrument to support performance and assessment interviews (T32, T114).

A teaching portfolio can bring teachers together (T121).

Anxiety-oriented conceptions (mean $=2.6$; SD $=.9$ ) were also recognised by our respondents. Teacher with anxiety-oriented conceptions are worried about the workload and the negative consequences that a teaching portfolio could bring. The following quotations illustrate the anxiety-oriented conceptions of the respondents:

Putting together a teaching portfolio costs a lot of time and effort (T5, T44, T47, T52, T55, T123, T74, T79). I am worried that a teaching portfolio will create a large administrative burden (T92, T97). If a teaching portfolio is used as a document holder, it has no value (T11, T128).

The workload of teachers is very high. A teaching portfolio is an extra burden for a teacher. I just want to teach. Leave us alone (T14, T62).

I am worried that a teaching portfolio brings too many rules. Freedom in the process of putting together a teaching portfolio is very important (T26, T33, T55, T116, T122, T75).

Too many educational innovations are not contributing to the quality of education (T34).

The perceptions of students are not always objective. I am worried that those evaluations carry too much weight in the portfolio process (T35, T75, T91).

I am worried about who has access to my teaching portfolio. The integrity and objectivity of the persons involved is very important (T40, T46, T50, T55, T63, T90, T91).

If a teaching portfolio is only used for evaluation purposes, it will lead to rivalry among colleagues (T45). The focus on quality assurance in education brings uncertainty and agitation (T68). 
Good communication in the organisation, loyalty and collegiality are important conditions for making a teaching portfolio work (T88).

I am worried about the hidden goal of working with a teaching portfolio. Maybe it will be used for reorganisation (T59).

Teachers with career-oriented conceptions witness how a teaching portfolio can steer their career. Career-oriented conceptions (mean $=2.8 ; \mathrm{SD}=.9$ ) were not mentioned following the open-ended question in part five of the questionnaire.

Teachers' conceptions of teaching portfolios are not significantly related to the background characteristics of the teachers ( $t$-test). Teachers' conceptions of teaching portfolios are not defined by educational institution, gender, age, years of experience, whether or not they are using a teaching portfolio, educational degree or whether they are currently working at a university or school for higher education.

\section{Attitudes (pro or con) towards teaching portfolios}

The majority of our respondents (76\%) had a positive attitude towards teaching portfolios. Only $24 \%$ of the respondents considered teaching portfolios to be redundant.

A logistic regression analysis was conducted with 'attitude (binomial variable; pro or con) towards teaching portfolios' as the dependent variable and three independent variables; support-oriented conceptions, anxiety-oriented conceptions and career-oriented conceptions. A backward stepwise regression analysis was conducted to determine the final model. The resulting model contained only support-oriented conceptions as a predictor of the attitude towards teaching portfolios (OR $=5.866, p=.000)$. For this model see Table 4 .

This means that if the supportive function of teaching portfolios is acknowledged, and if guidance is offered in order to develop this function, the attitude towards portfolios will be more pro. Hence, the portfolio implementation process may have a greater chance of success.

Table 4. Backward stepwise regression of attitude towards portfolios on support-oriented conceptions

\begin{tabular}{llrrrrrr}
\hline \multicolumn{7}{c}{ Variables in the Equation } \\
\hline \multirow{2}{*}{ Step 1} & B & S.E. & Wald & df & Sig. & $\operatorname{Exp(B)}$ \\
& $\begin{array}{l}\text { Support-oriented } \\
\text { conceptions } \\
\text { Constant }\end{array}$ & 1.769 & .357 & 24.585 & 1 & .000 & 5.866 \\
& & -4.683 & 1.176 & 15.870 & 1 & .000 & .009 \\
\hline
\end{tabular}

Note: Variable(s) entered on step 1: factor1. 


\section{Conclusion and discussion}

This study explores what teachers in higher education consider to be the relevant content of a teaching portfolio and looks into teachers' conceptions and attitudes (pro or con) towards teaching portfolios.

In summarising our findings on the content of teaching portfolios, we can state that teachers find self-reports and self-reflections to be important, but do not value the reports of their colleagues. The respondents saw it as important to communicate their own vision of good educational practice through their portfolio. Teachers are aware of subjective educational theory (Clark \& Peterson, 1986; Kelchtermans, 2005; Kelchtermans, 2009; Korthagen, 2003; Lasky, 2005). Furthermore, information about research activities is an important part of teaching portfolios.

Teachers have support-oriented conceptions, career-oriented conceptions and anxiety-oriented conceptions of the use of teaching portfolios. These perceptions are not related to the background characteristics of the participants. Most of the teachers had a positive attitude towards teaching portfolios. Support-oriented conceptions seem to influence teachers' attitudes towards teaching portfolios.

The literature suggests that a portfolio itself probably does not control the quality of reflection, but that discussions and cooperation with others are very important (Orland-Barak, 2005; Wray, 2007). Our results show that cooperation is not always valued, e.g., a report on the teacher's educational practice over a period of one semester from colleagues or a reflection report (formal and/or informal) on a lesson from colleagues is not really an appreciated content element. In addition, the majority believed that reports made by an external person are unnecessary in a portfolio. It is possible that these reactions are based on anxiety. The quotations regarding anxiety-oriented conceptions confirm this assumption.

The agreement that information about research activities constitutes important teaching portfolio content leads us to assume that educational careers are still the exception in higher education. Research activities are still seen as more important than teaching activities. We can conclude that a teaching portfolio could be a good instrument to be a counteract to the research-minded appraisals in higher education. However, a good instrument alone is not enough to make a change. Much more than a good instrument is needed.

Our instrument measured three different conceptions of teaching portfolios. For teachers with support-oriented conceptions, a teaching portfolio can be a tool which increases self-awareness in a systematic way (Smith \& Tillema, 2003). In their review, Mann, Gordon and MacLeod (2009) state that reflective thinking may develop in association with certain interventions. The implementation of a teaching portfolio provides a forum and a stimulus for reflective thinking (Beecher, Lindmann, Mozinski, \& Simpson, 1997). A teaching portfolio can help teachers with 
the process of reflection (LaBoskey, 2000; Lally, 2000; Smith \& Tillema, 2001). A teaching portfolio could include reflections from before, during and after teaching practice. The ability to reflect on action whilst doing something can be mirrored in a teaching portfolio (Schön, 1987; Schön, 1983). A teaching portfolio could provide structure to initiatives for the improvement of a teacher's teaching practices (LaBoskey, 2000; Lally, 2000; Smith \& Tillema, 2001). As a teaching portfolio makes efforts made in educational practice visible and available for discussion, a teacher could receive personal feedback from, for instance, a supervisor. A teaching portfolio can help to provide evidence of the efforts, progress and performance of a teacher (Järvinen \& Kohonen, 1995). A teaching portfolio is a tool that can be connected to constructivist learning theory (Imhof \& Picard, 2009; Smith \& Tillema, 2003). A teaching portfolio can help teachers to construct their identity as a teacher (Berrill \& Addison, 2010). Teachers who know and make use of their strengths and weaknesses are better educators. A teaching portfolio could support the teacher and can influence the quality of education within the educational institution in a positive way. Murray (1995) found that teaching portfolios can improve the quality of education provided by individual teachers as well as by the educational institution.

The study by Berrill and Addisson (2010) supports the implication of our findings, which is that if the supportive function of a teaching portfolio is acknowledged and if guidance is offered in order to develop this function, then the portfolio implementation process has a greater chance of success. Berrill and Addisson (2010) investigated teachers' perceptions of portfolios. They asked novice teachers whether the teaching portfolio (the process or the product) helped them: (1) to construct their identity as a teacher; (2) to get a job; (3) in teacher performance appraisals; and (4) in career development. The majority of the teachers who participated in Berrill and Addison's (2010) study claimed that the teaching portfolio was a powerful tool in supporting the construction of their identity as teachers.

For teachers with career-oriented conceptions, a teaching portfolio could be an instrument for steering their career. A teaching portfolio could be an attractive and customised collection of information given by teachers to their current or prospective employers (Frederick, McMahon, Shaw, \& Edward, 2000; Hurst et al., 1998; Lally, 2000; Ouellett, 2007; Wolf \& Dietz, 1998). Teaching portfolios could be used for promotions or job applications, and they could be a significant component of higher education certification programmes (Fitzpatrick \& Spiller, 2010).

As a teaching portfolio could disturb teachers' routines or push them out of their comfort zone, anxiety-oriented conceptions are understandable. When teachers learn new ways of becoming better educators, they have to challenge the personal assumptions which underpin their teaching practice. In doing so, teachers are putting their professional identity at risk. Emotionality is inherent in such a 
development process (Hargreaves, 1998). This process involves feelings of disturbance, insecurity and vulnerability. These experiences are often accompanied by emotions such as fear, anxiety and shame (Day \& Leitch, 2001; Hargreaves, 1998; Sachs, 1997). The results of the study by Imhof and Picard (2009) show that preservice teachers were concerned that their supervisors and mentors had access to their portfolios. Fitzpatrick and Spiller (2010) studied the emotions of a group of tertiary teachers during the compilation of teaching portfolios as a professional development activity. They found that producing a portfolio evoked a range of complex emotions. Recurrent themes in the results of this study could be categorised as uncertainty generated by the multiple purposes of the portfolio and emotional destabilisation experienced in the process of taking stock of oneself as a teacher (Fitzpatrick \& Spiller, 2010, p. 177). Buckridge (2008) argues that a portfolio, when separated from the pressure to make and defend claims, can be - without a doubt - an excellent instrument for supporting and encouraging development.

One could assume that negative emotions could inhibit learning and limit progress. However, negative emotions will not only have a negative effect on learning, just as positive emotions will not only have a positive effect on learning (Fitzpatrick \& Spiller, 2010). Fitzpatrick and Spiller (2010) shed light on how little we know about the way in which emotions affect the impact of professional development, which emotions are most beneficial, which are most detrimental and how emotions could be managed for success during professional development. Buckbridge (2008) maintains that a mechanism for using a portfolio for summative purposes can actively limit progressive potential. Our results give an initial indication that anxiety-oriented conceptions do not have the same effect. Anxietyoriented conceptions do not have a statistically significant relationship with participants' attitudes towards teaching portfolios.

Several limitations of the current study should be mentioned. Regarding the generalisation of the findings, it would have been better to have more respondents. This study assessed the perceptions and conceptions of teachers. Therefore, we relied on teachers' self-reports. Further research on the current findings using interviews or focus groups could provide additional interesting information.

It would be an interesting goal for further research to find out the extent to which guidance, supervision and peer learning play a beneficial role in learning through the portfolio process and the way in which these stimuli are reflected in the conceptions of teachers. Furthermore, it would be interesting to gain a deeper understanding of the conceptions presented and studied in the current article using narrative research methods.

Concluding, teaching portfolios are useful instruments in staff development. When aiming towards a more holistic approach to staff development, one should first consider teachers' perceptions and conceptions before implementing teaching portfolios. The study by Hauge (2006) revealed that the impact of portfolios varied 
depending on individuals' conceptions of technology, learning and teaching. Norton et al. (2005) stated that development will come about only by addressing teachers' underlying conceptions. Teachers' conceptions determine their actions (Korthagen, 2004). As conceptions are highly resistant to change, an expanded view of perceptions and conceptions of teaching portfolios is needed. Therefore, the expanded view of teachers' perceptions and conceptions of teaching portfolios which has resulted from this study might be useful for the successful implementation of teaching portfolios as an educational innovation. In accordance with O'Hara and Pritchard (2008) and Zeichner and Wray (2001), this study emphasises the importance of a feeling of ownership in the portfolio process. Taking perceptions and conceptions into account can contribute to this vital feeling of ownership.

\section{References}

Beecher, A., Lindemann, J., Morzinski, J., \& Simpson, D. (1997). Use of the educator's portfolio to stimulate reflective practice among medical educators. Teaching and Learning in Medicine, 9, 56-59.

Berk, R. A. (1999). Assessment for measuring professional performance. In D. P. Ely, L. E. Odenthal \& T. Plomp (Eds.), Educational science and technology: Perspectives for the future (pp. 30-48). Twente: University Press.

Berrill, D. P., \& Addisson, E. (2010). Repertoires of practice: Re-framing teaching portfolios. Teaching and Teacher Education, 26(5), 1178-1185.

Borko, H., Michalec, P., Timmons, M., \& Siddle, J. (1997). Student teaching portfolios: A tool for promoting reflective practice. Journal of Teacher Education, 48(5), 345-356.

Buckbridge, M. (2008). Teaching portfolios: Their role in teaching and learning policy. International Journal for Academic Development, 13(2), 117-127.

Burns, C. W. (1999). Teaching portfolios and the evaluation of teaching in higher education: Confident claims, questionable research support. Studies in Educational Evaluation, 25, 131-142.

Cattell, R. B. (1966). The screen test for the number of factors. Multivariate Behavioral Research, 1, 140161.

Centra, J. A. (1994). The use of the teaching portfolio and student evaluations for summative evaluation. Journal of Higher Education, 65(5), 555-570.

Clark, C. M., \& Peterson, P. L. (1986). Teachers' thought processes. In M. C. Wittrock (Ed.), Handbook of research on teaching (pp. 255-296). NY: Macmillan Publishing Company.

Darling-Hammond, L., \& Snyder, J. (2000). Authentic assessment of teaching in context. Teaching and Teacher Education, 16, 523-545.

Day, C., \& Leitch, R. (2001). Teachers' and teacher educators' lives: The role of emotion. Teaching and Teacher Education, 17(4), 403-415.

De Rijdt, C., Tiquet, E., Dochy, F., \& Devolder, M. (2006). Teaching portfolios in higher education and their effects: An explorative study. Teaching and Teacher Education, 22, 1084-1093. 
FitzPatrick, M. A., \& Spiller, D. (2010). The teaching portfolio: Institutional imperative or teacher's personal journey? Higher Education Research \& Development, 29(2), 167-178.

Frederick, L., McMahon, R., Shaw, J. R., \& Edward, L. (2000). Preservice teacher portfolios as autobiographies. Education, 120(4), 634-638.

Fullan, M. (2007). The new meaning of educational change (4th ed.). New York: Teachers College Press.

Hargreaves, A. (1998). The emotional practice of teaching. Teaching and Teacher Education,14(8), 835854.

Hauge, T. E. (2006). Portfolios and ICT as means of professional learning in teacher education. Studies in Educational Evaluation, 32(1), 23-36.

Ho, A., Watkins, D., \& Kelly, M. (2001). The conceptual change approach to improving teaching and learning: An evaluation of a Hong Kong staff development programme. Higher Education, 42(2), 143-169.

Hurst, B., Wilson, C., \& Cramer, G. (1998). Professional teaching portfolios: Tools for reflection, growth, and advancement. Phi Delta Kappan, 79(8), 578-582.

Imhof, M., \& Picard, C. (2009). Views on using portfolio in teacher education. Teaching and Teacher Education, 25, 149-154.

Järvinen, A., \& Kohonen, V. (1995). Promoting professional development in higher education through portfolio assessment. Assessment \& Evaluation in Higher Education, 20(1), 25-36.

Kelchtermans, G. (2005). Teachers' emotions in educational reforms: Self-understanding, vulnerable commitment and micropolitical literacy. Teaching and Teacher Education, 21(8), 995-1006.

Kelchtermans, G. (2009). Who I am in how I teach is the message. Self-understanding, vulnerability and reflection. Teachers and Teaching: Theory and Practice, 15(2), 257-272.

Kember, D., \& Kwan, K. (2000). Lecturers' approaches to teaching and their relationship to conceptions of good teaching. Instructional Science, 28, 469-490.

Korthagen, F. A. (2001). A reflection on reflection. In F. A. Korthagen (Ed.), Linking practice and theory: The pedagogy of realistic teacher education (pp. 51-68). Mahwah, NJ: Lawrence Erlbaum Associates.

Korthagen, F. A. (2003). In search of the essence of a good teacher: Toward a more holistic approach in teacher education. Teaching and Teacher Education, 20, 77-97.

LaBoskey, V. (2000). Portfolios here, portfolios there... Searching for the essence of 'educational portfolios.' Phi Delta Kappan, 81(8), 590-595.

Lally, A. (2000). Teaching portfolios and the continuous improvement of teaching. Art Documentation, 19(1), 48-49.

Lasky, S. (2005). A sociocultural approach to understanding teacher identity, agency and professional vulnerability in a context of secondary school reform. Teaching and Teacher Education, 21, 899-916.

Lotter, C., Harwood, W. S., \& Bonner, J. J. (2007). The influence of core teaching conceptions on teachers' use of inquiry teaching practices. Journal of Research in Science Teaching, 44, 1318-1347.

Mann, K., Gordon, J., \& MacLeod, A. (2009). Reflection and reflective practice in health professions education: A systematic review. Advances in Health Sciences Education, 14, 595-621.

Mansvelder-Longayroux, D. D., Beijaard, D., \& Verloop, N. (2007). The portfolio as a tool for stimulating reflection by student teachers. Teaching and Teacher Education, 23(1), 47-62. 
Meeus, W., Van Looy, L., \& Van Petegem, P. (2006). Portfolio in Higher Education: Time for a Clarificatory Framework. International Journal of Teaching and Learning in Higher Education, 17 (2), 127-135.

Meyer, D. K., \& Tusin, L. F. (1999). Preservice teachers' perceptions of portfolios: Process versus product. Journal of Teacher Education, 50, 131-139.

Murray, J. P. (1995). Successful faculty development and evaluation: The complete teaching portfolio. ASHE-ERIC Higher Education Report No. 8. Washington, DC: The George Washington University, Graduate School of Education and Human Development.

Nunnally, J. C., \& Bernstein, I. H. (1994). Psychometric theory (3rd ed.). New York: McGraw-Hill.

O'Hara, S., \& Pritchard, H. (2008). Meeting the challenge of diversity: Professional development for teacher educators. Teacher Education Quarterly, 35(1), 43-61.

Ouellett, M. L. (2007). Your teaching portfolio: Strategies for initiating and documenting growth and development. Journal of Management Education, 31(3), 421-433.

Orland-Barak, L. (2005). Portfolios as evidence of reflective practice: what remains 'untold', Educational Research, 47(1), 25-44.

Powell, L. A. (2000). Realizing the value of self-assessment: The influence of the business excellence model on teacher professionalism. European Journal of Teacher Education, 23(1), 37-48.

Prosser, M., Martin, E., Trigwell, K., Ramsden, P., \& Lueckhausen, G. (2005). Academics' experiences of understanding of their subject matter and the relationship of this to their experiences of teaching and learning. Instructional Science, 33, 137-157.

Prosser, M., Trigwell, K., \& Taylor, P. (1994). A phenomenographic study of academics' conceptions of science teaching and learning. Learning and Instruction, 4, 217-231.

Sachs, J. (1997). Reclaiming the agenda of teacher professionalism: An Australian experience. Journal of Education for Teaching, 23(3), 263-275.

Schön, D. A. (1983). The reflective practitioner: How professionals think in action. London: Basic Books.

Seldin, P. (1997). The teaching portfolio: A practical guide to improved performance and promotion/tenure decisions ( $2^{\text {nd }}$ ed.). Bolton, MA: Anker.

Smith, K., \& Tillema, H. H. (2001). Long term influences of portfolios on professional development. Scandinavian Journal of Educational Research, 45(2), 183-203.

Smith, K., \& Tillema, H. (2003). Clarifying different types of portfolio use. Assessment \& Evaluation in Higher Education, 28(6), 625-648.

Smith, K., \& Tillema, H. H. (2007). Use of criteria in assessing teaching portfolios: Judgmental practices in summative evaluation. Scandinavian Journal of Educational Research, 51(1), 103-117.

Strijbos, J., Meeus, W., \& Libotton, A. (2007). Portfolio assignments in teacher education: A tool for selfregulating the learning process? International Journal for the Scholarship of Teaching and Learning, $1(2)$.

Stokking, K., Leenders, F., De Jong, J., \& Van Tartwijk, J. (2003). From student to teacher: Reducing practice shock and early drop-out in the teaching profession. European Journal of Teacher Education, 26, 329-350.

Tabachnick, B. G., \& Fidell, L. S. (2007). Using multivariate statistics (5th ed.). Boston: Pearson/Allyn and Bacon. 
Tellez, K. (1996). Authentic assessment. In J. Sikula, T. J. Buttery \& E. Guyton (Eds.), Handbook of research on teacher education ( $2^{\text {nd }}$ ed., pp. 704-721). New York: Simon \& Schuster Macmillan.

Tillema, H. H., \& Smith, K. (2007). Portfolio assessment, in search of criteria. Teaching and Teacher Education, 23(4), 442-456.

Trigwell, K., Prosser, M., \& Waterhouse, F. (1999). Relations between teachers' approaches to teaching and students' approaches to learning. Higher Education, 37, 57-70.

Van Eekelen, I. M., Boshuizen, H. P. A., \& Vermunt, J. D. (2005). Self-regulation in higher education teacher learning. Higher Education, 50, 447-471.

Van Wagenen, L., \& Hibbard, K. M. (1998). Building teacher portfolios. Educational Leadership, 55(5), 2629.

Wolf, K. (1991). The schoolteacher's portfolio: Issues in design, implementation, and evaluation. Phi Delta Kappan, 73(2), 129-136.

Wolf, K. (1996). Developing an effective teaching portfolio. Educational Leadership, 32(6), 34-37.

Wolf, K., \& Dietz, M. (1998). Teaching portfolios: Purposes and possibilities. Teacher Education Quarterly, 25(1), 9-22.

Wray, S. (2008). Swimming upstream: Shifting the purpose of an existing teaching portfolio requirement. The Professional Educator, 32, 35-50.

Wray, S. (2007). Teaching portfolios, community, and pre-service teachers' professional development. Teaching and Teacher Education, 23(7), 1139-1152.

Zeichner, K., \& Wray, S. (2001). The teaching portfolio in US teacher education programs: What we know and what we need to know. Teaching and Teacher Education, 17(5), 613-621. 

Chapter 5

Teaching portfolios in higher education and their effects: An explorative study 


\section{Introduction}

During the last decade, not only learning has changed to a large extent in the direction of more co-operative learning and using authentic situations and problems as a starting point (Dochy, Segers, Van den Bossche, \& Gijbels, 2003; Gillies, 2004), but also teaching has changed and the need for monitoring teaching quality and professional development by means of portfolios has emerged (Kelchtermans, 1993; Smith \& Tillema, 2001). A teaching portfolio consists of a collection of documents and reflections about a person's teaching competences (Lally, 2000). Complementary to this, this collection must show us the efforts, the progress and the achievements of a teacher (Järvinen \& Kohonen, 1995). In the literature, teaching portfolios are seen to have several purposes. Smith and Tillema (2001) name four main purposes: documentation of performance, monitoring growth, revealing discrepancies in development, and enhancing self-responsibility. Reflective analysis and artifacts are seen as two major components of a teaching portfolio (Berk, 1999; Wolf, 1996). Järvinen and Kohonen (1995) state that a teacher is able to come to a deeper self understanding through reflection. In this way, a teaching portfolio can be seen as a vehicle for the growth and the learning of a teacher (Athanases, 1994). Järvinen and Kohonen (1995) call such further development of educational knowledge and skills the autobiography of growth. As personal development is mostly an action over time, also creating a teaching portfolio is not an activity at one particular moment in time, but a process that needs to be realised over a certain span of time (Meyer \& Tusin, 1999; Wolf, 1991; Wolf, 1996).

The way in which a teacher uses a teaching portfolio strongly depends on the objectives which are set (Centra, 1994; Zeichner \& Wray, 2001). Depending on the objectives, which people set themselves or are set by others, one can create a teaching portfolio to meet the demands of an external evaluation (Hurst, Wilson, \& Cramer, 1998) or to reflect upon one's own professional skills (Järvinen \& Kohonen, 1995; Smith \& Tillema, 1998; Tillema \& Smith, 2000).

In short, the portfolio can have two goals: development and evaluation (Burns, 1999; Centra, 1993; Doolittle, 1994; Seldin, 1997; Snadden, 1999; Tillema, 1998). Tillema and Smith (2000) placed these objectives of portfolios on a continuum. At one end of this is professional development, at the other is striving for a certificate for a promotion, selection of job offer. As well as this, they suggested a second dimension that measures whether the use of a teaching portfolio is voluntary or obligatory. If these two dimensions were combined, one would get four perceptions of the use of portfolios. Tillema and Smith (2000) place the terms self-review, self evaluation and self-assessment-distinguished by Powell (2000), speaking about the grammar of internal evaluation-on this continuum. Furthermore, Tillema and Smith add a fourth type of assessment, 'self-appraisal', to it. 
It can be noted that the way in which teachers use teaching portfolios depends, on the one hand, on the degree to which they strive towards optimising their professional development or towards obtaining a promotion and on the other hand, on the voluntary or obligatory formulation of a teaching portfolio (Smith \& Tillema, 2001).

There are teachers who put together a teaching portfolio to obtain a doctoral degree. They work towards the goal of an external evaluation. Such striving may, or may not, be stimulated by the teaching institution. If teachers put their teaching portfolios together from such a point of view, this can be named as self-review or self-appraisal, depending on whether there is any obligation from the teaching institution. However, there are also initiatives which have the objective of promoting teaching portfolios as instruments for the optimization of teachers' professional development by self-reflection on their performance. If a teacher creates a teaching portfolio because of the latter purpose, and does this voluntarily, one can say that the portfolio is being used for self-assessment. Self-evaluation is the term used if the teacher is aiming to optimise his professional development but is being forced by the educational institution to create a teaching portfolio (Powell, 2000; Smith \& Tillema, 2001).

In the past, teachers often used a teaching portfolio because by doing so their teaching practice could be confirmed by examples (Wolf, 1991). According to Wolf (1991), there are two reasons for this: either they were taking their doctoral degree and had to illustrate their teaching methods with good examples, or they had received a reprimand and had to look for evidence to prove that they were indeed good teachers. In other words, a product was being delivered. The big disadvantage of such a teaching portfolio was that only achievement mattered. No attention was given to the reflective process which teachers had to go through to get to such a product (Tillema, 1998). Since the majority of teachers are not eligible to take a doctoral degree or do not have to fear negative criticism, this group is not stimulated to draw up a teaching portfolio (Wolf, 1991). After all, they do not have to evaluate their teaching performance to meet external demands. Yet such investigations of one's own educational performance may prove to be beneficial to professional development (Tillema, 1998). Projects such as the 'Teacher Assessment Project' (Wolf, 1991) investigated the roles which teaching portfolios could play besides that of the one-sided tendency of achieving a positive evaluation. Wolf concluded that a teaching portfolio "can (and should) also serve such purposes as promoting the development of individual teachers and highlighting exemplary practices" (p. 131).

Frequently, authors make a primary distinction between different forms of portfolios: evaluation, employment and development portfolios (Frederick, McMahon, \& Shaw, 2000; Hurst, Wilson, \& Cramer, 1998; Lally, 2000). In both evaluation and employment portfolios, teachers mainly discuss their best work as a 
teacher (Frederick et al., 2000; Lally, 2000). They are advised to do this so that their educational skills can be demonstrated (Frederick et al., 2000; Lally, 2000; Smith \& Tillema, 2001). These two forms of teaching portfolios have evaluation as their final goals. A development portfolio is strongly focussed on the process of reflection that teachers have to undergo when creating a teaching portfolio. Teachers should undertake initiatives for improving their teaching practice via development portfolios (LaBoskey, 2000; Lally, 2000).

Although, the dictionary describes a teaching portfolio as a file or folder, authors use the term teacher portfolio or teaching portfolio in a lot of different ways, varying from small nuances to a whole other understanding of the term. For this reason we developed our own definition of a teaching portfolio, based upon recent literature (Athanases, 1994; Borko, Michalec, Timmons, \& Siddle, 1997; Darling, 2001; Doolittle, 1994; Lally, 2000; Järvinen \& Kohonen, 1995; Murray, 1995; Seldin, 1997; Wolf \& Dietz, 1998);

A teaching portfolio is a purposeful collection of evidence, consisting of descriptions, documents and examples of what is good teaching for the teacher. Moreover, it contains reflections upon one's educational practice (including illustrations of its complexity). Such a teaching portfolio can be managed by the teacher himself or by a central internal authority. Using a teaching portfolio, the teacher passes through a learning process aiming at improving the individual and institutional quality.

This definition is used in the following empirical study.

\section{Research question}

The main research question of this study is twofold: 'Are teaching portfolios really used in higher education, and if so, which effects could they bring about?' In order to find an answer to these main questions, we formulated the following, more specific, research questions:

1. Are teaching portfolios used by teachers?

2. Which forms of teacher portfolios are used?

3. How are teaching portfolios used?

4. What are the reasons for starting to use a teacher portfolio?

5. What do teachers see as possible consequences of a positively evaluated teaching portfolio (if the teaching portfolio is evaluated)?

6. What do teachers see as possible consequences of a negatively evaluated teaching portfolio (if the teaching portfolio is evaluated)?

7. Which effects are experienced due to the use of teaching portfolios?

8. What is the attitude of teachers (pro or con) towards the use of teaching portfolios in their educational organisation? 
9. Does the attitude of teachers (pro or con) towards the use of teaching portfolios in their educational organization depend on their gender, age or educational organisation?

\section{Design of the study}

\section{Procedure}

In order to investigate whether teaching portfolios are really used in higher education, and if so which effects they could bring about, an empirical study was set up by means of a survey. We also tried to understand the purposes and effects of the use of portfolios (Silverman, 2000). Furthermore, the attitudes of teachers (pro or con) towards the use of teaching portfolios were examined.

\section{Subjects}

This study took place in three schools for higher vocational education and in one university. Those institutions were selected at random. Three hundred and sixty four teachers were asked to fill out the questionnaire. School A had $33.04 \%$ of the respondents, school B 24.35\%, school C 9.57\% and university A 33.04\%. For each institution, at least one contact person was appointed to distribute and collect the questionnaires.

A higher proportion of female teachers (53.85\%) than male teachers (46.15\%) participated in this research. Furthermore, most of the respondents were older than 40 years: $36.8 \%$ of them were aged between 40 and 49 , and $36.8 \%$ of them were over $50.17 \%$ of the respondents were between 30 and 39 years old.

In total, 364 questionnaires were sent out, of which 129 were returned. The response rate was $44.5 \%$ for school A, $40 \%$ for school B, $11 \%$ for school C and $49.4 \%$ for university A. During the data collection and analysis, it was discovered that 12 of the received questionnaires were not filled out in a proper manner. Hence, 117 questionnaires were entered in the analysis, representing a total response of $32.1 \%$.

\section{Possible causes of non-response}

Analysis of the causes of non-response seemed to be of interest (Ryan \& Bernard, 2000). From interviews with the different contact persons in the schools, we learned that a possible cause of non-response could be the time at which the questionnaires were sent out. School A and university $A$ got the questionnaires at the end of the school year. This is quite a demanding time for teachers. Often exams are still taking place, exams must be evaluated and deliberations must be done. 
At university A, $49.4 \%$ of the filled in questionnaires were returned, in spite of the busy time of year. The contact person from university A remarked that a few respondents were working at different departments of the university from where the questionnaires were distributed. As a consequence, those respondents filled out the questionnaire only once.

A second possible explanation for non-response was fear on the part of the teachers. When the questionnaires were sent out for the second time, while all teachers were present, some of them told the researchers, who were there to clarify the goals of the research, that they did not want to participate because of the contact person. They doubted the strict anonymity of the gathered data. After all, due to the information about gender, age and educational organisation, the contact person could trace the identity of the respondent. Clarifying the fact that the contact person should only collect the questionnaires was not enough to persuade those teachers to participate.

From the written comments on the questionnaire and from a meeting at school $A$, it seemed that not all the teachers knew about 'teaching portfolios'. Some of them explained that they could not fill in the questionnaire because of this. Nevertheless, the questionnaire included a general definition of a teaching portfolio, in order to avoid this kind of problem.

A final explanation for non-response was the increasing workload with which teachers are dealing. This was also mentioned by the respondents in their written comments on the questionnaire. We can conclude that in this research, there are several different causes of non-response. This non-completion of the survey represents possibly a response bias which limits the studies generalization.

\section{Research instrument}

For the purpose of this explorative research a questionnaire was developed, consisting of open ended and multiple choice questions. The questionnaire consisted of three parts. In part A, personal data, such as gender, age, institution were gathered. Part $B$ contained questions about the teaching portfolio. Finally in part $\mathrm{C}$, teachers could record personal comments.

The questions about the teaching portfolio (part B) were prefaced by a definition of a teaching portfolio (see earlier). This definition was followed by questions dealing with the 'application' of the portfolios. Teachers were asked to indicate whether they kept a teaching portfolio or not, or whether someone else was keeping one for them. If so, they were asked how and why they were using it, how it was being used, etc. These questions were searching for an answer to the first part of the main research question: "Are teaching portfolios really used in higher education?" Furthermore, part B looked for reactions of teachers to the use of teaching portfolios and is aimed at the second part of the main research 
question: "Which effects could teaching portfolios bring out?". The development of the questions was based upon findings from the literature (Athanases, 1994; Centra, 1993, 1994; Lally, 2000; Smith \& Tillema, 1998). In part C of the questionnaire, teachers were asked for some general comments about teaching portfolios in higher education.

In a short introductory letter, attached to the questionnaire, we briefly clarified the purposes of the questionnaire.

\section{Data analysis}

For the analysis of the quantitative data we used descriptive statistics, $t$-tests, ANOVA and the Bonferroni method. The answers to the open questions were analysed in a qualitative way. We analysed the content of the answers and deduced some categories. Answers were classified according to these categories.

\section{Results}

\section{The use of teaching portfolios}

Only $13.3 \%$ of the respondents keep a teaching portfolio themselves; and for $8.8 \%$, the institution keeps a teaching portfolio for them. Respondents mainly use teaching portfolios in a paper version (43.5\%) or in a partial paper, partial electronic version (43.5\%). A completely electronic version of a teaching portfolio is only used by $13 \%$ of the portfolio users.

More than half of the respondents, namely $58.4 \%$, are free to give personal meanings and interpretations to the use of their teaching portfolios. On the other hand, one fifth of the respondents are not free to give personal meanings and interpretations (16.7\%: totally disagree, 4.2\%: partly disagree). Furthermore, $66.7 \%$ of the respondents agree with the statement that teachers have to follow the guidelines of the policy makers. Seventy one percent of the respondents say their teaching is evaluated by using their teaching portfolio. Sixteen percent say their teaching is not evaluated by using their teaching portfolio.

Eighty four percent of the respondents agree with the position that teaching portfolios are seen as a way to reflect on the educational practice of teachers. Sixteen percent of the respondents do not agree with this use of a teaching portfolio. Furthermore, $72 \%$ of the respondents believe that teaching portfolios improve the educational qualities of teachers. Finally, $58.3 \%$ of the respondents agree that teaching portfolios are also used to improve the quality of the institution. 


\section{Reasons to start using a teaching portfolio}

Since this question is only applicable to respondents who are using a teaching portfolio, this question is answered by $22.1 \%$ of the research population.

Many of the respondents (60.9\%) reported that they started creating a teaching portfolio on their own initiative. The results also show that $26.1 \%$ of the respondents are obliged by their employer, namely the educational institution, to keep a teaching portfolio.

The remaining respondents (13\%) started to use a teaching portfolio because it was recommended by the educational institution they are working for.

It is worth noting that none of the respondents started creating a teaching portfolio because it was recommended by colleagues.

\section{Consequences of a positively evaluated teaching portfolio}

Open ended questions concerning the consequences of a positively evaluated teaching portfolio delivered us written, qualitative data, which are sorted into categories. Next, these answers were counted. The results of this data processing are represented in the following paragraphs and listed in Table 1.

In total, 146 answers were counted. This means that some of the 117 respondents mentioned a few issues which were classified into more than one category. The non-response category represents 44 of the 146 answers. The next largest group is confirmation of a professional approach; $15.75 \%$ of the respondents think that confirmation of their professional approach is a possible positive consequence of a teaching portfolio. A few of the teachers' reactions will illustrate the given answers; "Recognition by the faculty instead of only by students", "A positive encouraging word by an authority". Opportunities for promotion also turn out to be a positively valued consequence of a teaching portfolio. This category holds $13.01 \%$ of the answers. The incentive to go on category counts for $8.9 \%$ of the answers. Increasing quality of education is another possible outcome for the respondents (6.16\%). Respondents report that working with a teaching portfolio brings more clarity and reduces ambiguity about teachers' responsibilities. The respondents suggest that portfolios can result in more responsibilities $(5.48 \%)$. The categories significant appraisal and no consequences each represent $4.79 \%$ of the answers. A few answers categorised under significant appraisal are: "pedagogical qualities will be taken into account for promotion and appointment to a post", "objectiveness (hopefully) of educational effort and qualities", "recognition of educational qualities in the personal portfolio, especially in the area of promotions". The following reactions illustrate the answers in the no consequences category: "I don't think that such a portfolio should be an instrument for evaluation throughout an authority. The pressure that lies on teachers is already high enough.", "no consequences, because I think that a teaching portfolio should be an 
instrument to stimulate personal growth.", "teaching portfolios as a result of a coached start of an educational career, of keeping up to date and adjusting, not of evaluation. A treasure-chest to look back and reflect on your own evolution.". The next category is a feeling of solidarity, with $4.11 \%$ of the answers. A few teachers defined this feeling of solidarity: "an example for other colleagues, they will be stimulated to reach the same goals", "especially more opportunities to tune to colleagues". The pay increase category includes $2.74 \%$ of the answers. Keeping syllabus/techniques up to date is mentioned in $1.37 \%$ of the answers. The rest of the answers could be classified according to: stimulating reflection, no extra pay increase, keep taking refresher courses and keep optimising, and more administrative work. Each of these counts for one answer from the respondents.

Table 1. Consequences of a positively evaluated teaching portfolio

\begin{tabular}{lr}
\hline Categories of Consequences & Percentage \\
\hline Non response & 30.14 \\
Confirmation of professional approach & 15.75 \\
Opportunities for promotion & 13.01 \\
Incentive to go on & 8.90 \\
Increasing quality of education & 6.16 \\
More responsibilities & 5.48 \\
Significant appraisal & 4.79 \\
No consequences & 4.79 \\
Feeling of solidarity & 4.11 \\
Pay increase & 2.74 \\
Keeping syllabus/techniques up to date & 1.37 \\
Stimulating reflection & 0.68 \\
No extra pay increase & 0.68 \\
Keep taking refresher courses/keep optimising & 0.68 \\
Administrative work & 0.68 \\
\hline
\end{tabular}

\section{Consequences of a negatively evaluated teaching portfolio}

The answers to the open ended questions concerning the consequences of a negatively evaluated teaching portfolio were also sorted into categories and counted. The following paragraphs and Table 2 show us the results.

We counted 142 reactions here. This means, again, that some of the 117 teachers gave answers which could be classified into different categories.

As with the question looking for possible consequences of a positively valued teaching portfolio, the non-response category is also the largest and counts for $30.29 \%$. The possible sanctions concerning the career category represents $16.9 \%$ of the answers. The respondents name transfer to another job in their institution, slower career development, stagnation in career development and being dismissed as possible consequences of a negatively valued teaching portfolio. The next categories, reduced motivation and taking refreshers count for $9.86 \%$ of the 
answers each. Some of the respondents (8.45\%) had the opinion that coaching could be a consequence of a negatively valued teaching portfolio. Respondents mean that coaching could help teachers to evolve to a positive evaluation. A quote from a teacher will illustrate this consequence: "Coaching within the educational institution (taking care of teachers) is essential. With this the working of it stands or falls." Additionally, we identified the categories increased motivation to change, obligatory flexibility, increase in workload, and no consequences. Each of them represents $3.52 \%$ of the answers. As an example of an answer in the increased motivation to change category, a respondent remarked "maybe a person is a bit more motivated to work on shortcomings, but this also happens without a teaching portfolio". Another teacher said that a possible consequence of a negatively valued teaching portfolio is "work to do". Examples of quotes from the obligatory flexibility category include: "obligation to ask advice from colleagues concerning another approach", "a lot of consultations", "looking for other methods for improving teacher tasks and textbooks or handbooks". A response illustrating the no consequences category is "I think there should only be consequences for a positively valued portfolio". The self-reflection, constructive appraisals, and bureaucracy categories each included $2.82 \%$ of the given answers. Finally there are three categories with one answer each: lack of concrete assistance, no financial sanctions and financial sanctions.

Table 2. Consequences of a negatively evaluated teaching portfolio

\begin{tabular}{lr}
\hline Categories of Consequences & Percentage \\
\hline Non respons & 30.29 \\
Possible sanctions concerning career & 16.90 \\
Reduced motivation & 9.86 \\
Taking refreshers & 9.86 \\
Coaching & 8.45 \\
Increased motivation to change & 3.52 \\
Obligatory flexibility & 3.52 \\
Increase in workload & 3.52 \\
No consequences & 3.52 \\
Self-reflection & 2.82 \\
Constructive appraisals & 2.82 \\
Bureaucracy & 2.82 \\
Lack of concrete assistance & 0.70 \\
No financial sanctions & 0.70 \\
Financial sanctions & 0.70 \\
\hline
\end{tabular}

\section{Effects experienced due to the use of teaching portfolios}

Since $77.9 \%$ of the respondents were not using a teaching portfolio, the vast majority $(80.6 \%)$ of the respondents were not able to answer the questions concerning experienced effects. Those who were using a teaching portfolio mainly 
reported personal benefits (16.7\%). Examples of effects noticed by teachers themselves include: "improved course materials", "more student centred approach", "a stimulus for myself to actualise and renew the course content in a constructive way, if necessary", "rethink how you dealt with a particular situation: which are the minus points in it and how can you prevent those minus points?", "stimulates reflection about your own educational approach", etc.

A small part of the respondents (7.8\%) experienced effects on their colleagues due to the use of teaching portfolios. A few examples of how those effects are verbalised are: "colleagues talk about what is in our portfolio", "you get more respect for the approach of other colleagues and there is the possibility to adopt those approaches".

Furthermore, $8.9 \%$ of the respondents using a teaching portfolio reported effects on their students. Examples of these are: "students show their appreciation for the efforts of the teacher", "there is more clarity for students because you as a teacher have thought about possible pitfalls in advance", "students are satisfied because of the fact they can and may show their own opinion and furthermore because consideration about it is shown (normally)", "students are stimulated to co-operate on innovations and they evaluate those innovations very seriously and dutifully".

Finally, effects by persons other than themselves, students or colleagues, were only experienced by $2 \%$ of the respondents. An example of such a person is a superior.

It must be noticed that respondents could choose more than one experienced effect.

\section{Attitude of teachers (pro or con) towards the realisation of teaching portfolios in their educational organisations}

Our research data show that $22.1 \%$ of the respondents were using a teaching portfolio. Nevertheless, it is interesting to find out what the attitudes (pro or con) of all the subjects are to the use of teaching portfolios in their educational organisations.

More than half of the respondents (53.3\%) had a positive attitude towards the use of teaching portfolios in their educational organisations, if this is introduced gradually in the long term. Respondents gave a few reasons for this: for example "there is already so much administrative work", "it must be adjusted to the working of the organisation", "because we are in the middle of an innovation and as a novice teacher I'm still trying out some things (searching for the role of a teacher)", "first we have to be acquainted with the contents, goals, usefulness and possibilities. Some respondents $(18.7 \%)$ shared the opinion that teaching portfolios should be introduced into their organisation as soon as possible. Those respondents 
specified why they were in favour of a quick introduction: "this is how they form an idea about what tasks I perform and their quality", "it can give a large contribution to self evaluation and feedback, and it has a direct benefit for students", "as a personal aid, not in the sense of evaluation; then you can do it by yourself and so it must not be enforced by the educational organisation". Our research also showed that a substantial percentage of the respondents (28\%) were set against the use of a teaching portfolio in their educational organisation. A few of the respondents clarified their opinions: "I do not believe in such paper and administrative work", "it is not a guarantee of good work", "they say that they have sympathy for the huge work pressure which we are under, but in psychological and material ways, we are loaded up more and more! Leave us alone!", "it seems useful for younger colleagues, but I have a lot of experience and daily I reflect on the quality of education and therefore I do not need a teaching portfolio", "because I believe that improving your education is a personal or collective aspiration, but it does not have to be documented", "it increases bureaucracy and is patronizing".

\section{Attitude of teachers (pro or con) depending on gender, age and educational organization}

In order to investigate the difference between male and female teachers (gender) with regard to attitudes, a $t$-test was performed. No significant differences were found between male and female teachers regarding attitudes towards the realisation of a teaching portfolio $(t=-1.34, d f=104, p=.1843$ ).

Using an ANOVA we investigated whether there were differences in the attitude of teachers towards the realisation of a teaching portfolio between the four age groups and the four educational organisations. The results showed that there was no significant difference among these research groups concerning age $(F(3,108)=$ .15 and $p=.9306)$. The ANOVA also showed that there were no significant differences between the four different educational institutions involving the attitudes of the respondents $(F(3,106)=.39$ and $p=.7607)$. We can conclude that there is no evidence to show that the attitude of teachers towards the realisation of teaching portfolios in their educational organisation is dependent on gender, age or educational organisation.

\section{Conclusion and discussion}

In order to answer the main research question 'Are teaching portfolios really used in higher education, and if so which effects could they bring about?', we investigated eight specific research questions and the general comments about teaching portfolios in higher education given by the respondents. 
In the current study, $22.1 \%$ of the respondents use a teaching portfolio. Some respondents are keeping a teaching portfolio by themselves (13.3\%) and for others their institution is keeping a teaching portfolio centrally $(8.8 \%)$. Most of the respondents keep a paper version or a partial paper, partial electronic version of a teaching portfolio. The majority of the respondents have started a teaching portfolio on their own initiative, but more than $1 / 4$ of the respondents were obliged to do so by their employers. The majority of the respondents stated that a teaching portfolio is a form of evaluation (see also Davies \& Le Mahieu, 2003), but they also see the instrument as a means to reflect on one's own education and educational skills (Schön, 1987; Taylor, 1994; Wade \& Yarbrough, 1996). It is seen as a way to improve the quality of their own education and also the quality of the educational institution.

To a large extent, the respondents reported effects regarding themselves. If a portfolio is positively valued, most of the respondents expect an increasing quality of education or personal merits. These finding are in line with the findings of Wright, Knight, and Pomerleau (1999) and the work of Barrett (2000). If a portfolio is negatively valued, respondents share the opinion that a process of change, freedom and sanctions could be a possible effect. Respondents acknowledge the supportive function of a portfolio (see also Bird, 1990; Collins, 1993; Knight \& Gallaro, 1994). The majority think that teaching portfolios are too time consuming and they worry about the extra administrative work portfolios will bring (see also Barton \& Collins, 1993; Taylor, 1997). The majority of the respondents share the opinion that teaching portfolios contribute to the quality of education and believe that portfolios give judgements on the efforts of teachers (see also Green \& O'Sullivan Smyser, 1996). Most of the respondents are in favour of the use of teaching portfolios, but $26 \%$ of the respondents in this study are against their use.

The results of this survey show that teachers in higher education are working with teaching portfolios, though only $1 / 5$ th of the research population were doing so. The majority of the respondents did not know about the concept of 'teaching portfolios' at all, or didn't know about them in an adequate way. Furthermore, the reactions of the respondents tell us that teachers often have different ideas about teaching portfolios as found by Grover (1991) earlier. Some of them see them as curriculum vitae, others as instruments for reflection, others as instruments for evaluation, and still others see them as instruments to improve teaching quality. This fits with the view that there are different kinds of teaching portfolios: for example employment portfolios (Lally, 2000; Wolf \& Dietz, 1998), evaluation portfolios (Lally, 2000; Smith \& Tillema, 2001), and development portfolios (Lally, 2000; Smith \& Tillema, 2001). Moreover, earlier research shows that teachers give highly personal interpretations to teaching portfolios (Doolittle, 1994; Wolf, 1991). Those remarks from the literature illustrate the findings from this research; namely that teachers cannot identify every type of portfolio with themselves. 
Furthermore, this study shows that the use of portfolios can lead to certain effects. It seems that the use of portfolios can optimise the quality of education. The respondents explained that, due to the use of portfolios, they were stimulated to reflect on their own teaching, to actualise the learning content, to improve course materials, to search for alternative educational methods, etc. Additionally, teaching portfolios are very useful for appraisals and make clear what the efforts of the teacher are. Teachers have certain benefits from the use of portfolios. These findings were also discovered in the literature (Berk, 1999; Järvinen \& Kohonen, 1995; Murray, 1995; Wolf, 1996). Järvinen and Kohonen (1995) state that, thanks to the use of teaching portfolios, the efforts, improvements and achievements of a teacher are demonstrated. Berk (1999) and Wolf (1996) find reflection a typical feature of a teaching portfolio. Murray (1995) states that the use of teaching portfolios can improve the teaching quality of individual teachers and of the educational institution.

Further, this research shows that not all teachers experience the same effects from the use of teaching portfolios. It is important to realise that the use of teaching portfolios does not only have positive effects for teachers. Respondents point out that a negatively valued teaching portfolio could demotivate. Moreover, making a teaching portfolio is time consuming. Such less positive effects of teaching portfolios can also be found in the literature. Centra (1993) concludes from research that teachers who had a negative summative evaluation could feel discriminated. Smith and Tillema (1998) stress the fact that producing a teaching portfolio is a time consuming and laborious process.

In conclusion, this research shows that a teaching portfolio is an assessment instrument that could bring about some important positive effects. This instrument could also give rise to a lot of questions, especially in the initial phase. This means that teaching portfolios are not the ideal assessment instrument for all teachers. It is possible that some teachers are more stimulated to reflect on their professional actions and competences, and optimise their teaching more effectively, with other assessment instruments (see also Baratz-Snowden, 1991; Haertel, 1992). When teachers are using teaching portfolios it is important that, besides the negative effects, they also experience positive effects. If this is not the case, teachers will see the teaching portfolio only as an extra administrative inconvenience. Finally, a formative use of a teaching portfolio seems to be obvious. After all, teachers want to have a clearer view of their own teaching, an improvement in their reflection on their own professional practices, a rethinking of the effectiveness of their own educational skills, etc. due to the use of a teaching portfolio (see also Mathers, Challis, Howe, \& Field, 1999). Such a portfolio can give form and content to the process of growth that teachers go through during their educational career (Weeks, 1996). Portfolios can also be used for summative goals. The correct application of 
portfolios is essential; teachers must know in advance which aspects of their portfolio will be evaluated.

\section{References}

Athanases, S. Z. (1994). Teacher's reports of the effects of preparing portfolios of literacy instruction. The Elementary School Journal, 94(4), 421-439.

Baratz-Snowden, J. (1991). Performance assessments for identifying excellent teachers: The National Board for Professional Teaching Standards charts its research and development course. Journal of Personnel Evaluation in Education, 5, 133-145.

Barrett, H. (2000). Electronic teaching portfolios: Multimedia skills + portfolio development = powerful professional development. University of Alaska Anchorage. Retrieved from http://electronicportfolios.com/portfolios/site2000.html

Barton, J., \& Collins, A. (1993). Portfolios in teacher education. Journal of teacher education, 44(3), 200209.

Berk, R. A. (1999). Assessment for measuring professional performance. In D. P. Ely, L. E. Odenthal, \& T. Plomp (Eds.), Educational science and technology: Perspectives for the future (pp. 30-48). Twente: University Press.

Bird, T. (1990). The schoolteacher's portfolio: An essay on possibilities. In J. Millman, \& L. DarlingHammond (Eds.), The new handbook of teacher evaluation: Assessing elementary and secondary school teachers (pp. 241-256). London: Sage.

Borko, H., Michalec, P., Timmons, M., \& Siddle, J. (1997). Student teaching portfolios: A tool for promoting reflective practice. Journal of teacher education, 48(5), 345-356.

Burns, C. W. (1999). Teaching portfolios and the evaluation of teaching in higher education: Confident claims, questionable research support. Studies in Educational Evaluation, 25, 131-142.

Centra, J. A. (1993). Reflective faculty evaluation. Enhancing teaching and determining faculty effectiveness. San Francisco: Jossey-Bass Publishers.

Centra, J. A. (1994). The use of the teaching portfolio and student evaluations for summative evaluation. Journal of higher education, 65(5), 555-570.

Collins, A. (1993). Performance-based assessment of biology teachers: Promises and pitfalls. Journal of Research in Science Teaching, 30, 1103-1120.

Darling, L. F. (2001). Portfolio as practice: The narratives of emerging teachers. Teaching and Teacher Education, 17, 107-121.

Davies, A., \& Le Mahieu, P. (2003). Assessment for Learning: Reconsidering Portfolios and Research Evidence. In M. Segers, F. Dochy, \& E. Cascallar (Eds.), Optimizing new modes of assessment: In search for qualities and standards. Boston/Dordrecht: Kluwer Academic.

Dochy, F., Segers, M., Van den Bossche, P., \& Gijbels, D. (2003). Effects of problem-based learning: A meta-analysis. Learning \& Instruction, 13(5), 533-556.

Doolittle, P. (1994). Teacher portfolio assessment. Washington, DC: ERIC Clearinghouse on Assessment and Evaluation (ERIC Document Reproduction Service No. ED 385 608). 
Frederick, L., McMahon, R., \& Shaw, E. L., Jr. (2000). Preservice teacher portfolios as autobiographies. Education, 120(4), 634-638.

Gillies, R. M. (2004). The effects of cooperative learning on junior high school students during small group learning. Learning \& Instruction, 14(2), 197-213.

Green, J. E., \& O'Sullivan Smyser, S. (1996). The teacher portfolio. A strategy for professional development and evaluation. Lancaster: Technomic Publishing Company.

Grover, B. W. (1991). The teacher assessment dilemma: What is versus what ought to be. Journal of Personnel Evaluation in Education, 5, 103-119.

Haertel, E. H. (1992). New forms of teacher assessment. Review of Research in Education, 17, 3-29.

Hurst, B., Wilson, C., \& Cramer, G. (1998). Professional teaching portfolios: Tools for reflection, growth, and advancement. Phi Delta Kappan, 79(8), 578-582.

Järvinen, A., \& Kohonen, V. (1995). Promoting professional development in higher education through portfolio assessment. Assessment \& Evaluation in Higher Education, 20(1), 25-36.

Kelchtermans, G. (1993). Getting the story, understanding the lives: From career stories to teachers' professional development. Teaching \& Teacher Education, 9(5/6), 443-456.

Knight, M. E., \& Gallaro, D. (Eds.). (1994). Portfolio assessment. Lanham: University Press of America.

LaBoskey, V. (2000). Portfolios here, portfolios there . . . : Searching for the essence of 'educational portfolios'. Phi Delta Kappan, 81(8), 590-595.

Lally, A. (2000). Teaching portfolios and the continuous improvement of teaching. Art Documentation, 19(1), 48-49.

Mathers, N. J., Challis, M. C., Howe, A. C., \& Field, N. J. (1999). Portfolios in continuing medical education-Effective and efficient? Medical education, 33, 521-530.

Meyer, D. K., \& Tusin, L. F. (1999). Preservice teachers' perceptions of portfolios: Process versus product. Journal of Teacher Education, 50, 131-139.

Murray, J. P. (1995). Successful faculty development and evaluation: The complete teaching portfolio. ASHE-ERIC Higher Education Report No. 8. Washington, DC: The George Washington University, Graduate School of Education and Human Development.

Powell, L. A. (2000). Realizing the value of self-assessment: The influence of the business excellence model on teacher professionalism. European Journal of Teacher Education, 23(1), 37-48.

Ryan, G. W., \& Bernard, H. R. (2000). Data management and analysis methods. In N. K. Denzin, \& Y. S. Lincoln (Eds.), Handbook of qualitative research ( $2^{\text {nd }}$ ed., pp. 769-803). Thousand Oaks: Sage Publications.

Schön, D. A. (1987). Educating the reflective practitioner. Toward a new design for teaching and learning in the professions. London: Jossey-Bass.

Seldin, P. (1997). The teaching portfolio: A practical guide to improved performance and promotion/tenure decisions ( $2^{\text {nd }}$ ed.). Bolton, MA: Anker.

Silverman, D. (2000). Doing qualitative research. A practical handbook. London: Sage Publications.

Smith, K., \& Tillema, H. (1998). Evaluating portfolio use as a learning tool for professionals. Scandinavian Journal of Education Research, 42, 193-205. 
Smith, K., \& Tillema, H. (2001). Long-term influences of portfolios on professional development. Scandinavian Journal of Educational Research, 45, 183-203.

Snadden, D. (1999). Portfolios-Attempting to measure the unmeasurable? Medical Education, 33, 478479.

Taylor, C. T. (1997). Using portfolios to teach teachers about assessment: How to survive. Educational assessment, 4(2), 123-147.

Taylor, L. (1994). Reflecting on teaching: The benefits of selfevaluation. Assessment \& Evaluation in Higher Education, 19(2), 109-117.

Tillema, H. H. (1998). Design and validity of a portfolio instrument for professional training. Studies in Educational Evaluation, 24, 263-278.

Tillema, H. H., \& Smith, K. (2000). Learning from portfolios: Differential use of feedback in portfolio construction. Studies in educational evaluation, 26, 193-210.

Wade, R. C., \& Yarbrough, D. B. (1996). Portfolios: A tool for reflective thinking in teacher education? Teaching and teacher education, 12(1), 63-79.

Weeks, P. (1996). The teaching portfolio: a professional development tool. International journal for academic development, 1, 70-74.

Wolf, K. (1991). The schoolteacher's portfolio: Issues in design, implementation, and evaluation. Phi Delta Kappan, 73(2), 129-136.

Wolf, K. (1996). Developing an effective teaching portfolio. Educational Leadership, 32(6), 34-37.

Wolf, K., \& Dietz, M. (1998). Teaching portfolios: Purposes and possibilities. Teacher Education Quarterly, 25(1), 9-22.

Wright, W. A., Knight, P. T., \& Pomerleau, N. (1999). Portfolio people: Teaching and learning dossiers and innovation in higher education. Innovative Higher Education, 24(2), 89-103.

Zeichner, K., \& Wray, S. (2001). The teaching portfolio in US teacher education programs: What we know and what we need to know. Teaching and Teacher Education, 17(5), 613-621. 

Chapter 6

Rigorously selected and well trained senior student tutors in problem based learning:

Student perceptions and study achievements 


\section{Introduction}

In problem based learning (PBL) settings (Barrows \& Tamblyn, 1980; Dochy, Segers, Van den Bossche \& Gijbels, 2003) groups of students are guided by staff tutors but also by student tutors (Schmidt, Van Der Arend, Kokx, \& Boon, 1995). Tutors guide discussions and promote in-depth discussion during group sessions. They are also expected to encourage the use of specific cognitive skills by students, such as making connections, giving appropriate feedback and monitoring the learning processes of students (Dolmans et al., 2002; Norman \& Schmidt, 1992). Student (peer) tutors can be fellow students (i.e. same level tutoring) or more advanced students (i.e. cross level tutoring). A recurring question is whether student tutors are able to successfully fulfil the complex responsibilities of a tutor.

\section{Theoretical background}

Student (peer) tutor

De Smet, Van Keer and Valcke (2009) define a student tutoring setting as a specific type of collaborative learning (Griffin and Griffin, 1997; Topping, 1996); Students are working together in small groups and a peer takes a supportive role as a student tutor. Through a scaffolding process offered by their peers, students learn or coconstruct (Duran \& Monereo, 2005).

Searching for advantages of teaching by student tutors in a PBL environment, we found that students that are familiar with PBL are better able to adjust to the difficult role of a PBL tutor (Lockspeiser, O'Sullivan, Teherani \& Muller, 2008; Schmidt et al., 1995). Although student tutors have less domain specific knowledge compared to staff tutors, they have the advantage of higher cognitive and social congruity with students. Student tutors are therefore likely as capable as staff tutors of promoting the learning of their 'peers' (Lockspeiser et al., 2008; Schmidt et al., 1995). Concluding his review Topping (1996) argues that cross level small group tutoring is an effective teaching method that merits wider use in practice. The review of Secomb (2008) reported mostly positive outcomes on the effectiveness of peer teaching; it can increase student's confidence and improve learning.

\section{Study achievements}

The achievements of students exposed to a student tutor versus a staff tutor can provide information about the quality of teaching by student tutors (Kassab, AbuHijleh, Al-Siboul, and Hamdy, 2005; Schmidt et al., 1995; Marsh and Roche, 1997; McKeachie, 1979). Results from earlier studies are diverse and the conclusions are not univocal. Schmidt et al. (1995) surveyed 800 health sciences students and found

differences in study achievements between students taught by cross level student versus staff tutors, with the latter obtaining higher grades. De Volder, De Grave \& 
Gijselaers (1985) also found variable study achievements in a study on cross level student tutors that attended the same three-day training course as the staff tutors. Student tutors were not selected. Volunteering students were accepted until the number of student tutors needed, was reached. In this study 148 first year students were involved. In one course students with a student tutor scored lower than students with a staff tutor, but other groups showed no such differences. No differences in student achievements were also reported by Kassab et al. (2005). This study had 91 participants taught by same level student versus staff tutors. Steele, Meddar and Turner (2000) investigated same level peer tutoring versus staff tutoring in a group of 127 students. They also found no differences in student achievements. Furthermore, no differences in student achievements were found in a study of cross level tutoring with 230 (course A) and 177 (course B) students by Moust and Schmidt (1994). De Grave, De Volder, Gijselaers and Damoiseaux (1990) found in their study, with 165 participants, no differences in achievement. Without making use of any selection procedure this study worked with cross level student tutors. Sobral (1994) reported no negative effect of cross level student tutoring on students' acquisition of knowledge ( $N=479)$.

Gielen, Tops, Dochy, Onghena and Smeets (2010) examined whether peer feedback can have an equally positive effect on learning as teacher feedback in a study comparing the effects of various forms of peer feedback. The results showed no significant differences between students' progress in essay marks after plain substitutional peer feedback or teacher feedback and the authors concluded that peer feedback can substitute teacher feedback without any significant loss of effectiveness in the long run (Gielen et al., 2010). Cho \& Schunn, (2007) show similar findings.

\section{Students' perceptions}

Also, students' perceptions of student tutors versus staff tutors vary. Feedback (Kassab et al., 2005) and cognitive congruity (Lockspeiser et al., 2008; Schmidt et al., 1995; Moust \& Schmidt, 1993) were perceived as more positive in groups with a student tutor. Students also indicated that staff tutors used more domain specific knowledge (Moust \& Schmidt, 1995; Schmidt et al., 1995).

Peterson and Swing (1985) stated that PBL tutors should facilitate students in an indirect manner by asking stimulating questions and regularly evaluating the group process. In a study examining the perceptions of students in relation to staff versus student tutors, Schmidt et al. (1995) found first-year students had a higher opinion of the relevant contribution of student tutors and their ability to encourage questioning, whereas staff tutors were more appreciated by more senior students. Compared to staff tutors, student tutors paid more attention to the evaluation of group functioning. 
Sobral (1994) found that in a PBL setting cross level tutoring increased students' motivation and participation.

Yang, Badger and Yu (2006) reported that teachers using their wide range of domain specific knowledge often provide feedback that is not always understood and sometimes misinterpreted by students because it is based on extensive knowledge of the complexities of subjects and domain specific considerations. Cho and Schunn (2007) also found that feedback from experts is often unhelpful or sometimes even harmful to novice writers' revision.

\section{Training and selection}

Research has taught us that it is of the utmost importance that student tutors are specially trained for their task (Arco, Fernandez, Espin \& Castro, 2006; Kassab et al., 2005; Lockspeiser et al., 2008; Nestell \& Kidd, 2003, 2005; Parr \& Townsend, 2002; Wadoodi \& Crosby, 2002). Training can enhance the didactic skills of student tutors and thereby positively affect students' study achievements and their perceptions of student tutors. A study by Groves, Régo and O'Rourke (2005) has implications for the recruitment and training of PBL tutors; training should focus on the development of a wide range of strategies to encourage optimal group functioning and stimulate the learning of students.

Research on peer feedback (Min, 2008; Sluijsmans, Brand-Gruwel, Van Merriënboer and Bastiaens, 2002) also showed that training in peer assessment skills can make peer feedback as effective as teacher feedback.

\section{Aim and research question}

The preceding shows that studies into student tutoring report differing results. Findings of previous research are diverse and conclusions of those studies are not univocal. Better evidence is needed. After all, as a result of growing attention and recognition that the quality of education is crucial, institutes have to assure that the teaching of their tutors is effective and excellent. Improving teaching has become a major topic in higher education (Biggs, 2003). Although there still is no consensus about the concept of 'teaching effectiveness', research refer to teaching effectiveness as "the degree to which an instructor facilitates student achievement" (McKeachie, 1979). Citing Marsh and Roche (1997, p. 1189): 'The most widely accepted criteria of effective teaching involves student's learning.'. Furthermore they stress the importance of combining those findings with other criteria such as students' evaluations of teaching. Students' perceptions (student ratings of instruction) can be seen as one of the most influential measure of teaching effectiveness (d'Apollonia, \& Abrami, 1997). The meta-analysis of Cohen (1981) provided strong support for the use of student ratings of instruction as a valid method to measure teaching effectiveness. Students are able to distinguish among 
teachers based on how much they have learned. Furthermore, Cohen's metaanalysis showed that the relation between ratings and achievement is strong. Whereas most earlier studies of staff and student tutors mainly focus on student achievement or examine process variables by seeking students' perceptions, we conducted a study in which we examined both.

Recent studies (Groves et al., 2005; Kassab et al., 2005; Lockspeiser et al., 2008; Nestell \& Kidd, 2005, 2003; Parr \& Townsend, 2002; Arco et al., 2006) emphasise the importance of training of student tutors. Therefore research on effects of student and staff tutoring should incorporate a profound training process for peer tutors and staff tutors. This study will take this in account. Furthermore, we will work with rigorous selected student tutors as the importance of this is accentuated in previous research (Weyrich et al., 2008).

In order to study the effects of student and staff tutoring, we conducted a comparative study. The design of the study was influenced by a study (Dolmans et al., 2002) proposing that studies of student tutoring should focus on student achievement and combine qualitative and quantitative methods. We therefore used a mixed design study combining quantitative and qualitative methods and investigated student tutors that had been selected from high achieving students and received extensive training. The first indicator of tutor effectiveness that we examined was students' study achievement, and this indicator was supplemented by students' perceptions obtained from a questionnaire and a focus group interview.

The study investigates the following research question: Is there a difference between staff tutors and rigorously selected and well trained student tutors with respect to students' achievements and perceptions?

\section{Methods}

\section{Setting}

The study was conducted at the Faculty of Law of the Maastricht University. This is a university with a fully problem-based curriculum. Hung (2009) defines problem based learning (PBL) as one of the most widely adopted instructional methods across various disciplines and professional studies, all age groups of learners, and around the globe. The student centered character, as well as significant, contextualized, real-world, ill-structured situations and providing resources, guidance, instruction and opportunities for reflection to learners as they develop content knowledge and problem skills, is distinctive for PBL (Hoffman \& Ritchie, 1997). PBL promotes the development of reflective thinking (Lim, 2009). 
In this study the curriculum is taught in eight week courses during which students work on assignments that require them to tackle real life problems. Small groups of students (10-14) meet twice weekly. During these group sessions the students prepare for self-study activities and they report and reflect upon the results of these self study activities. Group sessions are guided by a tutor. New groups of students are composed for each course. Students have different tutors in each course. Students were randomly assigned to a staff tutor versus a student tutor condition. In addition to the tutorials, students attend weekly lectures and practical classes.

\section{Selection of student tutors}

We invited the students with an average final mark of 7 or higher (ten-point scale) at the end of the first year to apply for a student tutorship. All the applicants took part in a rigorous selection procedure, based on the assessment centre method (Dochy \& de Rijke, 1995). The following selection criteria were used: motivation, knowledge, study achievements and inherent tutor skills. A committee consisting of two educationalists, a senior student and the dean of the faculty judged the students based on interviews, assignments and simulations.

\section{The tutor training programme and the tasks of the student tutors}

During their second year, the selected students tutors $(\mathrm{N}=23)$ received 36 hours of intensive training in tutoring skills, built around the following themes: stimulating cognitive processes, stimulating active involvement of students, scaffolding, fostering meta-cognitive strategies, reflecting on own conceptions of learning and teaching, creating awareness of own (individual) tutoring style and those of others. The interactive training methods that were used included observation with elaborate reflection, peer coaching, simulations and collaborative learning. These methods are based on Dolmans et al. (2002) and are in line with De Smet, Van Keer \& Valcke (2007).

During the third year of their own study the student tutors guided first-year students and attended further training and personal coaching (supervision and intervision) as well as weekly tutor meetings with staff tutors, led by the course supervisor, in which assignments and the best way to approach them were discussed. Before their actual work started, the student tutors observed each tutorial (14 different sessions) with an experienced staff tutor. This provided student tutors with new ideas and enabled them to learn from experienced tutors. Bell and Mladenovic (2008) emphasise the potential benefits from observing peers, especially when observation is integrated with an academic development programme. 
The training course for the student tutors was similar to the regular 38 hour teacher training course that is obligatory for newly recruited teaching staff during the first two years of their appointment. Other staff members are offered a variety of faculty and university based staff development activities that are tailored to their needs.

\section{Instruments}

\section{Study achievement}

The use of an achievement measure, such as course final examination, can be seen as the most appropriate way to assess student achievement (Cohen, 1981). The measure used to determine study achievement were the grades $(1-10 ; \geq 5.6$ is a pass) on the end-of-course exams, consisting of forty multiple choice questions and one or two open-ended questions. In order to assure the quality of these exams, a content expert and an assessment expert evaluate whether questions are well constructed, whether the answer options for the multiple choice questions are appropriate, whether content and difficulty of the exam reflect the subject matter covered by the course, etc.

\section{Student perceptions}

Student perceptions were elicited by an online questionnaire (five-point Likert scale) consisting of twelve closed questions and administered after each end-ofcourse exam. The questionnaire was based on a questionnaire for retrospective quality assurance (Biggs, 2001) developed by Pletinckx and Segers (2001), and contains items about the tutor, such as: 'The tutor encouraged the students to participate actively in group discussions'; 'The tutor encouraged the use of existing knowledge.'

In order to establish relationship patterns between the dependent variables and to explore the nature of the independent variables affecting them - factor analysis ( $n=683$ ) was performed on the 12 items (Table 1$)$, using principal component analysis followed by a Varimax rotation. Because of the cut off criterion of factor loadings above .35 and discrepancy of cross loadings of .20, two items ('The tutor understood the problems faced by the tutorial group regarding the subject ' and 'The tutor made regular use of his/her expert knowledge in guiding the group' were removed (Nunally \& Bernstein, 1994). Based on a factor analysis, using principal component analysis followed by a Varimax rotation, the remaining items of the questionnaire were reduced to four factors: stimulating function $(\alpha=.85)$, cognitive congruency $(\alpha=.87)$, use of domain specific expertise $(\alpha=0.83)$ and social congruency $(\alpha=.80)$.

The four factors together explained $81 \%$ of the variance. 
Table 1. Factor analysis: Rotated Component Matrix

\begin{tabular}{|c|c|c|c|c|}
\hline \multirow[t]{2}{*}{ Items } & \multicolumn{4}{|l|}{ Component } \\
\hline & 1 & 2 & 3 & 4 \\
\hline $\begin{array}{l}\text { The tutor encouraged the students to participate } \\
\text { actively in group discussions. }\end{array}$ & .647 & & & .360 \\
\hline $\begin{array}{l}\text { The tutor stimulated in-depth discussion of new } \\
\text { assignments (before the self study phase). }\end{array}$ & .810 & & & \\
\hline $\begin{array}{l}\text { The tutor stimulated that discussions (after the self } \\
\text { study phase) were sufficiently in-depth. }\end{array}$ & .760 & & & \\
\hline $\begin{array}{l}\text { The tutor understood the problems faced by the } \\
\text { tutorial group regarding the subject matter. }\end{array}$ & .447 & .626 & & \\
\hline $\begin{array}{l}\text { The tutor's remarks on content were made at the right } \\
\text { moment. }\end{array}$ & .418 & .667 & & \\
\hline The tutor asked questions which I could understand. & & .732 & & .376 \\
\hline $\begin{array}{l}\text { The tutor's style of presentation facilitated } \\
\text { understanding of the subject matter. }\end{array}$ & .382 & .639 & & \\
\hline The tutor encouraged use of existing knowledge. & & & .742 & \\
\hline $\begin{array}{l}\text { The tutor provided guidance to ensure that students } \\
\text { draw inference from the subject matter of this course. }\end{array}$ & & & .745 & \\
\hline $\begin{array}{l}\text { The tutor made regular use of his/her expert } \\
\text { knowledge in guiding the group. }\end{array}$ & & .577 & .579 & \\
\hline $\begin{array}{l}\text { The tutor showed himself/herself to be involved with } \\
\text { the group. }\end{array}$ & .364 & & .371 & .682 \\
\hline $\begin{array}{l}\text { The tutor invited students to express their own } \\
\text { opinions and ideas. }\end{array}$ & & .353 & & .816 \\
\hline
\end{tabular}

Note: Extraction Method: Principal Component Analysis.

Rotation Method: Varimax with Kaiser Normalization.

Rotation converged in seven iterations.

Values marked in grey represent the highest factor loadings. 
A semi-structured focus group interview was conducted after the end-of-course exams to gain more in-depth insight into students' perceptions of student and staff tutors. The participating students were encouraged to express their opinions about student tutors and staff tutors and to react to each other's opinions. The questioning route for the interview (Krueger \& Casey, 2000) was based upon the online questionnaire. The students were asked to identify and elaborate on differences between student and staff tutors in relation to each factor: stimulating function, cognitive congruency, use of domain specific expertise and social congruency. Additionally, they were asked to indicate differences between student and staff tutors in relation to the twelve questionnaire questions and to discuss these differences. Two educationalists were moderating the discussion.

A recapitulation of the answers from the participants was presented to them in order to let them reconsider their answer. Subsequently, the participants had the opportunity to reformulate or to enrich their opinion.

The focus group interview was audio-taped and transcribed verbatim.

\section{Participants}

\section{Study achievement}

The study was conducted among first-year students (novice students) in two consecutive years. Data were collected for four courses (A, B, C and D). This led to 2 cohorts of participants: cohort 1 , course $A(N=102)$, course $B(N=124)$, course $C$ $(N=114)$, course $D(N=56)$ and cohort 2 , course $A(N=107)$, course $B(N=85)$, course $C$ $(N=81)$, course $D(N=82)$. Exam results were collected for all the students who attended the courses. To study effects in study achievement we distinguish between cohort 1 and cohort 2 as they received different end-of-course exams for security reasons.

\section{Student perceptions Questionnaire}

All the students who attended these courses were requested to fill out the student perception questionnaire after the end-of-course exam. Informed consent was acquired. As for this study cohort is not a variable, there is no need to distinguish between both cohort groups. Respondents with missing values were removed from the dataset. The remaining number of participants of the questionnaire is represented in Table 2.

Table 2. Number of participants with the questionnaire per course

\begin{tabular}{rrrrr}
\hline & Course A & Course B & Course C & Course D \\
\hline $\mathrm{N}$ & 192 & 192 & 172 & 127 \\
\hline
\end{tabular}




\section{Student perceptions Focus group interview}

For the focus group interview we selected students who had been tutored by two student tutors and two staff tutors (Bloor, Frankland, Thomas \& Robson, 2001). From this group six students were randomly selected from each cohort and invited to take part in a focus group interview.

\section{Data analysis}

\section{Quantitative}

We used SPSS 15 to conduct the quantitative analyses. ANOVA was conducted to identify significant differences between students in study achievement and in answers to the questionnaire. When the assumption of homogeneity of variance was not fulfilled, a Kruskal-Wallis test was performed. Effect sizes (Cohen's d) were calculated, weighted by sample size and pooled variances (Hojat \& Xu, 2004).

\section{Qualitative}

The data were transcribed and indexed (Bloor et al., 2001) to combine all the data pertaining to a particular factor (stimulating function, cognitive congruency, use of domain specific expertise and social congruency). First the focus group responses were organized according to the question to which it is in response. Next, we coded the responses in accordance with the four factors (stimulating function, cognitive congruency, use of domain specific expertise and social congruency). As the goal of the focus group interview was to gain more in-depth insight into students' perceptions of student and staff tutors the following questions were guidelines while interpreting the focus groups data: What was known from the results of the questionnaire and is confirmed or contested by the focus group data?; What is new that was not previously suspected from the results of the questionnaire?.

Two researchers, one of which had no involvement in the actual focus group interview, interpreted the data separately. Through reflection and discussion they came to a consensus. The results are illustrated by quotes representing opinions that were consistently expressed during the interviews.

\section{Results}

The results are presented separately for study achievements and perceptions of staff tutors versus student tutors. The results for student perceptions are organized according to the four factors: stimulating function, cognitive congruency, use of domain specific expertise and social congruency. 


\section{Study achievements}

Descriptive statistics are presented in Table 3.

Table 3. Mean study achievements (on a ten-point scale) and standard deviations, per course and per cohort

\begin{tabular}{|c|c|c|c|c|c|c|c|}
\hline \multirow[b]{2}{*}{ Course } & \multirow[b]{2}{*}{ Condition } & \multicolumn{2}{|c|}{ Cohort 1} & \multicolumn{3}{|c|}{ Cohort 2} & \multirow[b]{2}{*}{ SD } \\
\hline & & $\mathrm{N}$ & Mean & SD & $\mathrm{N}$ & Mean & \\
\hline \multirow[t]{2}{*}{$A$} & Student tutor & 27 & 5.7 & 1.6 & 30 & 5.4 & 1.6 \\
\hline & Staff tutor & 68 & 5.7 & 1.6 & 70 & 5.7 & 1.7 \\
\hline \multirow[t]{2}{*}{ B } & Student tutor & 32 & 5.9 & 1.2 & 15 & 4.8 & 1.7 \\
\hline & Staff tutor & 92 & 5.7 & 1.5 & 70 & 5.6 & 1.6 \\
\hline \multirow[t]{2}{*}{ C } & Student tutor & 17 & 6.6 & 1.7 & 14 & 6.5 & 1.5 \\
\hline & Staff tutor & 79 & 6.4 & 1.8 & 67 & 6.6 & 1.9 \\
\hline \multirow[t]{2}{*}{ D } & Student tutor & 12 & 5.8 & 1.8 & 28 & 6.2 & 1.5 \\
\hline & Staff tutor & 44 & 6.4 & 1.3 & 54 & 6.4 & 1.6 \\
\hline
\end{tabular}

The differences in achievement between students guided by a student tutor and those guided by a staff tutor are not significant and all effect sizes are small $(d \leq .50)$ (Table 4).

Table 4. Study achievements of students: results of the analysis of variance and effect size

\begin{tabular}{|c|c|c|c|c|c|c|}
\hline & \multicolumn{3}{|c|}{ Cohort 1} & \multicolumn{3}{|c|}{ Cohort 2} \\
\hline & $F$-value & $p$-value & $d(\mathrm{a})$ & $F$-value & $p$-value & $d(\mathrm{a})$ \\
\hline Course A & $F(1.95)=.37$ & $p=.85$ & .00 & $F(1.107)=.98$ & $p=.32$ & .18 \\
\hline Course B & $F(1.124)=.29$ & $p=.59$ & .00 & $F(1.85)=2.89$ & $p=.09$ & .49 \\
\hline Course C & $F(1.96)=.16$ & $p=.69$ & .11 & $F(1.81)=.13$ & $p=.72$ & .05 \\
\hline Course D & $F(1.56)=1.33$ & $p=.25$ & .42 & $F(1.82)=.40$ & $p=.53$ & .13 \\
\hline
\end{tabular}

Note: (a) Cohen's $d$ : $d>.50=$ medium; $d>.80$ = large

\section{Student perceptions}

The analyses of the questionnaire and the focus group show positive perceptions of both student and staff tutors. There are some significant differences but these are not consistent across courses. Table 5 shows the results on the questionnaire for the four factors. 
Table 5. Student perceptions (questionnaire): mean scores (1-5) and standard deviations, per course

\begin{tabular}{|c|c|c|c|c|c|}
\hline Course & Factor & Condition & $\mathrm{N}$ & Mean & SD \\
\hline \multirow[t]{2}{*}{ A } & Stimulating function & Student tutor & 50 & 3.6 & 1.0 \\
\hline & & Staff tutor & 142 & 4.1 & 0.8 \\
\hline \multirow[t]{2}{*}{ A } & Cognitive congruence & Student tutor & 50 & 3.8 & 1.0 \\
\hline & & Staff tutor & 142 & 4.3 & 0.7 \\
\hline \multirow[t]{2}{*}{ A } & Use of domain specific expertise & Student tutor & 50 & 3.6 & 1.0 \\
\hline & & Staff tutor & 142 & 4.2 & 0.7 \\
\hline \multirow[t]{2}{*}{ A } & Social congruence & Student tutor & 50 & 4.1 & 0.9 \\
\hline & & Staff tutor & 142 & 4.4 & 0.7 \\
\hline \multirow[t]{2}{*}{ B } & Stimulating function & Student tutor & 43 & 3.7 & 1.0 \\
\hline & & Staff tutor & 149 & 3.8 & 0.9 \\
\hline \multirow[t]{2}{*}{ B } & Cognitive congruence & Student tutor & 43 & 3.9 & 1.1 \\
\hline & & Staff tutor & 149 & 4.2 & 0.9 \\
\hline \multirow[t]{2}{*}{ B } & Use of domain specific expertise & Student tutor & 43 & 4.0 & 1.0 \\
\hline & & Stafftutor & 149 & 4.1 & 0.9 \\
\hline \multirow[t]{2}{*}{ B } & Social congruence & Student tutor & 43 & 4.1 & 1.1 \\
\hline & & Staff tutor & 149 & 4.3 & 0.9 \\
\hline \multirow[t]{2}{*}{$\mathrm{C}$} & Stimulating function & Student tutor & 31 & 3.8 & 0.8 \\
\hline & & Staff tutor & 141 & 3.8 & 0.9 \\
\hline \multirow[t]{2}{*}{ C } & Cognitive congruence & Student tutor & 31 & 4.0 & 0.7 \\
\hline & & Staff tutor & 141 & 4.1 & 0.8 \\
\hline \multirow[t]{2}{*}{ C } & Use of domain specific expertise & Student tutor & 31 & 3.7 & 0.7 \\
\hline & & Staff tutor & 141 & 3.9 & 0.8 \\
\hline \multirow[t]{2}{*}{ C } & Social congruence & Student tutor & 31 & 4.1 & 0.7 \\
\hline & & Staff tutor & 141 & 4.1 & 0.8 \\
\hline \multirow[t]{2}{*}{ D } & Stimulating function & Student tutor & 35 & 4.0 & 0.7 \\
\hline & & Staff tutor & 92 & 3.7 & 1.0 \\
\hline \multirow[t]{2}{*}{ D } & Cognitive congruence & Student tutor & 35 & 4.2 & 0.7 \\
\hline & & Staff tutor & 92 & 3.9 & 0.9 \\
\hline \multirow[t]{2}{*}{$D$} & Use of domain specific expertise & Student tutor & 35 & 4.0 & 0.9 \\
\hline & & Staff tutor & 92 & 3.9 & 0.9 \\
\hline \multirow[t]{2}{*}{ D } & Social congruence & Student tutor & 35 & 4.3 & 0.7 \\
\hline & & Staff tutor & 92 & 4.0 & 0.8 \\
\hline
\end{tabular}

The results for course A show more positive perceptions of staff tutors compared to students tutors for three factors: stimulating function: $\left(X^{2}=7.8, d f=1, p=.005\right)$; cognitive congruency: $\left(X^{2}=12.3, d f=1, p=.000\right)$, use of domain specific expertise: $\left(X^{2}=10.7, d f=1, p=.001\right)$. The effect sizes are medium $(d>.50)$ for stimulating function, cognitive congruency and use of domain specific expertise. There are no significant differences for social congruence in course A. Small effect size is found for social congruence. There are no significant differences between the perceptions of staff and student tutors for courses B, C and D. Small effect sizes were found for courses B, C and D.

During the focus group interview the importance of a good tutor was strongly emphasized by the students. The general view is that a good tutor is enthusiastic, knowledgeable and keeps students focused. The results of the focus group 
interview also indicate that students' perceptions of both staff tutors and student tutors are positive with regard to all the factors.

The stimulating function of the tutor The focus group interview shows that the stimulating function of the tutor is deemed very important by the students and that students see no differences between student and staff tutors in this respect.

"If you feel comfortable in a group and the tutor makes sure that all the students are actively involved and not afraid to ask questions, the discussion is better. In this respect, I don't see any difference between student tutors and staff tutors. No, they do it both, it depends on individual tutors."

Students say that both student tutors and staff tutors ask stimulating questions. Differences are related to individual tutors. The tutor's enthusiasm is considered a very important aspect of the stimulating function and students report no differences between staff and student tutors in this respect. According to the students, student tutors pay more attention to the introduction of new assignments.

"Student tutors take more time for the preliminary talk. They spend more time discussing the learning goals. Staff tutors are more likely to state: 'this is important."

Students agree that during the group sessions student tutors give more feedback about the assignments provided in the course book. Student and staff tutors both stimulate in-depth reporting of the results of self-study activities.

Cognitive congruency

Students indicate that student tutors show more cognitive congruency than do staff tutors.

"A staff tutor knows the literature so well that they don't see a difficult question as a problem. A student tutor can better relate to the students." "Student tutors are better able to give clear explanations. Student tutors do not use difficult terminology so often." "Student tutors can explain things more clearly, because to staff tutors everything is self-evident." "Staff tutors explain things differently. Student tutors are better at explaining things. Of course the best part is that I understand it." "Student tutors make remarks with respect to content at the right time. Staff tutors elaborate more on a subject because they have more knowledge." 
Students also remark that student tutors make more use of schemes and the whiteboard. This contributes to students' perception that student tutors explain more clearly. Additionally, students say that student tutors formulate questions in such a way that they are easier to understand.

"Student tutors ask a question that is clear and staff tutors ask such vague questions that everybody thinks: what is he talking about. Then a whole explanation has to follow. And then you think: oh yes, this is how we should interpret the question."

Students also say that student tutors have a better idea of students' prior knowledge.

"Student tutors know better what you already know and they can work with that. That's an advantage."

Domain specific expertise

Students think that staff tutors have more and make more use of domain specific expertise. This can be an advantage according to the students. Nevertheless, respondents noted that in the first year domain specific expertise is not so very important.

"Staff tutors use more difficult terminology. At first you think 'what am I supposed to do with that', but it is also nice to look it all up." "Staff tutors are more aware of the latest developments in their domain of expertise. When they tell you about that, you remember it."

\section{Social congruence}

There is unanimity among students that, compared to staff tutors, student tutors are more involved with the group and more open to their opinions.

"Some staff tutors may be quite open to students' opinions, but you don't have to give your opinion very often." "The advantage of student tutors is that they know what it is like to be a student. That studying is not the only thing you do, because older people think all you do is study and that is not true." "With student tutors the atmosphere is more open, because they know what it is like to study and that is also very nice."

\section{Discussion and conclusions}

Based on the assumption that the tutor's domain specific expertise can play an important role in the learning processes of students, one would expect that groups 
with a staff tutor do better on exams than groups with a student tutor (Schmidt et al., 1995). However, similar to studies by Kassab et al. (2005), Steele et al. (2000) and Moust \& Schmidt (1994), our study finds no such differences. The definition of domain specific expertise is of course arguable. The level of domain specific expertise required to promote effective learning in a PBL environment is not a given, but depends on students' prior knowledge and familiarity with PBL (Neville, 1999). Considering that tutors' domain specific expertise gains importance as students advance in knowledge (Moust, 1993; Schmidt et al., 1995), this factor might be of less importance in the first year of the curriculum. This appears to be born out by the results of the interviews in this study, which show that first-year students do not attach great importance to the tutor's domain specific expertise. Studies have shown that student tutors are likely to show more cognitive congruency (Moust \& Schmidt, 1995; Moust, 1993) and social congruency (Lockspeiser et al., 2008; Schmidt et al., 1995; Moust \& Schmidt 1995) with students. The results of the questionnaire do not support this, but the results of the focus group interview are in line with the differences reported in the literature between student tutors and staff tutors in domain specific expertise and in cognitive and social congruency. These results appear to support findings by Moust and Schmidt (1995) that student tutors' strong cognitive congruency compensates for their lack of domain specific expertise. The results of the focus group interview are also in line with claims that teacher-initiated revisions are less successful than peerinitiated revisions due to more interpretations of teacher feedback (Yang et al., 2006). The results of the focus group interview indicate that differences between staff and student tutors in domain specific expertise and cognitive and social congruency do not affect students' general perceptions of tutors. Finally, it appears from the interviews that students see the tutor role as very important to their learning and think that staff and student tutors are equally able to perform this role effectively. In general, students showed no preference for either group of tutors.

The quantitative results for perceptions in one of the four courses indicate that students take a more positive view of staff tutors than of student tutors. These significant differences in findings appeared in the first course of the year and may be explained by the fact that first-year students are unfamiliar with student tutors. Those differences in perceptions are not found consistently across courses. Further research would be needed to identify the causes of the incidental differences between perceptions of students and staff tutors.

Several limitations of the current study should be mentioned. A recurring question in research and in educational practice is what really influences achievement in PBL. This study is focussing on the advantages and disadvantage of working with student tutors in PBL. Also research on group dynamics, the quality of course materials, tutor interventions, motivation, expertise, the effects of reflective 
thinking could result in a clearer view on this important question. The limited number of variables is a limitation to the current study.

The grades of the end-of-the course exams, consisting of multiple choice questions and open-ended questions, are used to determine the study achievement. It would be interesting to search for effects with different assessment forms. A limitation of using the current assessment form with combination of multiple choice questions and open-ended questions is that those exams could asses mainly a knowledge construct, while the tutorial within PBL emphasizes other aspects.

Although the focus group sample size was appropriate for our goal, because of the specific selection of participants, it may be useful to work with more focus groups. The study has been conducted in a particular setting with freshmen PBL courses in only one university setting. Regarding the generalization of findings it would be better to have more respondents and more tutors.

Notwithstanding these limitations, the results of our study suggest several valuable and promising directions for future research. Overall, the added value of this study compared to earlier studies of peer tutoring is that the student tutors were carefully selected and extensively trained. The results of this study do not warrant conclusions with regard to the concrete impact and the importance of tutor selection and training. Because of the belief (Groves et al., 2005) that training and selection of tutors in a PBL curriculum is conducive to successful task performance, it seems worthwhile to examine whether there is a relationship between selection and training of student tutors and their performance. The design of this study - a rigorous selection of the student tutors and a profound training process - could explain why some previous studies comparing student tutors with staff tutors found effects disadvantageous for the student tutors. Further research, conforming those findings with well selected and well trained student tutors, is needed to elucidate on this.

In this study we studied student achievement and perception. As there are much more variables, giving valuable information about this student-staff comparison we would like to make some suggestions for further research hereupon. Further research could focus on level of interactivity in the groups, motivation, quality of course materials, expertise or the effects of reflective thinking. Also, it would be very interesting to analyze tutors' contributions in this research setting in a future study. Furthermore, research on differences in deep and surface approaches to learning between the student tutor and staff tutor condition would be useful.

Looking at the study achievements of students as an indicator for the quality of tutors, it is interesting to ask the question whether increasing grades over time and course could be attributed to the growth in expertise of the student tutor. It would be useful to offer all the student tutors of this study a second year of tutoring and 
then compare study achievement and perceptions of students over time with regard to the tutor growth in expertise of the student tutors. It is also a challenge to find out whether working with other assessment forms within a PBL setting shows similar results.

New studies should try to verify our findings by involving other knowledge domains and other educational settings. Future research could use a proxy measure in order to compare equal groups. Furthermore, it would be very interesting to look at the effects for the student tutors in further research. Also individual characteristics of the student tutors, such as experience in working with groups, can be considered in further research.

Concluding, the results for students' perceptions and exam results suggest that carefully selected and trained student tutors have neither a positive nor a negative impact. Student tutors are inevitably less experienced than staff tutors, but in the first curricular year this apparently does not translate to poorer exam results. The results of this study therefore warrant a negative answer to the research question. There appears to be no difference between staff tutors and rigorously selected and well trained student tutors with respect to students' achievements and perceptions. This study proves that well selected and well trained student tutors are ready to successfully undertake complex tutor responsibilities (Dolmans et al., 2002; Norman \& Schmidt, 1992). Giving good students the opportunity to participate in a student tutor programme thus appears to be justified, and can offer first year students an extra stimulus to get high grades in order to get selected for the programme.

\section{References}

Arco, J.L., Fernandez, D, Espin, A., \& Castro, M. (2006, October). A Cross-Age Peer Tutoring Program to Prevent Academic Failure and Drop-Out among first Year University Students. Paper presented at 36th ASEE/IEEE Frontiers in Education Conference, San Diego, CA.

Barrows, H.S., \& Tamblyn, R.M. (1980). Problem-based learning. New York, NY: Springer Publishing.

Bell, A., \& Mladenovic, R. (2008). The benefits of peer observation of teaching for tutor development. Higher Education, 55, 735-752.

Biggs, J. (2001). The reflective institution: assuring and enhancing the quality of teaching and learning. Higher Education, 41(3), 221-38.

Biggs, J.B. (2003). Teaching for quality learning at university. Buckingham: Open University Press.

Bloor, M., Frankland, J., Thomas, M., \& Robson, K. (2001) Focus Groups in Social Research. London: SAGE Publications Ltd.

Cho, K., \& Schunn, C. D. (2007). Scaffolded writing and rewriting in the discipline. Computers and Education, 48, 409-426.

Cohen, P. A. (1981). Student ratings of instruction and student achievement: A meta-analysis of multisection validity studies. Review of Educational Research, 51(3), 281-309. 
d'Appollonia, S., \& Abrami, P. C. (1997). Navigating student ratings of instruction. American Psychologist, 52(11), 1198-1208.

De Grave, W. S., De Volder, M. L., Gijselaers, W. H., \& Damoiseaux, V. (1990). Peer teaching and problembased learning: Tutor characteristics, tutor functioning, group functioning, and student achievement. In A. M. Nooman, H. G. Schmidt, \& E. S. Ezzat (Eds.), Innovation in Medical Education: An Evaluation of its Present Status (pp. 123-134). New York: Springer Publishing.

De Smet, M., Van Keer, H., \& Valcke, M. (2009). Cross-age peer tutors in asynchronous discussion groups: A study of the evolution in tutor support. Instructional Science, 37(1), 87-105.

De Smet, M., van Keer, H., \& Valcke, M. (2007). Peer tutoring in het hoger onderwijs: Een studie naar tutorgedrag binnen een online en face-to-face setting. [Peer tutoring in higher education: A study towards tutor behaviour within an online and face-to-face setting.] Tijdschrift voor Hoger Onderwijs, 25(1), 32-44.

De Volder, M. L., De Grave, W. S., \& Gijselaers, W. (1985). Peer teaching: Academic achievement of teacher-led versus student-led discussion groups. Higher Education, 14, 643-650.

Dochy, F., Segers, M., Van den Bossche, P., \& Gijbels, D. (2003). Effects of problem-based learning: a meta analysis. Learning and Instruction, 13, 533-568.

Dochy, F.J.R.C., \& de Rijke, T.R. (1995). Assessment centers. Nieuwe toepassingen in opleiding, onderwijs en HRM. Utrecht, Lemma.

Dolmans, D.H.J.M., Gijselaers, W.H., Moust, J.H.C., De Grave, W.S., Wolfhagen, I.H.A.P., \& van der Vleuten, C.P.M. (2002). Trends in research on the tutor in problem-based learning: conclusions and implications for educational practice and research. Medical Teacher, 24(2), 173-180.

Duran, D., \& Monereo, C. (2005). Styles and sequences of cooperative interaction in fixed and reciprocal peer tutoring. Learning and Instruction, 15, 179-199.

Gielen, S., Tops, L., Dochy, F., Onghena, P., \& Smeets, S. (2010). A comparative study of peer and teacher feedback and of various peer feedback forms in a secondary school writing curriculum. British Educational Research Journal, 36(1), 143-162.

Griffin, B. W., \& Griffin, M. M. (1997). The effects of reciprocal peer tutoring on graduate students' achievement, test anxiety, and academic self-efficacy. The Journal of Experimental Education, 65, 197-209.

Groves, M., Régo, P., \& O’Rourke, P. (2005). Tutoring in problem-based learning medical curricula: the influence of tutor background and style on effectiveness. BMC Medical Education, 5(20).

Hoffman, B., \& Ritchie, D. (1997). Using multimedia to overcome the problems with problem based learning. Instructional Science, 25(2), 97-115.

Hojat, M., \& Xu, G. (2004). A Visitor's Guide to Effect Sizes; Statistical Significance Versus Practical (Clinical) Importance of Research Findings. Advances in Health Sciences Education, 9, 241-249.

Hung, W. (2009). The 9-step problem design process for problem-based learning: Application of the 3C3R model. Educational Research Review, 4, 118-141.

Kassab, S., Abu-hijleh, M.F., Al-Shboul, Q.A., \& Hamdy, H. (2005). Student-led tutorials in problem-based learning: educational outcomes and students' perceptions. Medical teacher, 27(6), 521-526.

Krueger, R. A., \& Casey, M.A. (2000). Focus Groups: A practical guide for applied research (3 ${ }^{\text {rd }}$ ed.). California: SAGA Publications, Inc. 
Lockspeiser, T. M., O'Sullivan, P., Teherani, A., \& Muller, J. (2008). Understanding the experience of being taught by peers: the value of social and cognitive congruence. Advances in Health Sciences Education, 13, 361-372.

Marsh, H. W., \& Roche, L. A. (1997). Making students' evaluation of teaching effectiveness effective: The critical issues of validity, bias and utility. American Psychologist, 52(11), 1187-1197.

McKeachie, W.J. (1979). Student ratings of faculty: A reprise. Academe, 65(6), 384-397.

Min, H.-T. (2008). Reviewer stances and writer perceptions in EFL peer review training. English for Specific Purposes, 27, 285-305.

Moust, J.C., (1993). De rol van tutoren in probleemgestuurd onderwijs: contrasten tussen student- en docent-tutoren. [The role of the tutors in Problem Based Learning: contrasts between student- and staff-tutors.] (with English summary). Universitaire Pers, Maastricht, Nederland.

Moust, J., \& Schmidt, H. (1993). Comparing students and faculty as tutors: how effective are they?, in: P. Bouhuis (Ed.), PBL as an Educational Strategy (pp. 121-134). Maastricht: Network Publications.

Moust J.C., \& Schmidt, H.G. (1994). Effects of staff and tutors on student achievement. Higher Education 28, 471-482.

Moust, J.C., \& Schmidt, H.G. (1995). Facilitating small-group learning: a comparison of student and staff tutors' behavior. Instructional Science, 22, 287-301.

Nestel, D., \& Kidd, J. (2003). Peer tutoring in patient-centred interviewing skills: Experience of a project for first year students. Medical Teacher, 25, 398-403.

Nestel, D., \& Kidd, J. (2005). Peer tutoring in patient-centred interviewing skills: The impact on student tutors. Medical Teacher, 27, 439-444.

Neville, A.J. (1999). The problem-based learning tutor: Teacher? Facilitator? Evaluator? Medical teacher, 21(4), 393-401.

Norman, G., \& Schmidt, H. (1992). The psychological basis of problem-based learning: A review of the evidence. Academic Medicine, 67(9), 557-565.

Nunally, J. C., \& Bernstein, I. H. (1994). Psychometric theory ( ${ }^{\text {rd }}$ ed.). New York: McGraw-Hill.

Parr, J.M., \& Townsend, M.A.R. (2002). Environments, processes, and mechanisms in peer learning. International Journal of Educational Research, 37, 403-423.

Peterson, P.L., \& Swing, S.R. (1985). Students' cognitions as mediators of the effectiveness of small-group learning. Journal of Educational Psychology, 77, 299-312.

Pletinckx, J., \& Segers, M (2001). Programme Evaluation as an instrument for quality-assurance in a student-oriented educational system. Studies in Educational Evaluation, 27, 355-372.

Schmidt, H., Van Der Arend, A., Kokx, I., \& Boon, L. (1995). Peer versus staff tutoring in problem based learning. Instructional Science, 22, 279-285.

Secomb, J.A. (2008). A systematic review of peer teaching and learning in clinical education. Journal of Clinical Nursing, 17(6), 703-716.

Sluijsmans, D., Brand-Gruwel, S., van Merriënboer, J.J.G., \& Bastiaens, T. (2002). The training of peer assessment skills to promote the development of reflection skills in teacher education. Studies in Educational Evaluation, 29, 23-42.

Sobral, D. (1994) Peer tutoring and student outcomes in problem based learning course. Medical Education, 28, 284-289. 


\section{CHAPTER 6}

Steele, D.J., Medder, J.D., \& Turner, P. (2000). A comparison of learning outcomes and attitudes in student- versus faculty-led problem-based learning: an experimental study. Medical Education, 34, 23-29.

Topping, K.J. (1996). The Effectiveness of Peer Tutoring in Higher and Further Education: A typology and review of the literature. Higher Education, 32(3) 321-345.

Wadoodi, A., \& Crosby, J. R. (2002). Twelve tips for peer-assisted learning: A classic concept revisited. Medical Teacher, 24, 241-244.

Weyrich, P., Schrauth, M., Kraus, B., Habermehl, D., Netzhammer, N., Zipfel, S., Jünger, J., Riessen, R., \& Nikendei. C. (2008). Undergraduate technical skills training guided by student tutors. Analysis of tutors' attitudes, tutees' acceptance and learning progress in an innovative teaching model. BMC Medical Education, 8(18).

Yang, M., Badger, R., \& Yu, Z. (2006). A comparative study of peer and teacher feedback in a Chinese EFL writing class. Journal of Second Language Writing, 15, 179-200.

Yuen Lie Lim, L.-A. (2011). A comparison of students' reflective thinking across different years in a problem-based learning environment. Instructional Science, 39(2), 171-188. 
Chapter 7

Predictors and moderators of transfer of learning to the workplace within the area of staff development: Research review and critique 


\section{Introduction}

The goal of all staff development in higher education is that teachers apply the knowledge, skills and beliefs gained during staff development initiatives to their teaching practices. Changing teacher practices to positively influence student learning is the aim. In other words, the goal is the transfer of learning to the workplace. However, in their regular work environment teachers have to overcome a lot of barriers before they can really use their newly acquired knowledge, skills and beliefs. Management studies mention that only $10 \%$ of learning actually transfers to job performance (Fitzpatrick, 2001; Holton \& Baldwin, 2000; Kupritz, 2002). Transfer of learning to the workplace is not easy to achieve and is complex.

\section{Studying the impact of staff development}

An overview of educational articles studying the impact of staff development is given in earlier educational reviews. The reviews reveal some interesting findings. The first one is that they prove the complexity of transfer to the workplace. The reviews accentuate the difficulty of measuring the impact of staff development on transfer of learning to the workplace (McAlpine, 2003). More attention should be given to research studying the impact of staff development on transfer of learning, especially measuring actual changes in teacher performance (Stes et al., 2010b).

In order to gain insight into this complex process, previous reviews also emphasise the importance of more qualitative or mixed method studies (LevinsonRose \& Menges, 1981; Weimer \& Lenze, 1998; Steinert et al., 2006). The reviews reveal that well-designed studies are scarce and elucidate the importance of more and better-designed research on the impact of staff development (Levinson-Rose \& Menges, 1981; Steinert et al., 2006; Stes et al., 2010b; Weimer \& Lenze, 1998). A satisfying conclusion of Stes et al. (2010b) is that research on the impact of staff development is gaining importance.

Next to this the reviews make a call to researchers to take the individual differences of teachers participating in staff development initiatives into account (Levinson-Rose \& Menges, 1981). Also, a framework is needed for studies to build upon each other and to enable comparability of study results (Steinert et al., 2006; Stes et al., 2010b). Furthermore, the reviews illuminate the importance of taking related fields into account (Weimer \& Lenze, 1998).

Taking these conclusions of educational staff development reviews into account, we will describe what is lacking in educational research in the following paragraphs. In the succeeding part the research questions of the current review are presented. 


\section{Critique on the studies measuring the impact of staff development on transfer of learning}

Educational reviews by Levinson-Rose and Menges (1981), Steinert et al. (2006), Stes et al. (2010b), and Weimer and Lenze (1998) on the impact of staff development cluster studies on the basis of level of outcome (Kirkpatrick, 1998) measured. The model of Kirkpatrick (1998) distinguishes four levels of outcome: reaction, learning, behaviour and results (effect on the environment such as student learning outcomes). This model has become an accepted cornerstone of the classification of outcomes of interventions of staff development. The description of impact on the level of behaviour, being level three of Kirkpatrick's model, is the transfer of learning to the workplace.

Although Kirkpatrick's four level model serves a useful purpose because of its ease in classifying outcomes, we can criticise the model for the same reason. The lack of detail could be problematic with regard to the many different staff development initiatives existing. They differ in goal, method, length and so on. To make an accurate assessment of these staff development initiatives one must consider the variety of factors that can influence the learning of teachers. As stated in the educational review of Lawless and Pellegrino (2007) we must consider what works for whom and under what conditions. Unless we understand which factors influence the impact of staff development on transfer of learning it will be challenging to improve staff development. We need to understand which predictors actually lead to consequential effects. Furthermore, we have to gain insight into moderators in the relationship between predictors and transfer of learning. This means we have to broaden our view because major intervening variables affecting transfer of learning are not specified in Kirkpatrick's four level evaluation model (Holton, 1996).

Hence, it would be interesting to study the results of transfer studies in areas other than the educational field. Furthermore, it would be useful to investigate whether the results of this study could be of importance within the context of staff development in higher education. Such an approach enriches staff development research with knowledge from an interdisciplinary scientific angle, which could possibly lead to new insights and relevant suggestions for further research. In this review we will take such an approach. We will study management, HRD and organisational psychological research. With the insights of this study process we will review the educational research measuring the impact of staff development. Therefore this review will generate new knowledge to improve staff development by discovering new horizons in the research on the impact of staff development. 


\section{Research questions}

The findings of reviews on the impact of staff development demand more than isolated descriptive studies and call for information to assist staff developers in understanding the extent to which staff development initiatives are effective. As previous research lacks a systematic and clear predictor-moderator-transfer relationship, this review attempts to provide useful insights into the constitution of effective transfer of learning for teachers in higher education.

If we want to improve staff development we need to understand which factors and moderators do have influence. Therefore, the overall attempt of this review is to generate guidelines for further research to improve staff development, by revealing gaps in earlier research on the impact of staff development on transfer of learning to educational practice.

For this purpose we formulated the following research questions:

1. Which influencing factors - revealed in management, HRD and organisational psychology research - have an impact on transfer of learning?

2. Which moderating factors - revealed in management, HRD and organisational psychology research - have an impact on the relationship between predictors and transfer of learning?

3. Which of these influencing factors can be of importance within the context of staff development in higher education?

4. Which of these moderating factors can be of importance within the context of staff development in higher education?

5. Which influencing factors, additional to those found in management, HRD and organisational psychology research, can be found by studying the impact of staff development on transfer of learning to the workplace within the context of staff development in higher education?

\section{Method}

The method section consists of two parts. First we will present the method used to answer research questions 1 and 2 . In the second part we will explain the method used to answer research questions 3, 4 and 5. We will present the criteria for inclusion in our analysis. Afterwards we will present the procedures of our literature search, followed by the results of this search. Subsequently we introduce coding study characteristics and our synthesising research method. 


\section{Method part 1. Management, HRD and organisational psychology research}

\section{Inclusion criteria}

In our search for relevant literature on transfer in an attempt to answer research questions 1 and 2, the following criteria for inclusion were selected.

1. Studies had to be reviews.

2. Studies had to be in the field of management, HRD or organisational psychology.

3. Studies had to involve transfer of learning to the workplace or transfer of training to the workplace.

\section{Literature search procedures and search results}

We used the following keywords: transfer, learning, training, review. We conducted a search in the electronic database PsycINFO, Econlit and ERIC in February 2011. With each search the keywords 'transfer' and 'review' had to be in the title, in combination with the keywords 'learning' or 'training'. We did not limit the search in time, nor did we limit it in publication source.

This search resulted in 30 references. We read these articles and selected the manuscripts that reported a review study presenting a clear, extensive overview of predictors and moderators of transfer with support from extant evidence of previous research. As a result of this selection, three review studies (Baldwin \& Ford, 1988; Blume, Ford, Baldwin \& Huang, 2010; Burke \& Hutchins, 2007) were selected to build a framework upon.

\section{Method part 2. Educational research}

\section{Inclusion criteria}

In order to answer research questions 3, 4 and 5 we searched for relevant educational studies. Before searching the literature for work pertaining to the impact of staff development we determined the criteria for inclusion of our analysis. The following criteria had to be met for a study to be included in this review.

1. Studies had to involve a staff development activity or initiative in higher education. Based on De Rijdt, Dochy and Bamelis (2007) we defined staff development as follows: "Staff development is the coherent sum of activities targeted to strengthen and extend the knowledge, skills and beliefs of teachers in a way that will lead to changes in their way of thinking and their educational behaviour and to the maximisation of the learning process of their students. These changes continuously take place within the context of schools for higher education as organisations, and are aimed at the school team as an organised group. The focus is on the needs of the individual teacher and the school team. Staff development is the sum of 
the formal (e.g. workshops) and the informal (e.g. exchange of ideas among teachers) learning experiences of the teacher."

2. Studies had to involve a measure of transfer of learning to the workplace as a central object of the study. Based on Baldwin and Ford (1988) we defined transfer of learning to the workplace as a result of staff development as: 'the effective (generalization) and continuing (maintenance) application in the job environment of the skills, knowledge and beliefs gained in a staff development context'.

3. Studies had to be empirical.

\section{Literature search procedures and search results}

Because of differences in terminology in previous research the literature search is based on a variety of terms that can refer to staff development. Based on Stes, MinLeliveld, Gijbels and Van Petegem (2010) and Taylor and Rege Colet (2009) we composed a list of keywords: staff development, instructional development, instructional training, academic development, faculty development, faculty training, professional development, educational development, educational training, pedagogical training, and university teacher.

We conducted a search in the electronic database ERIC in February 2011. With each search one of the previously mentioned 11 keywords was indicated in the title in combination with the term 'teaching', which had to appear in the abstract. We did not limit the search in time, nor did we limit it in publication source.

This search resulted in 2211 references. We read the abstracts of these articles and selected the manuscripts that met the inclusion criteria. As a result of this selection, 134 studies were selected to be examined. One study was published in two different journals. We included this study only once. After careful reading of the full manuscripts of the 134 selected studies, 44 articles met our criteria for inclusion. Two of those selected articles report on two different interventions. Therefore, those studies are divided into two parts. The a part and the $b$ part are seen as two different studies in order to gain more specified insights. Two studies by Postareff, Lindblom-Ylänne and Nevgi $(2007,2008)$ investigate the same staff development interventions. Postareff et al., 2008 is a follow up study presenting the longitudinal effects. Both publications are coded. Both studies report on three staff development interventions varying in length. Because all three interventions are extended over time, we decided to categorise them in each of the two publications as one study. We coded the largest staff development intervention (30 ECTS-points or more). This brings us to a total of 46 studies included in our review.

\section{Coding of the studies}

The results of research questions 1 and 2 provided the conceptual framework we used for the coding of the educational studies measuring the impact of staff 
development. Each study was coded using the factors influencing transfer. We distinguished three groups of influencing variables, namely learner characteristics, intervention design, and work environment as presented in Figure 1 and explained in Table 1. Furthermore, outcomes measured were coded using the moderators in the relationship between predictors and transfer as presented in Figure 1 and explained in Table 2.

With the intention to refine Figure 1 with specific findings from educational research, we studied the articles with an open view looking for more influencing factors, retrieved from earlier educational reviews. Therefore, we put down characteristics of the learners and the staff development design in addition to those mentioned in the framework.

The following information was recorded in tables: (a) first author or two authors and year of publication, (b) learner characteristics, (c) intervention design, (d) work environment, (e) moderating factors, (f) research design, and (g) results (impact measured).

From the studies that met the criteria of inclusion we selected methods and results with regard to transfer measure. For example, an assessment which is part of a particular study but which measures the resulting increase in knowledge is not taken into account as this is no transfer measure.

Three coders with experience in educational research methodology and in the area of staff development were involved in the coding procedure. The coding procedure consisted of three stages. First, the three coders independently coded an initial set of seven studies. After doing so the three coders discussed problems encountered and lack of clarity, and as a result of this the guidelines for coding were revised. In the second phase one of the authors coded all the studies independently. In the third phase aspects that the coder felt unsure about were discussed by the three coders together until a consensus among all coders was reached. With these phases we increased coder consistency.

\section{Synthesising research}

The studies that met our inclusion criteria were 10 quantitative studies (22\%), 21 qualitative studies (46\%) and 15 studies with a mixed design (32\%). None of the quantitative studies mentioned effect sizes.

There are three methods of reviewing literature: meta-analyses, quantitative methods and qualitative reviews. Meta-analyses have one major advantage. Studies can vary substantially and still be integrated without being greatly influenced by the interpretation of the reviewer. Quantitative methods utilise simple mathematical procedures like vote counting. This means counting frequencies into box scores. Quantitative methods are more objective, however they give less in-depth information than a qualitative review. A qualitative, narrative review gives the author the opportunity to make sense of the literature in a creative way. By reading 
the studies carefully the author is interpreting the studies and is looking for patterns in the results.

For our review purposes and with the search results mentioned we opted for a quantitative vote counting method in combination with a narrative review method.

The vote counting method is used to search for predictors and moderators mostly mentioned in educational research (research questions 3, 4 and 5). The narrative method is used to interpret the selected reviews on transfer with the goal of answering research questions 1 and 2 . Furthermore, the narrative method is used to interpret the counting results and to decide on which variable further research is most needed (research questions 3, 4 and 5). The narrative method is also used for proposing additional influencing factors (research question 5).

\section{Results}

Part one of the results section reports on conclusions from management, HRD and organisational psychology research to answer research questions 1 and 2 . The findings are presented as new horizons in the research on the impact of staff development and are summarised in a conceptual framework.

Part two of the results section reports on conclusions from management, HRD and organisational psychology research mirrored in educational research. The conceptual framework is the guideline for those results. First we present an overview of our findings answering research questions 3 and 4. Next we elaborate on those findings in order to generate guidelines for further research to improve staff development. We take a closer look at the predictors of transfer that are most mentioned in educational research (research question 3). As those influencing factors are not measured in the educational studies, we look the strength of the relationship of that specific influencing factor with transfer in management, HRD and organisational psychology research. The review of Burke and Hutchins (2007) is used for this exercise. If in the review of Burke and Hutchins (2007) no strong or moderate relationship with transfer is proven, we indicate that research on this topic in the educational field is needed. We present our interpretations for the three groups of influencing variables, namely learner characteristics, intervention design and work environment. Subsequently we take a closer look at the moderators with the intention of providing guidelines for further research (research question 4). To do so our findings are compared with conclusions from the three selected reviews from the field of management, HRD and organisational psychology (Baldwin \& Ford, 1988; Blume, Ford, Baldwin \& Huang, 2010; Burke \& Hutchins, 2007).

Part three of the results section introduces new elements into the conceptual framework. We indicate factors, additional to those found in management, HRD and 
organisational psychology research, which can be of importance for the transfer of learning to the workplace within the field of staff development. These additional factors are retrieved from educational reviews of studies on the impact of staff development. In an attempt to guide staff developers and to generate guidelines for further research we refine the conceptual framework by including those new elements. Part three of this results section gives an answer to the fifth research question.

\section{Part 1. New horizons in the research on the impact of staff development}

In management, HRD and organisational psychological reviews on transfer we find similar descriptions of transfer to those in the staff development area: transfer of learning is defined as the degree to which learners effectively apply the knowledge, skills and beliefs gained in a learning context to the job (Baldwin \& Ford, 1988). Blume et al. (2010) conducted a meta-analytic review and defined transfer as consisting of two dimensions (Figure 1, right column). The first dimension is called generalisation. This is the extent to which the knowledge, skills and beliefs acquired in a learning setting are applied in different settings, or situations from those trained. The second dimension is maintenance. This is the extent to which changes that result from a learning experience persist over time. Also Baldwin and Ford (1988) stress that learned behaviour must be generalised to the job context and maintained over a period of time on the job in order to conclude that transfer has occurred.

Burke and Hutchins (2007) synthesise the knowledge of factors influencing transfer. An overview of these influencing factors is presented in Figure 1 (left column) and reveals three groups of influencing variables, namely intervention design, learner characteristics and work environment. Those influencing factors are substantiated by findings from a meta-analysis or at least two empirical studies in peer-reviewed journals. The influencing variables may either imply a benefit or a barrier to transfer occurring. For a description of the different influencing factors we refer to Table 1.

The most recent review on transfer of training is a meta-analysis of 89 empirical studies (Blume et al., 2010). The study quantitatively examines how decisions on research design affect reported relationships between influencing factors and transfer of learning. These research design decisions are labelled as moderators in the predictor-transfer relationship. These moderating factors are portrayed in Figure 1 (middle column). For a description of the different moderators we refer to Table 2.

We can conclude that the management, HRD and organisational psychology literature shows clear predictor-moderator-transfer relationships, which are interesting for research on impact of staff development. 
The outcomes from this research on reviews within the field of management, HRD and organisational psychology may provide our conceptual framework (Figure 1) for studying transfer within the area of staff development.

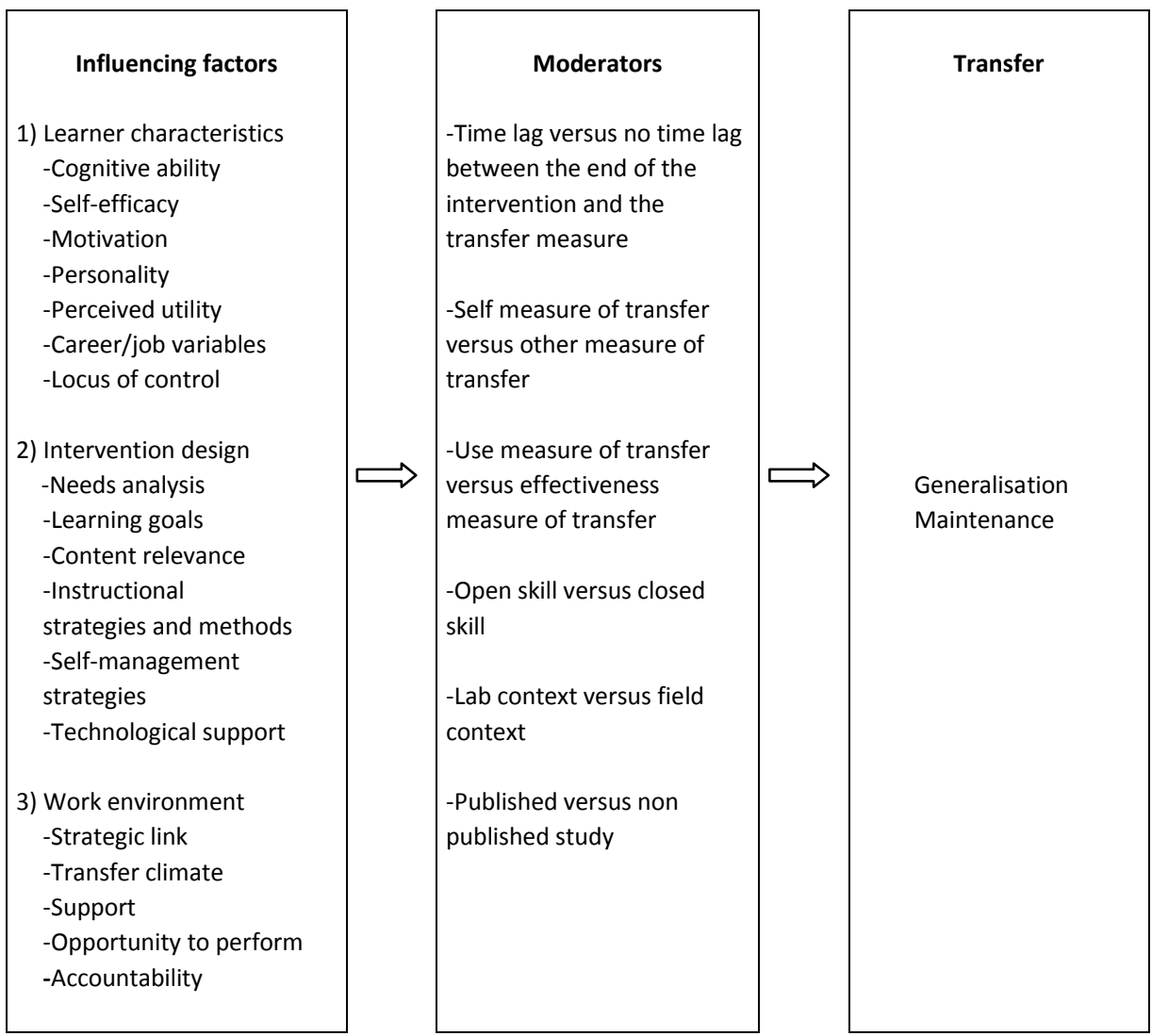

Figure 1. Conceptual framework for potential variables involved in transfer of learning in staff development interventions

Table 1. Predictors of transfer (based on Burke \& Hutchins, 2007).

Predictors Description

\section{LEARNER CHARACTERISTICS}

Cognitive ability

(1.Cognitive ability)

Self-efficacy

(2. Self-efficacy)
General mental ability.

Judgements individuals make about their competency to perform defined tasks. 


Predictors Description

Pre-intervention motivation

(3. Motivation)

Motivation to learn

(3. Motivation)

Motivation to transfer

(3. Motivation)

Extrinsic vs. intrinsic motivation

(3. Motivation)

Anxiety/Negativity

(4. Personality)

Affectivity

(4. Personality)

Conscientiousness

(4. Personality)

Openness to experience

(4. Personality)

Extroversion

(4. Personality)

Perceived utility

(5. Perceived utility)

Career planning

(6.Career/job variables)

Organisational commitment

(6.Career/job variables)

External vs. internal locus of control

(7. LOC)

\section{INTERVENTION DESIGN}

Needs analysis

(1. Needs analysis)

Learning goals

(2. Learning goals)

Content relevance

(3. Content relevance)
The intensity and persistence of efforts that learners apply in a learning-oriented improvement activity as measured before the intervention.

The intensity and persistence of efforts that learners apply in a learning-oriented improvement activity.

The learner's intended efforts to utilise skills and knowledge learned in a staff development setting to a real world work situation.

Extrinsic versus intrinsic reasons to attend a staff development intervention.

State of worry and nervousness.

The dispositional tendency of individuals to feel negative emotions.

The quality of being in accord with the motivation deriving logically from ethical or moral principles that govern a person's thoughts and actions.

Intellectual curiosity.

Being highly sociable.

Perceived value associated with staff development interventions.

The extent to which employees create and update specific plans for achieving their goals.

The degree to which an employee identifies with the job and actively participates in the organisation.

The extent to which individuals believe that they can control events that affect them.

Assess the cause of a performance situation to ensure an appropriate intervention is employed, prior to staff development interventions.

Explicitly communicated objectives.

The extent to which content, goals and materials are closely relevant to the transfer task. 


Predictors Description

Practice and feedback

(4. Instructional strategies and methods)

Over-learning

(4. Instructional strategies and methods)

Cognitive overload

(4. Instructional strategies and methods)

Active learning

(4. Instructional strategies and methods)

Behavioural modelling

(4. Instructional strategies and methods)

Error-based examples

(4. Instructional strategies and methods)

Self-management strategies

(5. Self-management strategies)

Technological support

(6. Technological support)

\section{WORK ENVIRONMENT}

Strategic link

(1. Strategic link)

Transfer climate

(2. Transfer climate)

Supervisory support

(3. Support)

Peer support

(3. Support)

Opportunity to perform

(4. Opportunity to perform)

Accountability

(5. Accountability)
The extent of rehearsal, practice and feedback that is given.

Repeated practice even after correct performance has been demonstrated.

Attempting to understand and interpret too much or irrelevant information at one time.

The use of models of instruction that focus the responsibility of learning on learners.

Learners are encouraged to mimic their specified role models in similar situations.

Sharing with the learner what can go wrong if they do not use the trained skills back on the job.

Equip learners with necessary skills to transfer what is learned to the workplace.

Information Technology tools geared specifically toward transfer.

The extent to which interventions support organisational goals and strategies.

Situations and consequences in organisations that either inhibit or facilitate the use of what is learned, during a staff development intervention, back on the job.

The support learners receive from their supervisor to use what is learned.

The support learners receive from their peers and colleagues to use what is learned.

Opportunities to use new learning in their work setting.

The degree to which the organisation, culture, and/or management expects learners to use new learning on the job and holds them responsible for doing so. 
Table 2. Moderators in the relationship between predictors and transfer (based on Blume et al., 2010)

\begin{tabular}{ll}
\hline Moderators & Description \\
\hline $\begin{array}{l}\text { Time lag versus no time lag between the } \\
\text { end of the intervention and the transfer }\end{array}$ & $\begin{array}{l}\text { Transfer measure can be taken immediately after the staff } \\
\text { measure }\end{array}$ \\
$\begin{array}{l}\text { Self measure of transfer versus other } \\
\text { measure of transfer }\end{array}$ & $\begin{array}{l}\text { The source of transfer rating: Self measure of transfer versus } \\
\text { other measure of transfer. }\end{array}$ \\
$\begin{array}{ll}\text { Use measure of transfer versus } \\
\text { effectiveness measure of transfer }\end{array}$ & $\begin{array}{l}\text { Transfer can be measured as the use of what is learned or as } \\
\text { the effectiveness of the learner in applying the knowledge and } \\
\text { skills. } \\
\text { Open skill versus closed skill }\end{array}$ \\
$\begin{array}{l}\text { Closed skills are skills that trainees have to adopt in essentially } \\
\text { the same form as they are presented in training. The trainee }\end{array}$ \\
has to imitate the trained behaviour. Open skills means that \\
the trainee has to be creative with the new information, skills \\
and beliefs in order to fit their personal needs. \\
The study is using a lab context versus field context.
\end{tabular}

\section{Part 2. Conclusions from management, HRD and organisational psychological research mirrored in educational research}

The results of our analysis of the research studying the impact of staff development are summarised in Table 3. From the three groups of predictors of transfer, the intervention design group received most attention in articles studying the impact of staff development. We will, however, discuss our results in the following paragraphs for the three predictor groups and for the moderator group chronologically.

\section{Influencing factor: Learner characteristics}

On the basis of our review we can conclude that motivation may be an influencing factor on transfer of staff development learning. As illustrated in Table 4, motivation to learn and especially motivation to transfer seem to be possible predictors of transfer in staff development initiatives. However, these are not the strongest predictors in management, HRD and organisational psychology research. Minimal empirical management, HRD and organisational psychology research exists on these two topics. Therefore, further educational research on motivation to learn and motivation to transfer is much needed. Educational empirical findings of direct or indirect relationships between those influencing factors and transfer of learning to teaching practices could establish our preliminary findings. 
CHAPTER 7

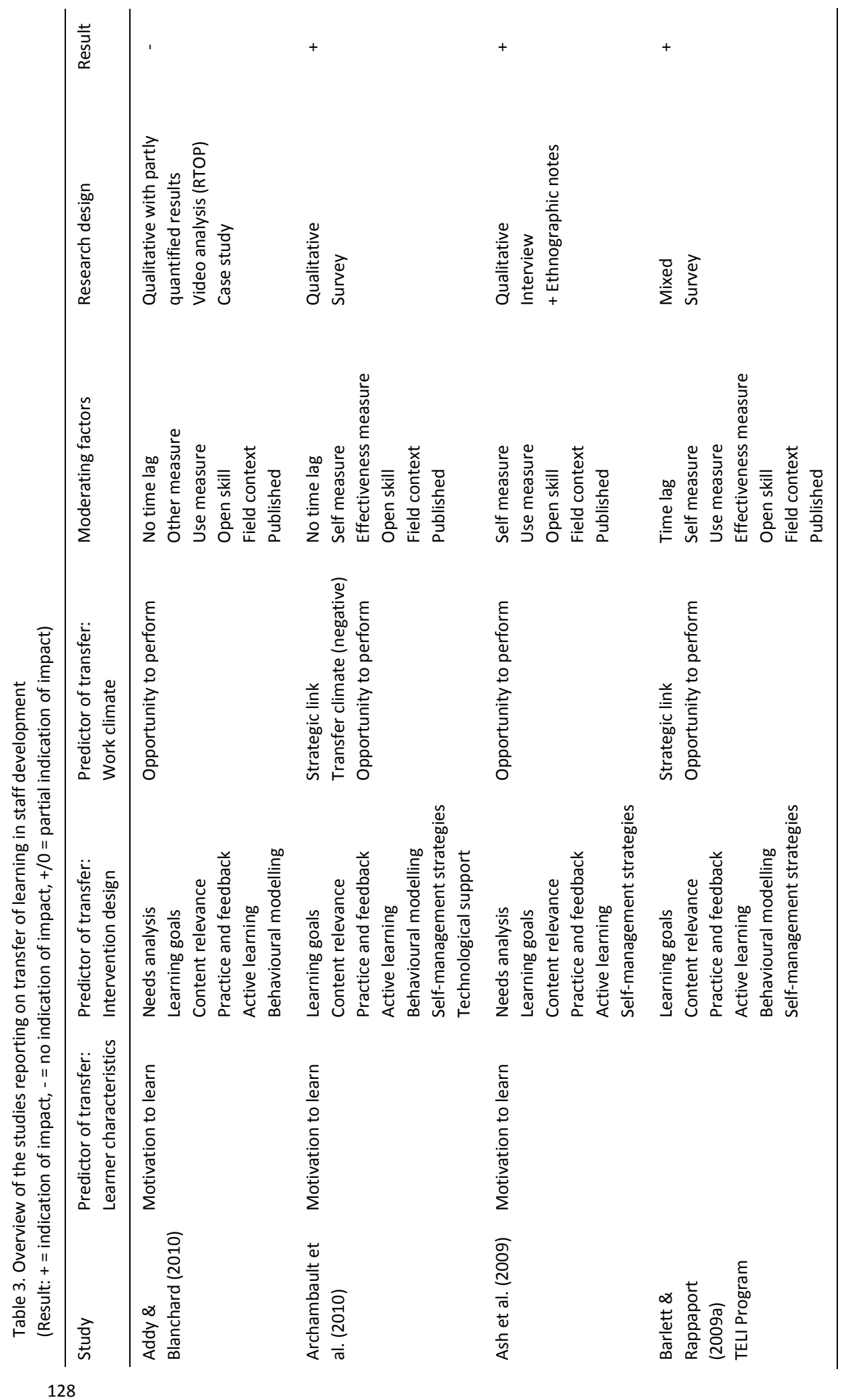


PREDICTORS AND MODERATORS OF TRANSFER OF LEARNING TO THE WORKPLACE

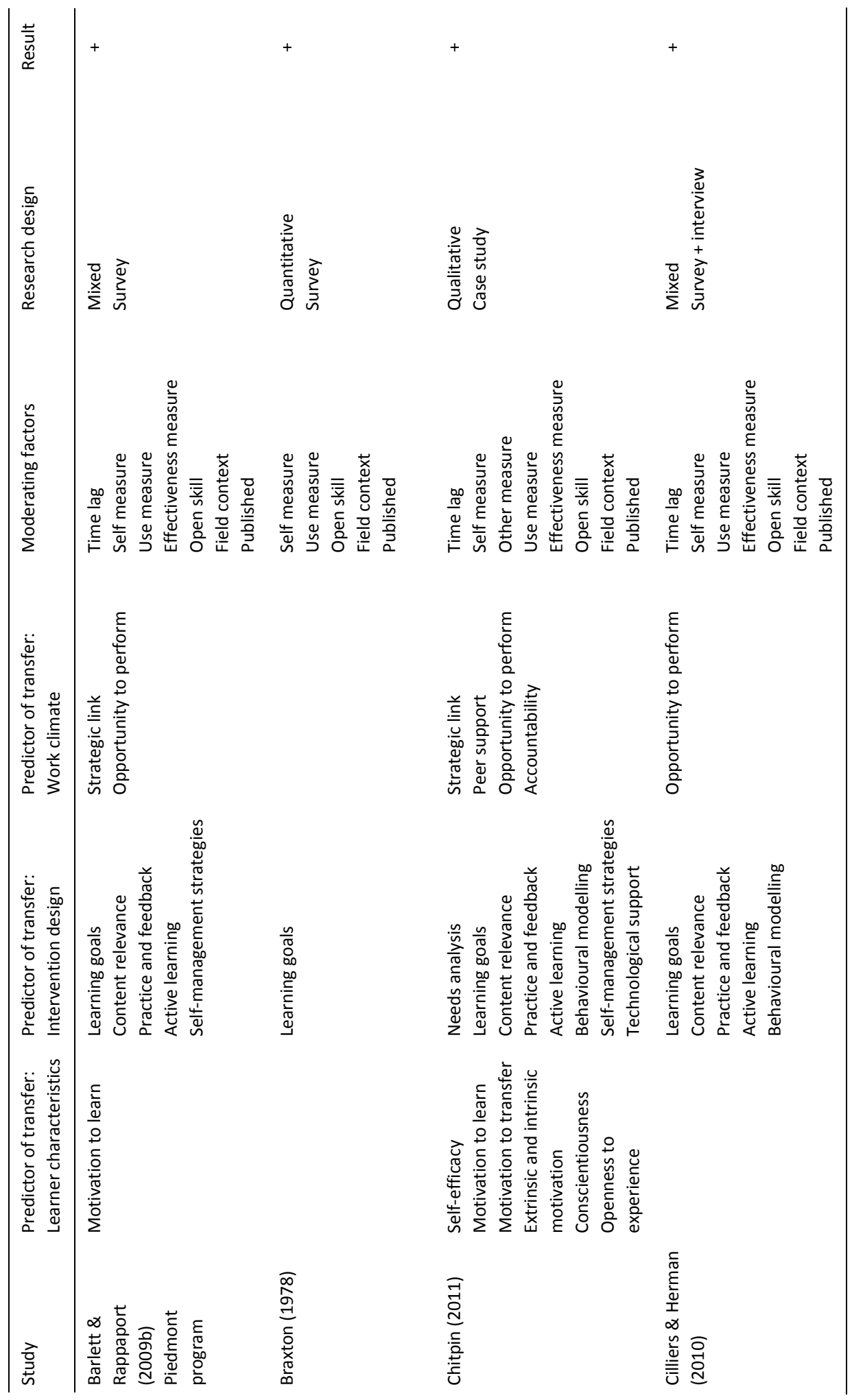


CHAPTER 7

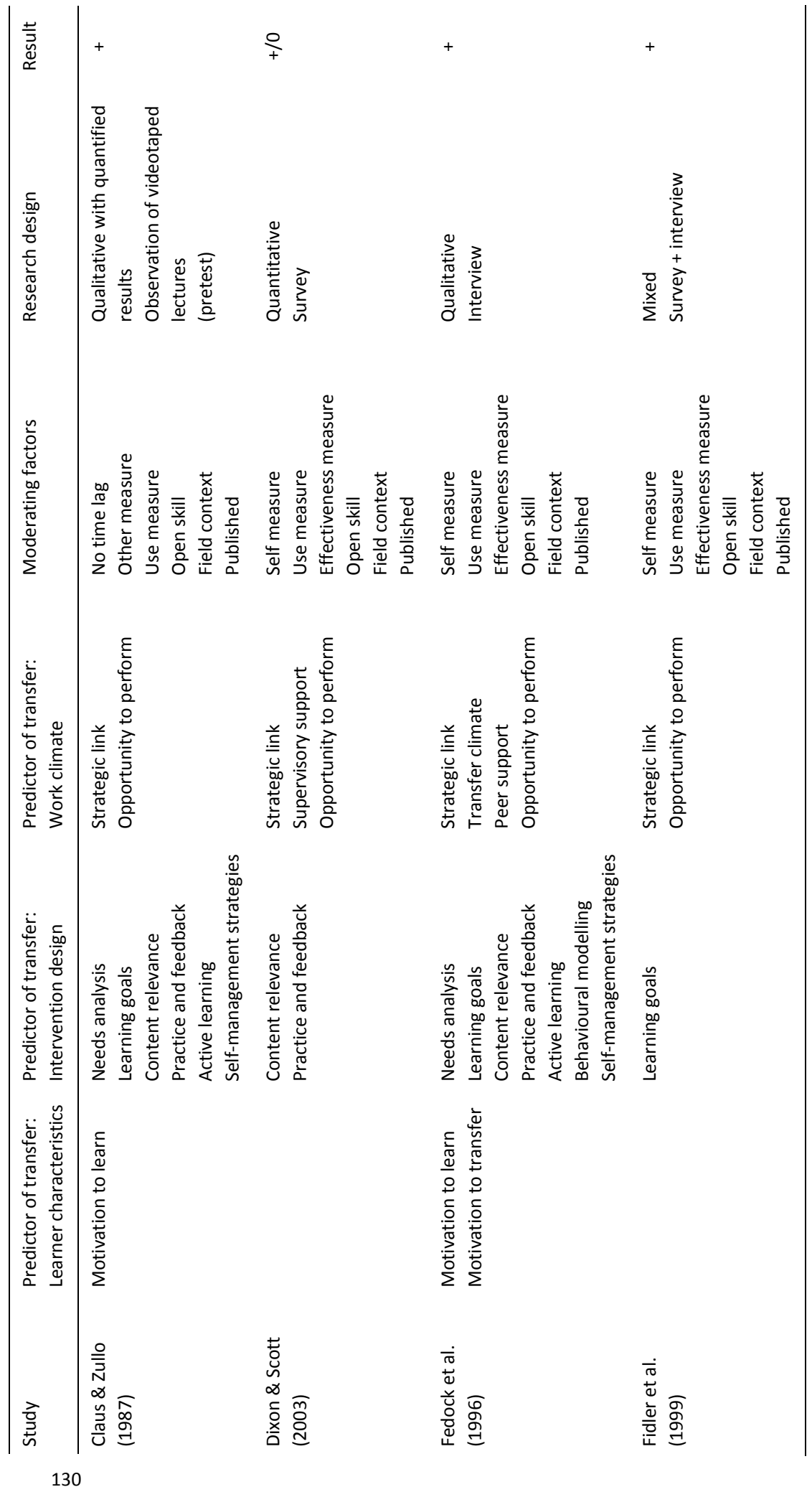


PREDICTORS AND MODERATORS OF TRANSFER OF LEARNING TO THE WORKPLACE

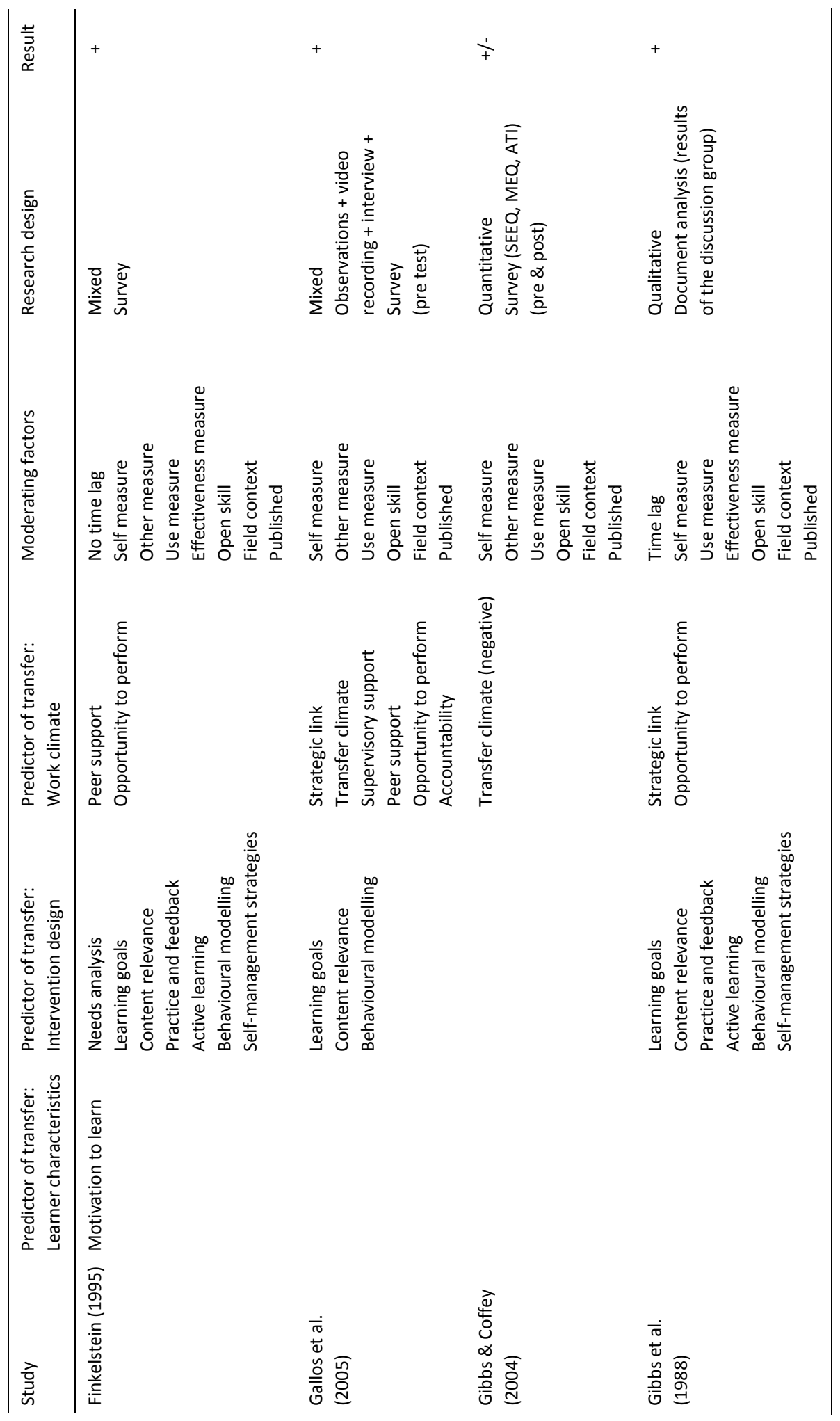


CHAPTER 7

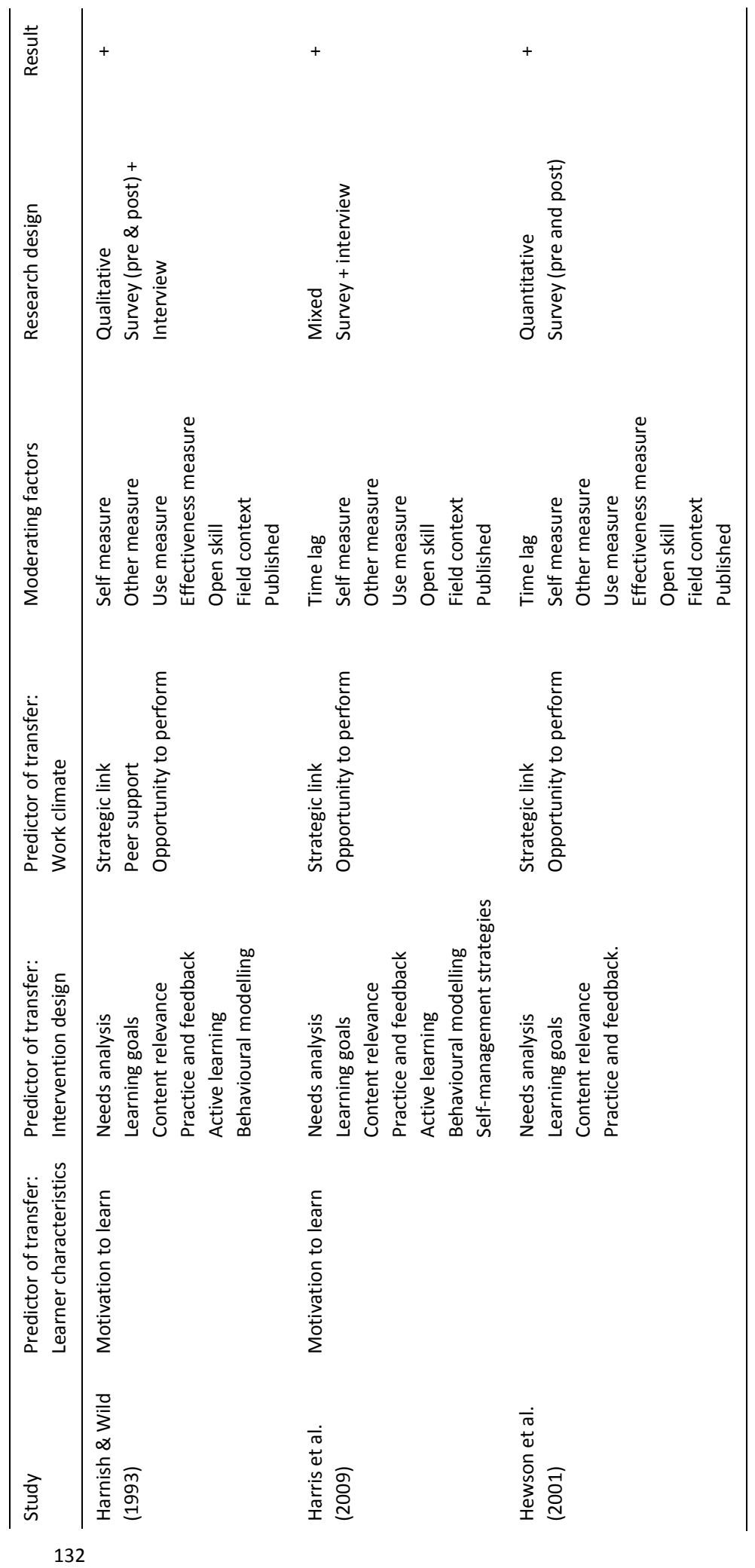


PREDICTORS AND MODERATORS OF TRANSFER OF LEARNING TO THE WORKPLACE

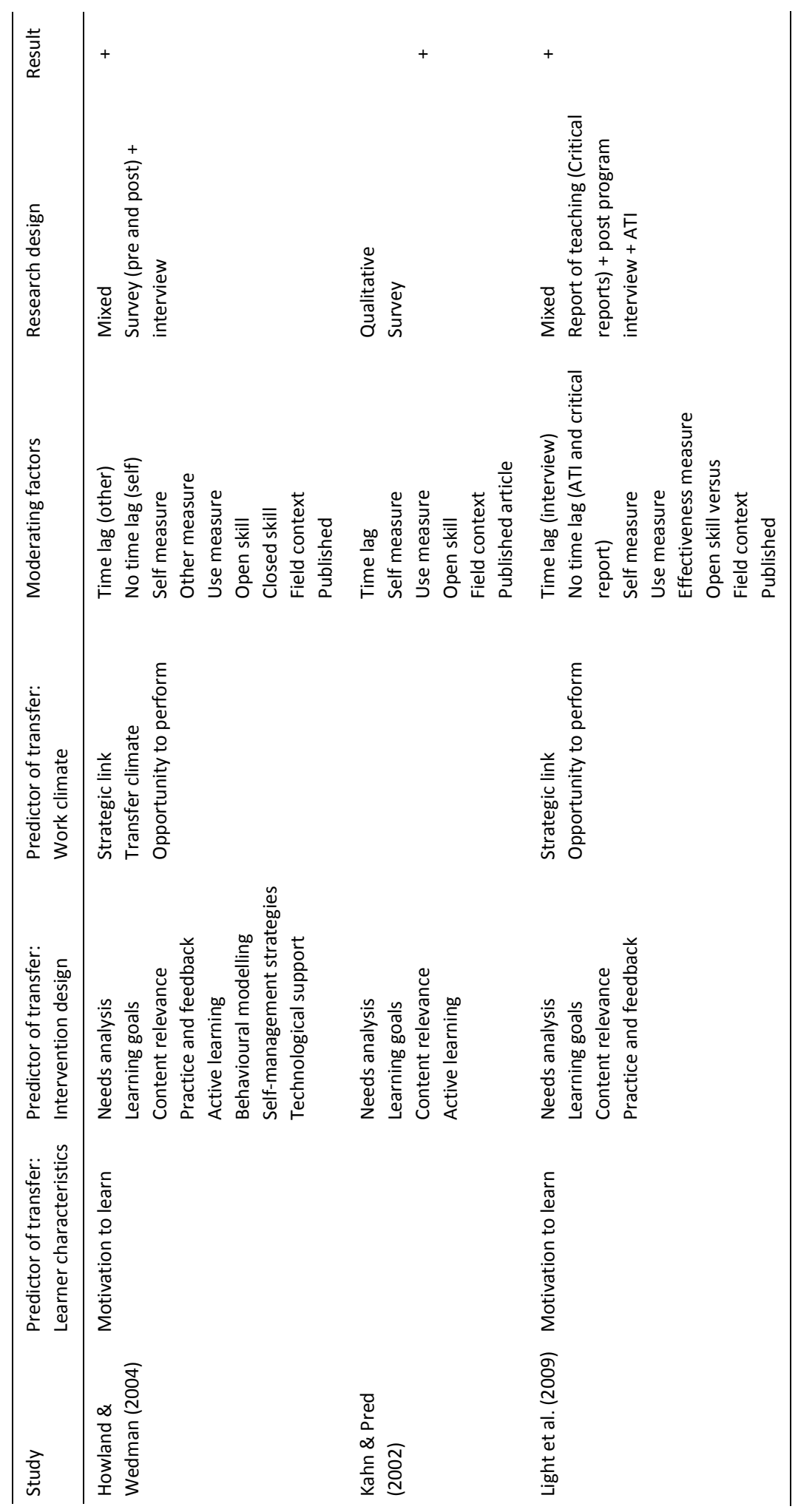


CHAPTER 7

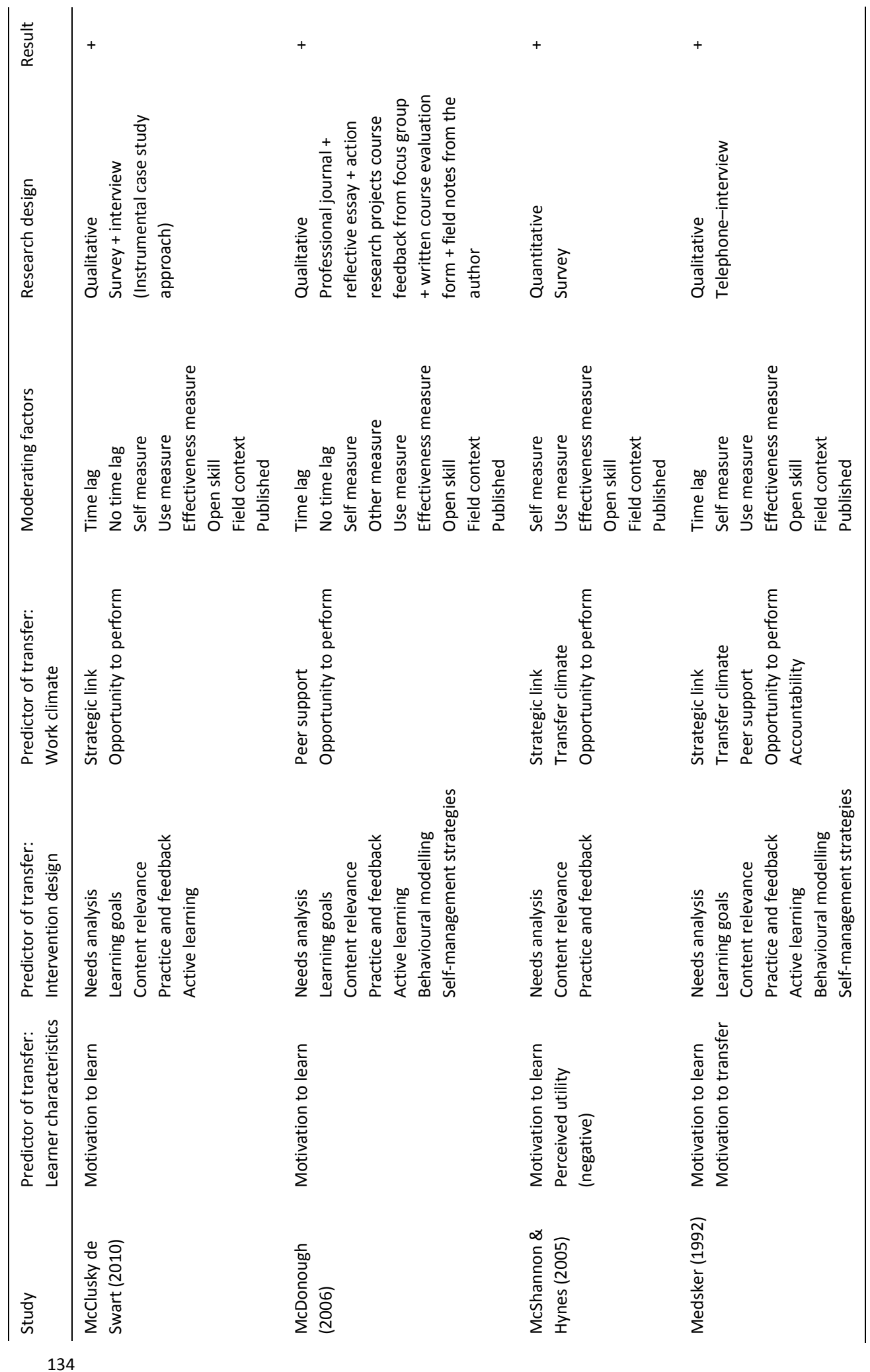




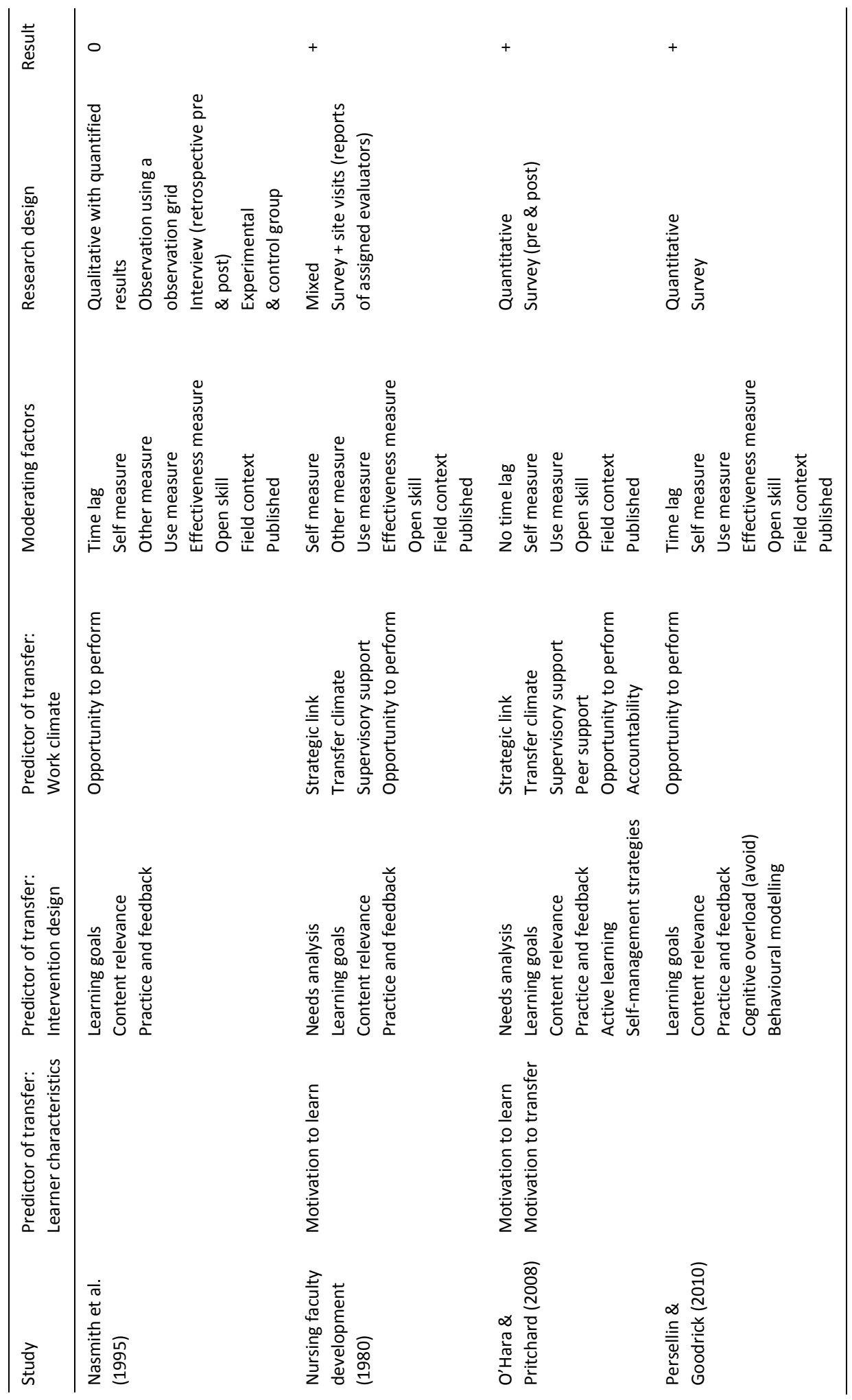


CHAPTER 7

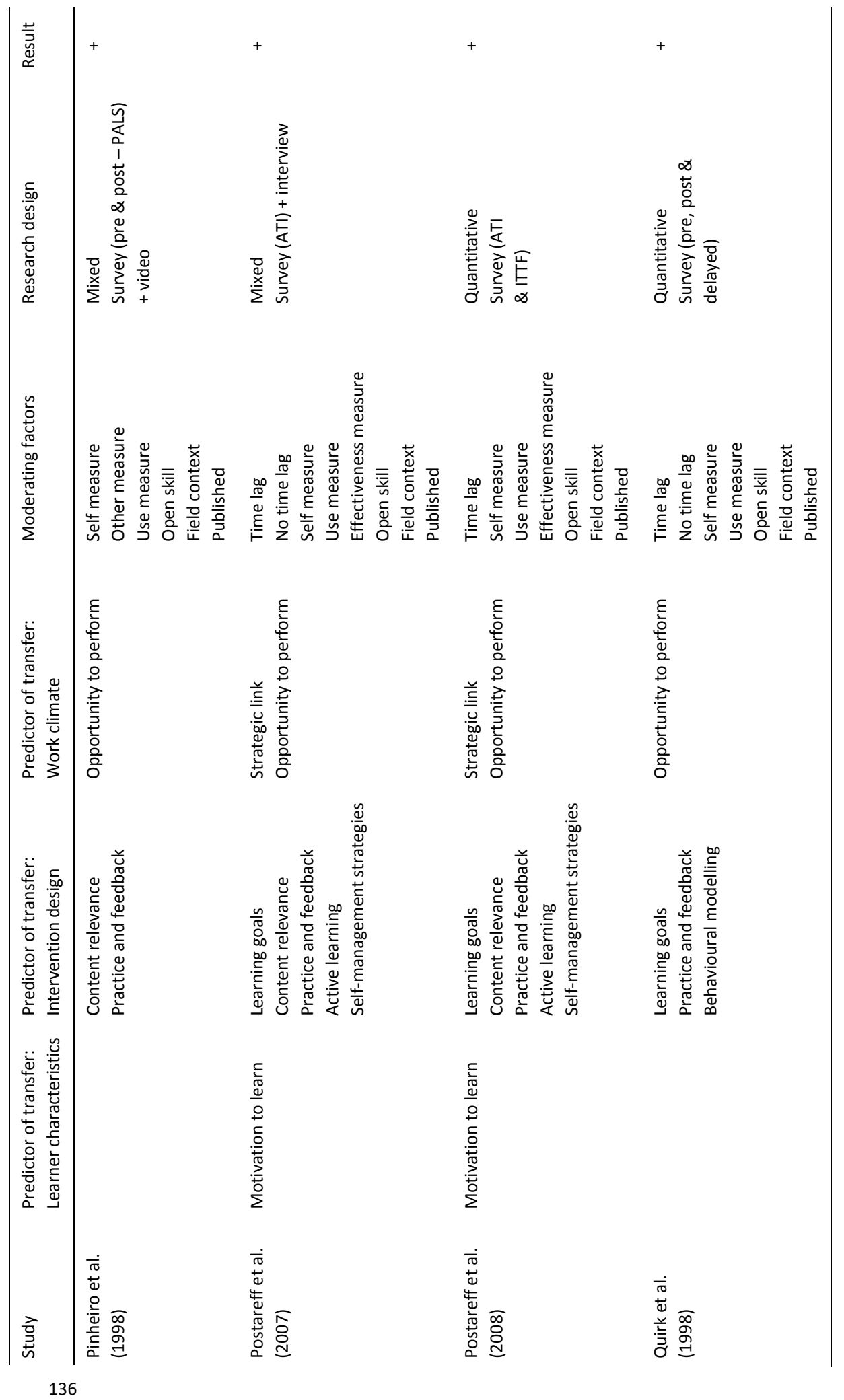


PREDICTORS AND MODERATORS OF TRANSFER OF LEARNING TO THE WORKPLACE

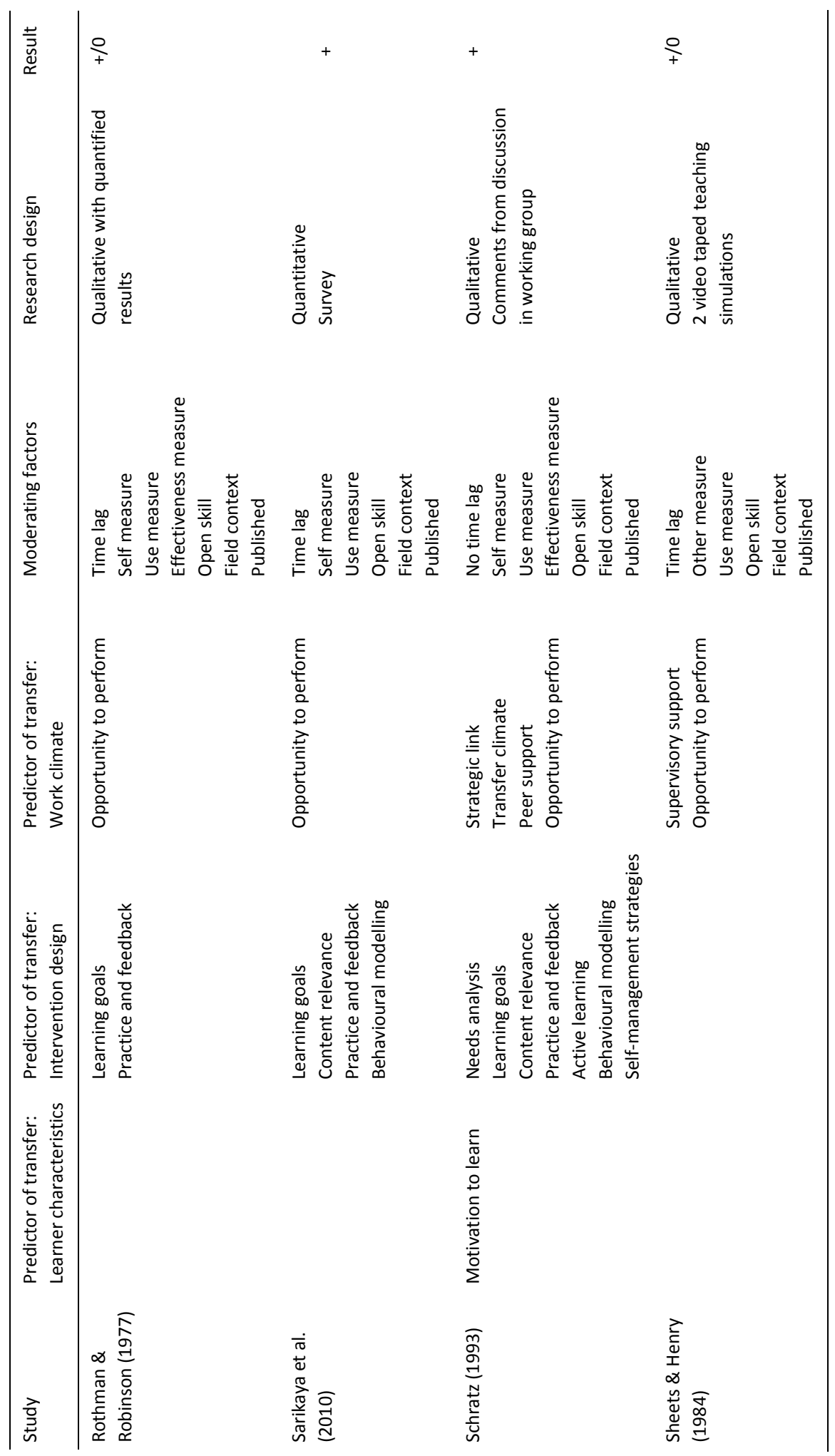


CHAPTER 7

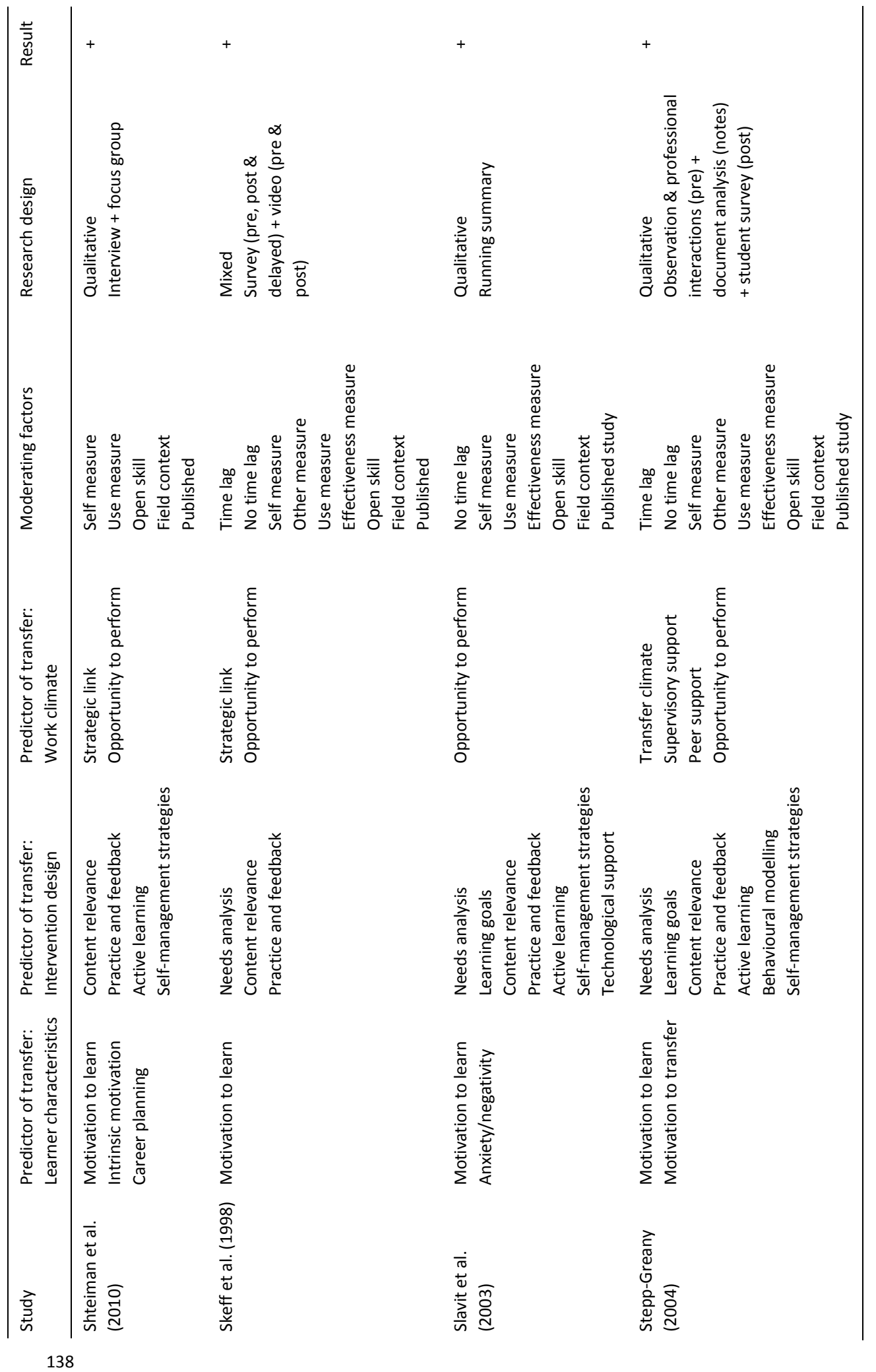


PREDICTORS AND MODERATORS OF TRANSFER OF LEARNING TO THE WORKPLACE

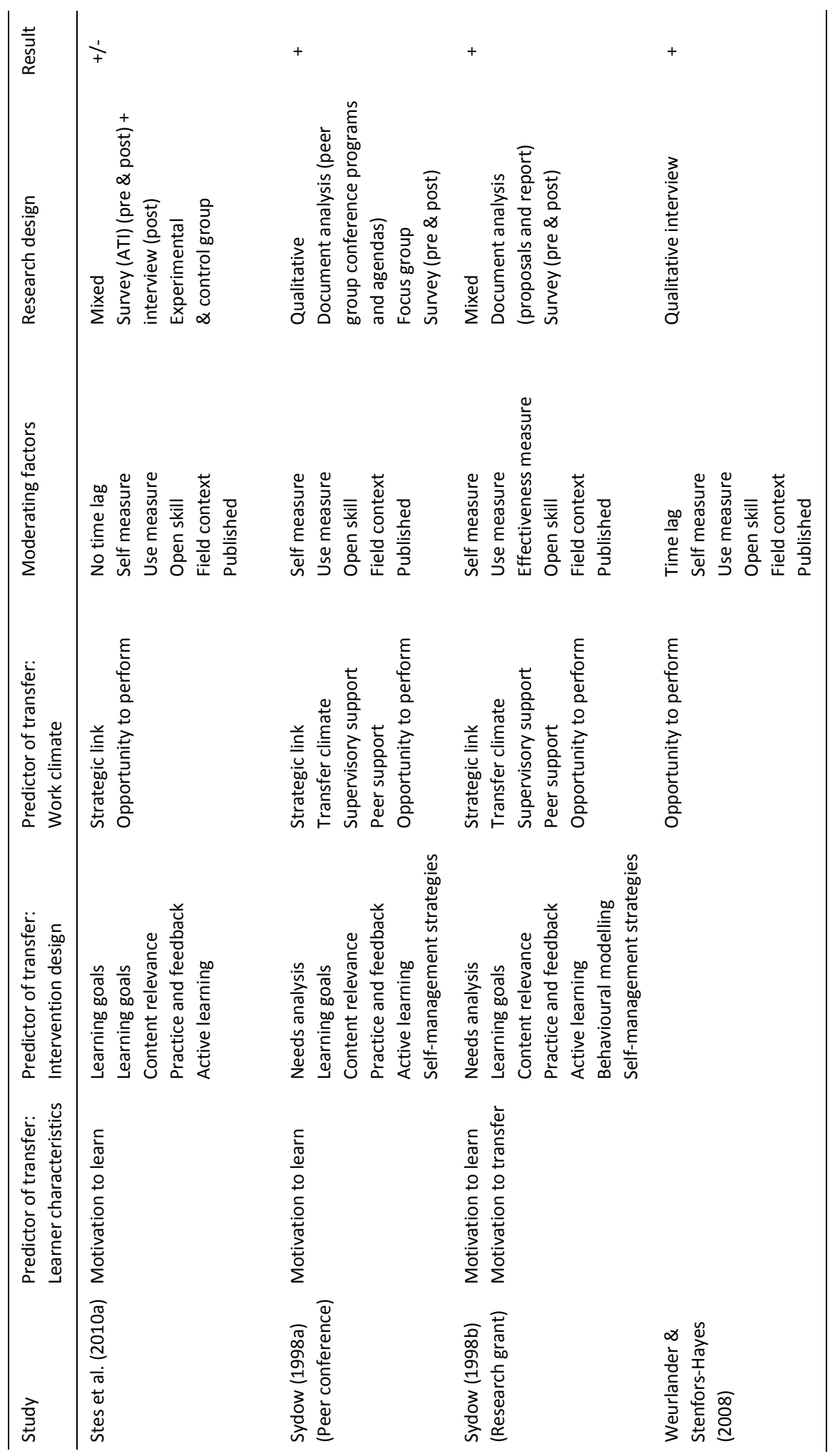


Table 4. Summary of learner characteristics

\begin{tabular}{|c|c|c|c|c|}
\hline $\begin{array}{l}\text { Predictor } \\
\text { LEARNER } \\
\text { CHARACTERISTICS }\end{array}$ & $\begin{array}{l}\text { Number of times a } \\
\text { relationship with } \\
\text { positive transfer } \\
\text { measure is found }\end{array}$ & $\begin{array}{l}\text { Number of times a } \\
\text { relationship with } \\
\text { mixed transfer } \\
\text { measure is found }\end{array}$ & $\begin{array}{l}\text { Number of times a } \\
\text { relationship with } \\
\text { negative transfer } \\
\text { measure is found }\end{array}$ & $\begin{array}{l}\text { Research within } \\
\text { the field of staff } \\
\text { development is } \\
\text { needed to clarify or } \\
\text { to build findings }\end{array}$ \\
\hline Cognitive ability & 0 & 0 & 0 & \\
\hline Self-efficacy & 1 & 0 & 0 & \\
\hline $\begin{array}{l}\text { Pretraining } \\
\text { motivation }\end{array}$ & 0 & 0 & 0 & \\
\hline Motivation to learn & 26 & 1 & 1 & $x$ \\
\hline $\begin{array}{l}\text { Motivation to } \\
\text { transfer }\end{array}$ & 6 & 0 & 0 & $x$ \\
\hline $\begin{array}{l}\text { Extrinsic vs. intrinsic } \\
\text { motivation }\end{array}$ & $\begin{array}{l}1 \text { (Extrinsic) } \\
2 \text { (Intrinsic) }\end{array}$ & 0 & 0 & \\
\hline Anxiety/Negativy & 1 & 0 & 0 & \\
\hline Affectivity & 0 & 0 & 0 & \\
\hline Conscientiousness & 1 & 0 & 0 & \\
\hline $\begin{array}{l}\text { Openness to } \\
\text { experience }\end{array}$ & 1 & 0 & 0 & \\
\hline Extroversion & 0 & 0 & 0 & \\
\hline Perceived utility & $\begin{array}{c}1 \text { (negative } \\
\text { perceived utility) }\end{array}$ & 0 & 0 & \\
\hline Career planning & 1 & 0 & 0 & \\
\hline $\begin{array}{l}\text { Organisational } \\
\text { commitment }\end{array}$ & 0 & 0 & 0 & \\
\hline $\begin{array}{l}\text { External vs. internal } \\
\text { locus of control }\end{array}$ & 0 & 0 & 0 & \\
\hline
\end{tabular}

\section{Influencing factor: Intervention design}

Management, HRD and organisational psychology research lacks empirical evidence for the relationship between needs analysis and transfer of learning. On the other hand, management, HRD and organisational psychology research shows a strong or moderate relationship between learning goals and content relevance.

As illustrated in Table 5, these three factors (needs analysis, learning goals and content relevance) seem to be possible predictors of transfer in staff development initiatives. We could hypothesise that needs analysis has an indirect relationship with transfer. The basic idea of this hypothesis is that appropriate learning goals, content, methods and environment can be assigned through needs analysis. Further educational research into this hypothesis must bring clarification. 
Table 5. Summary of intervention design

\begin{tabular}{|c|c|c|c|c|}
\hline $\begin{array}{l}\text { Predictor } \\
\text { INTERVENTION } \\
\text { DESIGN }\end{array}$ & $\begin{array}{l}\text { Number of times a } \\
\text { relationship with } \\
\text { positive transfer } \\
\text { measure is found }\end{array}$ & $\begin{array}{l}\text { Number of times a } \\
\text { relationship with } \\
\text { mixed transfer } \\
\text { measure is found }\end{array}$ & $\begin{array}{l}\text { Number of times a } \\
\text { relationship with } \\
\text { negative transfer } \\
\text { measure is found }\end{array}$ & $\begin{array}{l}\text { Research within } \\
\text { the field of staff } \\
\text { development is } \\
\text { needed to clarify or } \\
\text { to build findings }\end{array}$ \\
\hline Needs analysis & 23 & 0 & 1 & $x$ \\
\hline Learning goals & 34 & 2 & 2 & \\
\hline Content relevance & 35 & 2 & 2 & \\
\hline $\begin{array}{l}\text { Practice and } \\
\text { feedback }\end{array}$ & 34 & 3 & 2 & \\
\hline Over-learning & 0 & 0 & 0 & \\
\hline Cognitive overload & $\begin{array}{c}1 \text { (avoid } \\
\text { overload) }\end{array}$ & 0 & 0 & \\
\hline Active learning & 26 & 1 & 1 & $x$ \\
\hline $\begin{array}{l}\text { Behavioural } \\
\text { modelling }\end{array}$ & 19 & 0 & 1 & \\
\hline Error-based examples & 0 & 0 & 0 & \\
\hline $\begin{array}{l}\text { Self-management } \\
\text { strategies }\end{array}$ & 22 & 0 & 0 & $x$ \\
\hline $\begin{array}{l}\text { Technological } \\
\text { support }\end{array}$ & 4 & 0 & 0 & \\
\hline
\end{tabular}

Practice and feedback and behavioural modelling seem to have a positive impact on transfer of staff development learning. Empirical management, HRD and organisational psychology research have proven a strong relationship with transfer.

Most of the educational studies with an active learning intervention design show positive transfer results. However, no prior management, HRD or organisational psychological studies have reported on the relationship with transfer; active learning is not studied as a predictor of transfer of learning. This is a noteworthy gap in management, HRD and organisational psychological research. Also, none of the educational studies reviewed has measured the impact of active learning on transfer of learning within the area of staff development. We do not question that learners should be cognitively engaged during learning. However, this gap in the research on transfer of learning in the area of management, HRD and organisational psychological studies and in the area of impact of staff development needs to be resolved. Therefore, we indicate active learning as an important subject for further research.

All educational studies describing an intervention design with self management strategies only report positive outcomes on transfer. As minimal empirical 
management, HRD and organisational psychology research exists on this topic, further research is needed. Table 5 displays a summary of our findings on intervention design.

\section{Influencing factor: Work environment}

In educational research the existence of a 'strategic link' and a positive 'transfer climate' are associated with positive transfer outcomes. In management, HRD and organisational psychology research these influencing factors are subjects for further research, although positive effects are registered. Therefore, further research within the complex and specific context of higher education is desirable.

In management, HRD and organisational psychology research just as in educational research, we find indications that peer support positively influences transfer of learning. Adversely, the influence of supervisory support needs further clarification in both research areas. Table 6 shows a summary of our findings on work environment.

Table 6. Summary of work environment

\begin{tabular}{|c|c|c|c|c|}
\hline $\begin{array}{l}\text { Predictors } \\
\text { WORK } \\
\text { ENVIRONMENT }\end{array}$ & $\begin{array}{l}\text { Number of times } \\
\text { a relationship } \\
\text { with positive } \\
\text { transfer measure } \\
\text { is found }\end{array}$ & $\begin{array}{l}\text { Number of times } \\
\text { a relationship } \\
\text { with mixed } \\
\text { transfer measure } \\
\text { is found }\end{array}$ & $\begin{array}{l}\text { Number of times } \\
\text { a relationship } \\
\text { with negative } \\
\text { transfer measure } \\
\text { is found }\end{array}$ & $\begin{array}{l}\text { Research within } \\
\text { the field of staff } \\
\text { development is } \\
\text { needed to clarify } \\
\text { or to build } \\
\text { findings }\end{array}$ \\
\hline Strategic link & 26 & 2 & 0 & $\mathrm{x}$ \\
\hline Transfer climate & 12 & 1 (negative) & 0 & $\mathrm{x}$ \\
\hline $\begin{array}{l}\text { Supervisory } \\
\text { support }\end{array}$ & 6 & 2 & 0 & $\mathrm{x}$ \\
\hline Peer support & 12 & 0 & 0 & \\
\hline $\begin{array}{l}\text { Opportunity to } \\
\text { perform }\end{array}$ & 37 & 4 & 2 & \\
\hline Accountability & 4 & 0 & 0 & \\
\hline
\end{tabular}

\section{Moderating factors}

On the one hand one could predict that impact measures without a time lag show more positive results because this situation refers to near transfer in a temporal context. However, as change is a complex process we could also assume that the learner needs time for the transfer process to take place. Furthermore, the learner could need that time lag to have the opportunity to transfer knowledge, skills and beliefs. Our review shows no clear trends on this moderator. With regard to time lag 
versus no time lag in educational impact studies, no conclusions can be drawn. Burke and Hutchins (2007) accentuate that the research design of studies into transfer of learning should change from a short term measure to a retention interval of 12 months. Nevertheless, because of the inconclusiveness in educational research we suggest further research with both time lag conditions (short and long term time lag).

Most of the educational studies rely on self reports. Blume et al. (2010) reveal that transfer measures based on self reports have consistently stronger relationships with predictor variables than transfer measures based on the reports of others. In educational research self reports as estimations of competencies systematically show that self reports are not valid (Eva \& Regehr, 2005; Gordon, 1991). Therefore, educational research on transfer of learning needs to switch from a single source data to a multiple source design. A combination of self and multiple other measures, such as supervisor, colleague and student measures, is necessary to gain more insight into the process of transfer.

In our review we make a distinction between a use measure of transfer (the use of what is learned) and an effectiveness measure of transfer (the effectiveness of the learner in applying the knowledge and skills). The majority of the educational studies examined describe a use measure of transfer. In management, HRD and organisational psychology research, use measures yield a slightly stronger predictortransfer relationship than effectiveness measures (Blume et al., 2010). However, because of the small amount of studies involved, no strong conclusions can be drawn in management, HRD and organisational psychology research. We consider both measures, use and effectiveness measures, to be important for further educational research on staff development.

All of the studies mention open skills. One study mentions both open and closed skills. Teaching aims to diagnose and make use of variability, rather than implement uniform techniques or routines (Darling-Hammond \& Snyder, 2000). It seems logical that impact studies measure open skills.

All of the educational studies report a field context. However, it would be interesting to create a lab context for studies measuring the impact of staff development.

Table 7 shows a summary of our findings on moderating factors. 
Table 7. Summary of moderating factors

\begin{tabular}{|c|c|c|c|c|}
\hline $\begin{array}{l}\text { Moderators in the } \\
\text { relationship } \\
\text { between } \\
\text { predictors and } \\
\text { transfer }\end{array}$ & $\begin{array}{l}\text { Number of times } \\
\text { a relationship } \\
\text { with positive } \\
\text { transfer measure } \\
\text { is found }\end{array}$ & $\begin{array}{l}\text { Number of times } \\
\text { a relationship } \\
\text { with mixed } \\
\text { transfer measure } \\
\text { is found }\end{array}$ & $\begin{array}{l}\text { Number of times } \\
\text { a relationship } \\
\text { with negative } \\
\text { transfer measure } \\
\text { is found }\end{array}$ & $\begin{array}{l}\text { Research within } \\
\text { the field of staff } \\
\text { development is } \\
\text { needed to clarify } \\
\text { or to build findings }\end{array}$ \\
\hline $\begin{array}{l}\text { Time lag between } \\
\text { the end of the } \\
\text { intervention and } \\
\text { the transfer } \\
\text { measure }\end{array}$ & 21 & 2 & 1 & $x$ \\
\hline $\begin{array}{l}\text { No time lag } \\
\text { between the end } \\
\text { of the } \\
\text { intervention and } \\
\text { the transfer } \\
\text { measure }\end{array}$ & 14 & 1 & 1 & $x$ \\
\hline $\begin{array}{l}\text { Self measure of } \\
\text { transfer }\end{array}$ & 38 & 4 & 0 & $x$ \\
\hline $\begin{array}{l}\text { Other measure of } \\
\text { transfer }\end{array}$ & 13 & 2 & 2 & $x$ \\
\hline $\begin{array}{l}\text { Use measure of } \\
\text { transfer }\end{array}$ & 38 & 5 & 2 & $x$ \\
\hline $\begin{array}{l}\text { Effectiveness } \\
\text { measure of } \\
\text { transfer }\end{array}$ & 25 & 2 & 0 & $x$ \\
\hline Open skill & 39 & 5 & 2 & $x$ \\
\hline Closed skill & 1 & 0 & 0 & \\
\hline Lab context & 0 & 0 & 0 & \\
\hline Field context & 39 & 5 & 2 & \\
\hline
\end{tabular}

\section{Part 3. Refining the conceptual framework: Additional influencing factors and moderators}

In the previous section we clarified whether predictors and moderators revealed by management, HRD and organisational psychology research are likewise of importance within the context of staff development in higher education. We pointed out the variables that need further research the most.

In the following part we rely on earlier educational reviews on the impact of staff development to suggest some more possible predictors which are not mentioned in management, HRD and organisational psychology research. We describe the additional predictors and review the studies that met our inclusion criteria regarding these additional predictors of transfer of learning. For each 
additional influencing factor a preliminary conclusion is presented. With these new elements we refine the conceptual framework.

In the following section we present four additional predictors of transfer of learning, namely amount of experience, nature of the intervention, amount of time spent and learning climate.

\section{Amount of experience}

Many staff development activities target new faculty members (Weimer \& Lenze, 1998). Weimer and Lenze (1998) make a call for studies looking at the impact of staff development on specific faculty groups. The review of Stes et al. (2010b) searched for evidence that staff development initiatives targeting teaching assistants or new faculty members had more positive outcomes than other or non specific target groups. The results of the review showed a lack of evidence. No conclusions could be formulated. In reaction to these previous reviews we label the amount of experience (novices versus experienced teachers) as an additional predictor of transfer of learning in staff development.

In our review teachers with less than five years of experience are defined as novices. Teachers with more than five years of experience are defined as experts. We classified our studies into three classes depending on the amount of experience of the target group: novice teachers, experienced teachers or both novice and experienced teachers.

Table 8 shows the results of our findings on amount of experience. Six studies examine the transfer of learning of novice teachers. Three of those six studies report positive transfer results. Two studies show partial impact and one study finds no impact on transfer of learning. All of the studies (6) with experienced teachers report positive results. Most of the studies (20) report on staff development interventions for both novice and experienced teachers. One of those 20 studies shows negative results and two studies report partial impact. A preliminary conclusion is that experienced teachers show more transfer of learning to the workplace than their novice colleagues. Another preliminary finding is that those novice teachers show more transfer of learning after collaboration with more experienced colleagues. Novice teachers will gain from methods where novices can learn through collaboration with others and by working alongside more experienced colleagues. Communities of practice are an example of such a method (Barab MaKinster \& Scheckler, 2003). As these conclusions are preliminary and further research into the hypothesis is needed. 
CHAPTER 7

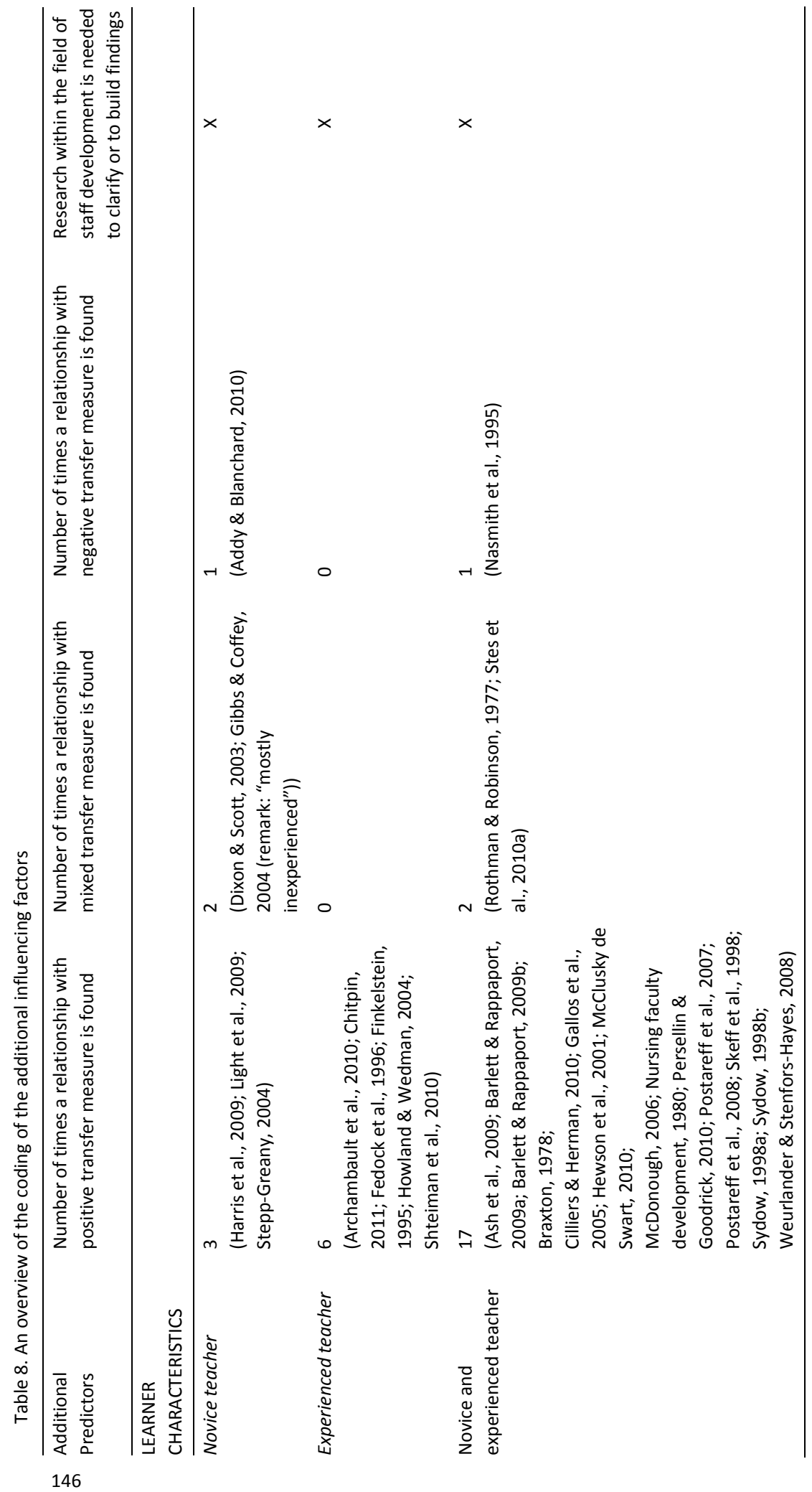




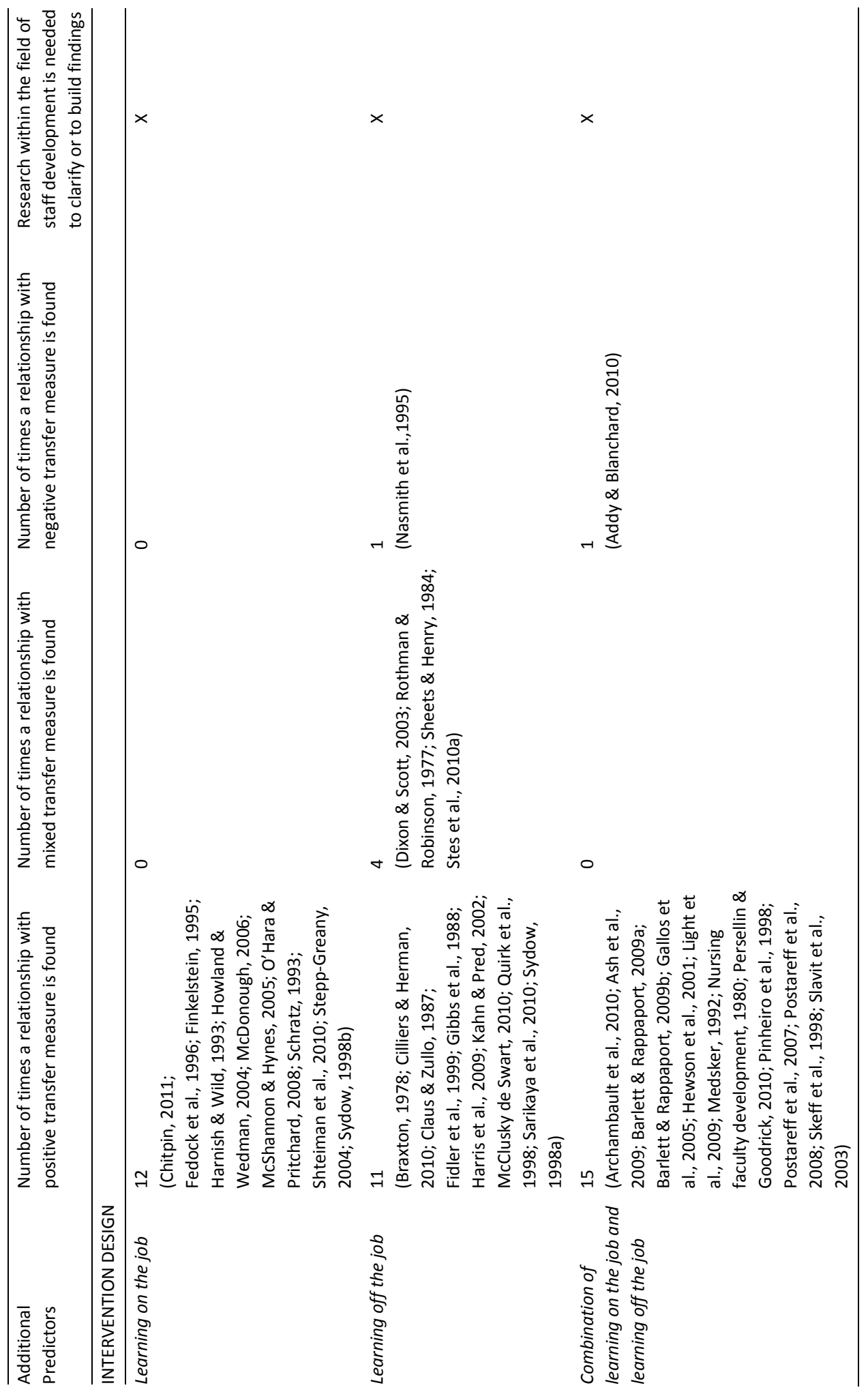


CHAPTER 7

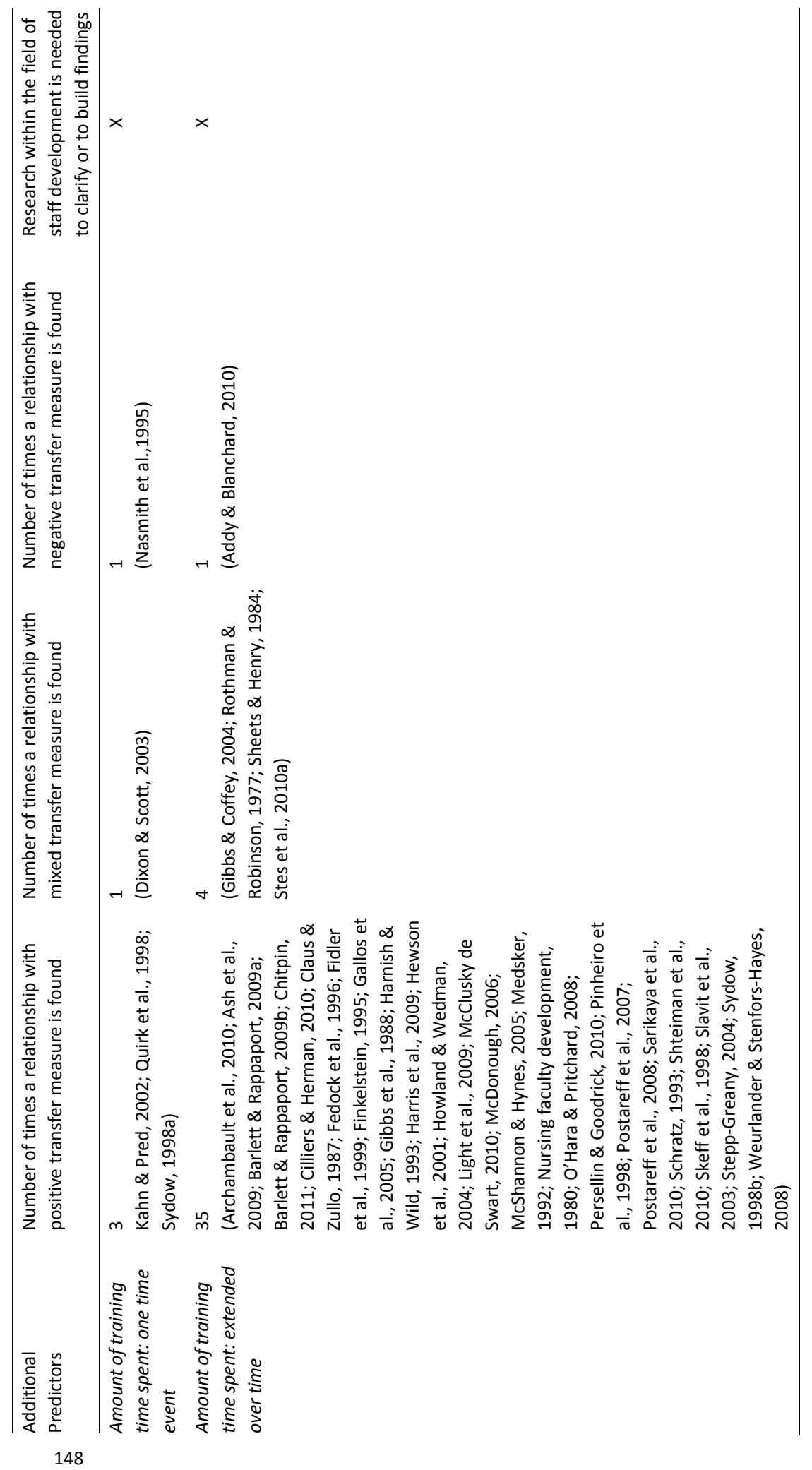




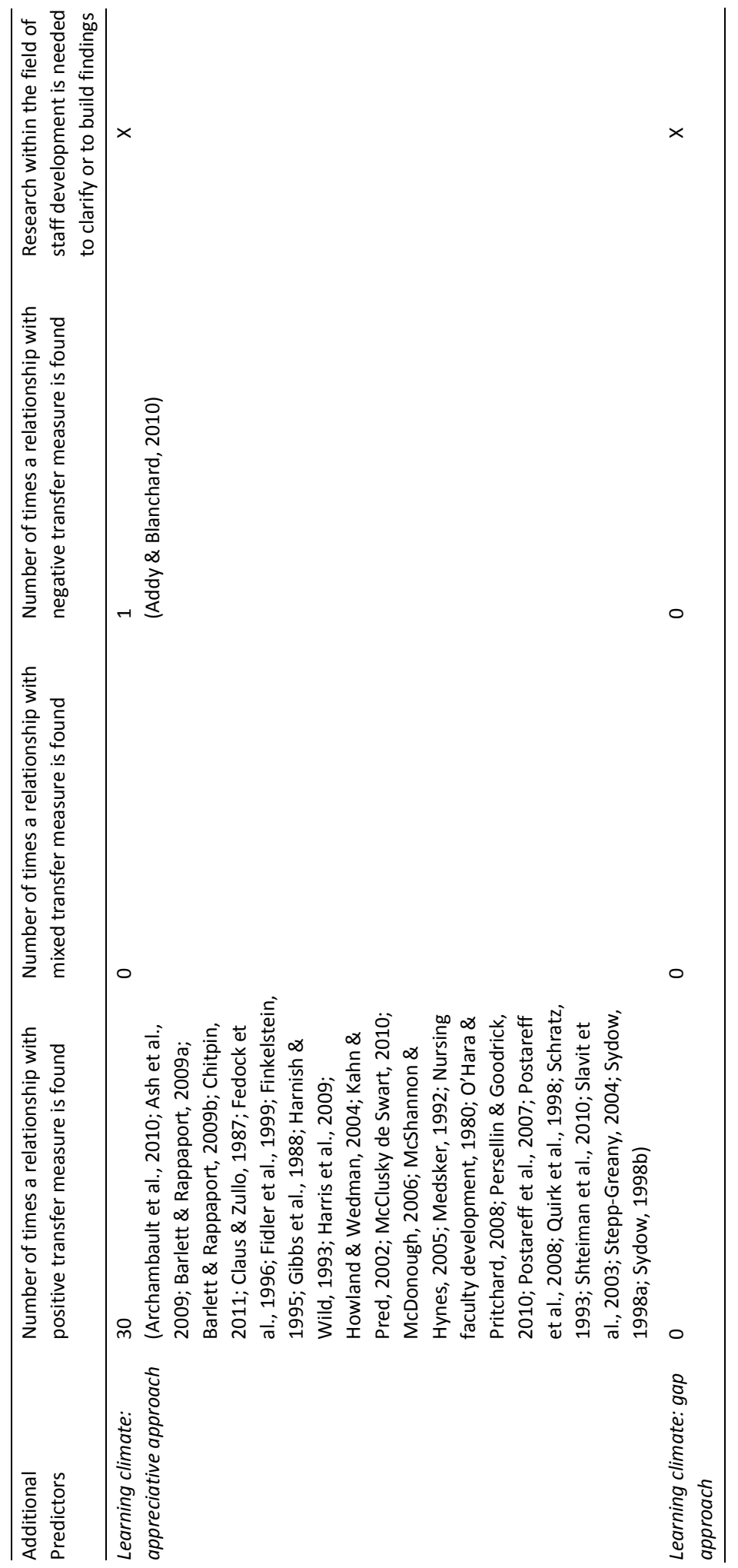




\section{Nature of the intervention}

The review of Stes et al. (2010b) gives some evidence that the nature of the staff development intervention influences its impact. The review concludes with a call for further research into the impact of interventions with varying formats. Therefore the current review searches for the effect of the nature of the intervention on transfer to the workplace. Earlier reviews all used different categorisation to cluster studies based on the nature of the staff development intervention presented (Levinson-Rose \& Menges, 1981; Weimer \& Lenze, 1998, Steinert et al., 2006, Stes et al., 2010b). In reaction to these previous reviews we label the nature of the intervention (learning on the job versus learning off the job) as an additional predictor of transfer of learning in staff development. This dichotomy, being on the job/off the job, has never been used before in a review investigating the impact of staff development.

In our review, learning on the job means that the learning of teachers occurs as they engage in their teaching practices. The learning is situated in educational contexts with actual students, an actual curriculum, or actual problems of practice. On the job learning can be both formal and informal. Learning on the job means workplace learning. Forms of on the job learning include study groups, reflective logs (portfolio, case study), action research, community of practice, experiential learning, self directed professional development, (peer) coaching and mentoring. Off the job learning is when the staff development intervention takes place away from the normal work situation or away from teachers' practices. Off the job learning can make use of authentic materials and real life problems encountered by the teachers. Examples of off the job learning are workshops, training sessions or seminars.

Table 8 shows the results of our findings on the nature of the intervention.

Twelve of the studies that met our criteria for inclusion used an on the job approach. All of them present positive transfer results. Four of the 16 studies with an off the job approach show partly positive results, and one study shows a negative result. Sixteen studies report on a combination of learning on the job and learning off the job. One of those 16 studies shows negative transfer results. Fifteen of those 16 studies present positive transfer results. A preliminary conclusion is that on the job learning has a positive impact on transfer of learning but further research is needed.

\section{Amount of time spent}

McAlpine (2003), Steinert et al. (2006) and Stes et al. (2010b) conclude that staff development interventions extended over time could be associated with more positive outcomes than one time events. Further research on this assumption is suggested by the authors. In reaction to these previous reviews we present the 
amount of time spent on staff development interventions as a possible predictor of transfer.

In our review we code our studies as one-time interventions if the amount of time spent on the staff development intervention varies from one hour/one day to two consecutive days. If the amount of time spent on the staff development intervention is more than one day with a time lag between the sessions, or more than two consecutive days, the study is coded as an extended over time intervention.

Only five studies report on one time events. Three of them report positive results, one study reports partial impact and one study shows negative results. Up to 40 studies report on an intervention extended over time. Most of the time (35) a positive impact is found. One of the 40 studies reports a negative impact and four of them show partial impact. The results of the coding are presented in Table 8. A preliminary conclusion is that staff development interventions extended over time show more positive results of transfer of learning than one-time interventions. Staff development must be an ongoing activity. Further research is needed.

\section{Learning climate}

The review of Weimer and Lenze (1998) stresses the importance of incorporating the results of studies on adult learning into further research on the impact of staff development. An important finding of research on adult learning is that the learning climate influences retention of employees (Kyndt, Dochy, Michielsen \& Moeyaert, 2009). Thus, since continuous learning and development is prerequisite of retention (Govaerts, Kyndt, Dochy \& Baert, 2011; Kyndt et al., 2009) we present the learning climate as a possible additional predictor transfer. In our review we categorise two different approaches to the learning climate, these being the 'appreciative approach' and 'gap approach' (Baert, De Rick \& Van Valckenborgh, 2006; Govaerts et al., 2011; Kyndt et al., 2009). The emphasis of the 'gap approach' is on what is lacking or what is going wrong in an organisation. The focus of this approach is on diagnosing the problem and subsequently implementing an action plan. The focus of the 'appreciative approach' is to find and ameliorate solutions that already exist. In this approach staff development interventions are used to further develop the strengths and talents of the teacher. The basic idea of this approach is that knowing your strengths and the further development of these talents offers the most room for teacher growth. We coded the studies following this dichotomy.

Deducing this information from the articles studied led to 31 studies offering information on an appreciative approach. Only one of those 31 studies showed a negative result on transfer of learning. Table 8 shows the result of our coding. It is conspicuous that no studies with a gap approach were found. As a consequence we suggest that further research on the effects of learning climate as an influencing 
factor on transfer to the workplace is needed. No preliminary conclusions can be formulated.

\section{An adapted conceptual framework}

We refined the conceptual framework by including the additional predictors of transfer as mentioned above. With this adapted version of the conceptual framework, presented in Figure 2, we intend to provide guidelines for researchers and practitioners concerning staff development in higher education.

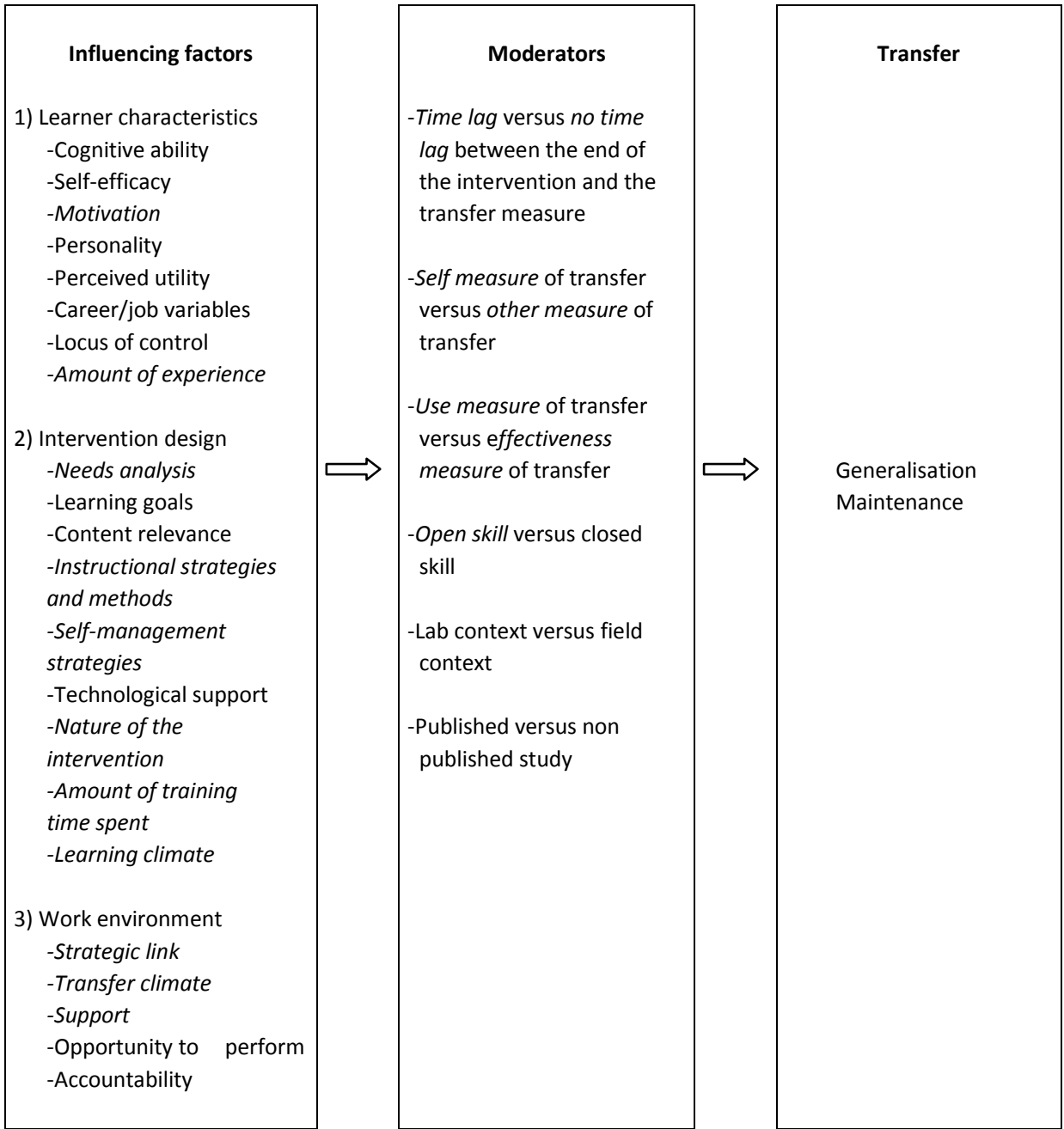

Figure 2. Transformed conceptual framework for factors potentially influencing transfer of learning in staff development interventions

Note: Italics = Further research is needed. 


\section{Conclusion and discussion}

If we wish to improve staff development we need to know which factors really make a difference in the complex process of achieving transfer of learning. To gain new insights into this process, evidence from solid research is required. On the basis of our review we conclude that educational research on the following predictors is most needed: motivation to learn, motivation to transfer, needs analysis, active learning, self-management strategies, strategic link, transfer climate, supervisory support, amount of experience, nature of the intervention, amount of training time spent and learning climate.

With our conceptual framework we intend to present some guidance for staff developers and educational researchers. As for effective learning and effective teaching, there is no single recipe for successful transfer of learning. This means that the task of the staff developer is a challenging one. With our framework we intend to give some guidance in this complex task. The framework is also an answer to our critique on previous research. It is highly curious that such limited documentation about factors influencing transfer is presented in studies measuring the impact of staff development. The framework gives an overview of factors which are relevant in our search for comprehension of transfer processes. Further research on the impact of staff development should carefully describe trainee characteristics, intervention characteristics and context characteristics such as work environment.

With our findings we draw attention to a possible positive outcome bias in the research on transfer of learning and impact of staff development. Already in 1979 Rosenthal had introduced the term "file-drawer problem" reporting on this effect (Rosenthal, 1979). Of the 46 educational studies that met our inclusion criteria, 39 report positive transfer results. In other words, $80 \%$ of the studies show that learning actually transfers to job performance. This is in sharp contrast with management, HRD and organisational psychology studies showing that only $10 \%$ of learning actually transfers to job performance. So, it is possible that the studies published are not representative for the field. If the positive publication bias is a fact, it may distort our review results. With this remark we appeal to authors and editors. If we want to fully understand the complex process of transfer of learning, studies with negative results do matter.

From this point of view (that negative result studies do matter) we will take a closer look at the no impact studies in our review. Two studies that met our inclusion criteria reported negative transfer results (Nasmith, Saroyan, Steinert, Lawn \& Franco, 1995; Addy \& Blanchard, 2010). We will search for predictors and moderators that probably inhibit transfer of learning. Doing so, we apply our transformed conceptual framework (Figure 2) to those two specific cases. 
Applying our transformed conceptual framework (Figure 2) we must conclude that unfortunately the study of Nasmith et al. (1995) includes minimal information on learner characteristics, intervention design and work environment. The study reports on a one-time event (two days) and off the job learning. The subjects of the study are experienced teachers. Transfer is measured by observation by a trained observer (other measure) and by a retrospective intervention and post intervention interview (self measure). The time lag between the end of the intervention and the transfer measure is six months to five years.

Interpreting those predictors and moderators mentioned, we conclude that maybe the effects of staff development learning decayed over time. The large time lag between the end of the intervention and the transfer measure could have a negative influence on the results. In addition, a remark must be made on the design of the study. We question the value of the control group in the study. The study mentions a developmental growth (from attended workshops, fellowship years and personal interest in techniques and methods related to small scale teaching) of the control group during the time lag between intervention and measure. This development of the control group could have influenced the results.

Despite the attention on a lot of influencing factors (motivation to learn, needs analysis, content relevance, practice and feedback, active learning, behavioural modelling and opportunity to perform) a negative result is found in the study of Addy and Blanchard (2010). The message of this study is that bottom up reform is problematic if curriculum redesign is not taken into account. The authors believe that, although teaching assistants had the chance to teach and to use their gained knowledge, skills and beliefs, this was not sufficient. Teaching assistants were limited by the structure of the course they were teaching. The structure of the course did not allow the teaching assistants flexibility in terms of reform-minded choices. The authors conclude that teacher perceptions of environmental constraints can weaken the alignment of practices and beliefs (Addy \& Blanchard, 2010 , p. 1068). Furthermore, the authors question whether the RTOP was a good instrument regarding the context of their study.

These two studies are good examples of negative outcome studies giving an added value to our understanding of transfer of staff development learning.

The research design of the studies measuring the impact of staff development can also have an impact on the outcome measured. Studies with a pretest design or control group design are scarce. Further research on this assumption is needed. Previous educational reviews studying the impact of staff development stressed the importance of more qualitative or mixed method studies (Levinson-Rose \& Menges,1981; Weimer \& Lenze, 1998). From our review we can conclude that the research field has taken this recommendation into account. Most of the studies that reached our criteria of inclusion were characterised by a qualitative or mixed method approach. On the other hand, despite the call of Levinson-Rose and Menges 
(1981) to take the individual differences of teachers participating in staff development initiatives into account, our review concludes that taking learner characteristics into consideration is still not common in studies looking into the impact of staff development on transfer level. This review shows that, in relation to the review of Stes et al. (2010b), during the last three years there has been a considerable growth in the amount of empirical research studying the impact of staff development. However, this growing body of evidence only brings limited clarity in the process of transfer. We hope this review illuminates some guidelines for further research. With this study we went one step further than the previous reviews and looked at what could work for whom under what conditions. A lot of influencing factors seem to matter.

A next step, especially towards the practical implications of impact studies, is searching for ways to successfully modify those predictors of transfer of learning. What specific changes in, for example, intervention design are needed? Such an evolution would be interesting for educational practice and policy makers but also for educational research.

A limitation of the current review is that we define the results of our study as preliminary. We have two reasons to do so. The first reason is the possible positive outcome bias in the research on transfer of learning and impact of staff development. Therefore, our suggestion for further research is to publish more negative outcome studies. The second reason is that most of the studies that met the inclusion criteria do not include a measure of the predictors of transfer. Future research could focus on some important predictors of transfer and incorporate a real measure of these predictors into the study design. As a complement to this, Holton's Learning Transfer System Inventory (Holton, Bates \& Ruona, 2000) could bring some guidance and an effective diagnosis. The Learning Transfer System Inventory is a validated instrument that could help researchers and practitioners to focus on the most important transfer issues for a particular group of learners. Staff development interventions and research design could target those transfer issues diagnosed.

As development will come about only by addressing teachers' underlying conceptions of teaching and learning (Norton et al., 2005), a final suggestion for further research is incorporating the conceptions of teachers as an influencing factor on transfer of learning. The study of the conceptions of learners and teachers is a hot issue in educational research (Lotter, Harwood \& Bonner, 2007). Maybe the field of management, HRD and organisational psychology research can adopt this interesting topic for further research on transfer of learning. 


\section{References}

\section{References marked with an asterisk indicate studies included in the present review.}

*Addy, T. M., \& Blanchard, M. R. (2010). The problem with reform from the bottom up: instructional practices and teacher beliefs of graduate teaching assistants following a reform-minded university teacher certificate program. International Journal of Science Education, 32(8), 1045-1071.

*Archambault, L., Wetzel, K., Foulger, T. S. \& Williams, M. K. (2010). Professional development 2.0: transforming teacher education pedagogy with $21^{\text {st }}$ century tools. Journal of Digital Learning in Teacher Education, 27(1), 4-11.

*Ash, D., Brown, C., Kluger-Bell, B., \& Hunter, L. (2009). Creating hybrid communities using inquiry as professional development for college science faculty. Journal of College Science Teaching, 38(6), 6876.

Baert, H., De Rick, K., \& Van Valckenborgh, K. (2006). Towards the conceptualization of "Learning Climate". In: R. V. De Castro, A. V. Sancho, \& P. P. Guimaraes (Eds.), Adult education: new routes in a new landscape (pp. 87-111). Braga: University of Minho.

*Baldwin, T. T., \& Ford, J. K. (1988). Transfer of training: A review and directions for future research. Personal Psychology, 41, 63-105.

Barab, S. A., MaKinster, J. G., \& Scheckler, R. (2003). Designing system dualities: Characterizing a websupported professional development community. The Information Society, 19(3), 7-256.

*Barlett, P. F., \& Rappaport, A. (2009). Long-term impacts of faculty development programs: the experience of Teli and Piedmont. College Teaching, 57(2), 73-82.

*Blume, B. D., Ford, J. K., Baldwin, T. T., \& Huang, J. L. (2010). Transfer of training: A meta-analytic review. Journal of Management, 36(4), 1065-1105.

*Braxton, J. M. (1978, May). Impact of workshops for instructional improvement: The results of an evaluation of a component of faculty development program. Paper presented at the annual Association for Institutional Research Forum, May 21-25, Houston, Texas.

*Burke, L. A., \& Hutchins, H. M. (2007). Training transfer: An integrative literature review. Human Resource Development Review, 6, 263-296.

*Chitpin, S. (2011). Can mentoring and reflection cause change in teaching practice? A professional development journey of a Canadian teacher educator. Professional Development in Education, 37(2), 225-240.

*Cilliers, F. J., \& Herman, N. (2010). Impact of an educational development program on teaching practice of academics at a research-intensive university. International Journal for Academic Development, 15(3), 253-267.

*Claus, J. M., \& Zullo, T. G. (1987). An adaptive faculty development program for improving teaching skills. Journal of Dental Education, 51(12), 709-712.

Darling-Hammond, L., \& Snyder, J. (2000). Authentic assessment of teaching in context. Teaching and Teacher Education, 16(5-6). 523-545.

De Rijdt, C. C. E., Dochy, F. J. R. C. \& Bamelis, S. (2007). Staff development in Hoger Onderwijs: Drie macromodellen en gepercipieerde effecten. [Staff development in Higher Education: Three macro models and perceived effects] Tijdschrift voor Hoger Onderwijs, 25(2), 58-68. 
*Dixon, K., \& Scott, S. (2003). The evaluation of an offshore professional-development programme as part of a university's strategic plan: a case study approach. Quality in Higher Education, 9, 287-294.

Eva, K. W., \& G. Regehr (2005). Self-assessment in the health professions: A reformulation and research agenda. Academic Medicine, 80(10S), S46-S54.

*Fedock, P., Zambo, R., \& Cobern, W. (1996). The professional development of college science professors as science teacher educators. Science Education, 80(1), 5-19.

*Fidler, P. P., Neururer-Rotholz, J., \& Richardson, S. (1999). Teaching the freshman seminar: Its effectiveness in promoting faculty development. Journal of the First-Year Experience \& Students in Transition, 11(2), 59-74.

*Finkelstein, M. (1995). Assessing the teaching and student learning outcomes of the Katz/Henry faculty development model. Report written by the New Jersey Institute for Collegiate Teaching and Learning, South Orange.

Fitzpatrick, R. (2001). The strange case of the transfer of training estimate. Industrial-Organizational Psychologist, 39(2), 18-19.

*Gallos, M. R., van den Berg, E., \& Treagust, D. F. (2005). The effect of integrated course and faculty development: Experiences of a university chemistry department in the Philippines. International Journal of Science Education, 27(8), 985-1006.

*Gibbs, G., \& Coffey, M. (2004). The impact of training of university teachers on their teaching skills, their approach to teaching and the approach to learning of their students. Active Learning in Higher Education, 5(1), 87-100.

*Gibbs, L. E., Browne, M. N, \& Keeley, S. M. (1988). Stimulating critical thinking through faculty development: Design, evaluation, and problems. Wisconsin University, Eau Claire, American Association of State Colleges and Universities, Washington, DC.

Gordon, M. J. (1991). A review of the validity and accuracy of self-assessments in health professions training. Academic Medicine, 66(12), 762-769.

Govaerts, N., Kyndt, E., Dochy, F., \& Baert, H. (2011). The influence of learning and working climate on the retention of talented employees. Journal of Workplace Learning, 23(1), 35-55.

*Harnish, D., \& Wild, L. A. (1993). Peer mentoring in higher education: A professional development strategy for faculty. Community College Journal of Research and Practice, 17(3), 271-82.

*Harris, G., Froman, J., \& Surles, J. (2009). The professional development of graduate mathematics teaching assistants. International Journal of Mathematical Education in Science and Technology, 40(1), 157-172.

*Hewson, M. G., Copeland, H. L., \& Fishleder, A. J. (2001). What's the use of faculty development? Program evaluation using retrospective self-assessments and independent performance ratings. Teaching and Learning in Medicine, 13(3), 153-160.

Holton, E. F. (1996). The flawed four-level evaluation model. Human Resource Development Quarterly, 1, $5-21$.

Holton, E. F. III, \& Baldwin, T. T. (2000). Making transfer happen: An action perspective on learning transfer systems. Advances in Developing Human Resources, 2(4), 1-6.

Holton, E. F., Bates, R. A., \& Ruona W. E. (2000). Development of a generalized learning transfer system inventory. Human Resource Development Quarterly, 11(4), 333-360. 
*Howland, J., \& Wedman, J. (2004). A process model for faculty development: individualizing technology learning. Journal of Technology and Teacher Education, 12, 239-263.

*Kahn, J., \& Pred, R. (2002). Evaluation of a faculty development model for technology use in higher education for late adopters. Computers in the Schools, 18, 127-150.

Kirkpatrick, D. L. (1998). Evaluating training programs: the four levels. San Francisco, CA: Benett-Koehler Publishers.

Kupritz, V. W. (2002). The relative impact of workplace design on transfer. Human Resource Development Quarterly, 13, 427-447.

Kyndt, E., Dochy, F., Michielsen, M., Moeyaert, B. (2009). Employee retention: Organisational and personal perspectives. Vocations and Learning, 2(3), 195-215.

Lawless, K. A., \& Pellegrino, J. W. (2007). Professional development in integrating technology into teaching and learning: Knowns, unknowns, and ways to pursue better questions and answers. Review of Educational Research, 77(4), 575-614.

Levinson-Rose, J., \& Menges, R. J. (1981). Improving college teaching: A critical review of research. Review of Educational Research, 51, 403-434.

*Light, G., Calkins, S., Luna, M., \& Drane, D. (2009). Assessing the impact of a year-long faculty development program on faculty approaches to teaching. International Journal of Teaching and Learning in Higher Education, 20(2), 168-181.

Lotter, C., Harwood, W. S., \& Bonner, J. J. (2007). The influence of core teaching conceptions on teachers' use of inquiry teaching practices. Journal of Research in Science Teaching, 44, 1318-1347.

McAlpine, L. (2003). Het belang van onderwijskundige vorming voor studentgecentreerd onderwijs: de praktijk geëvalueerd. [The importance of instructional development for student centred teaching: An examination of practice.] In N. Druine, M. Clement, M., \& K. Waeytens (Eds.), Dynamiek in het hoger onderwijs. Uitdagingen voor onderwijsondersteuning [Dynamics in higher education: Challenges for teaching support] (pp. 57-71). Leuven: Universitaire Pers.

*McClusky de Swart, S. (2010). Learning fellows seminars: a case study of a faculty development program using experiential learning theory to improve college teaching. Ph.D. Dissertation, Case Western Reserve University.

*McDonough, K. (2006). Action research and the professional development of graduate teaching assistants. Modern Language Journal, 90(1), 33-47.

*McShannon, J., \& Hynes, P. (2005). Student achievement and retention: Can professional development programs help faculty GRASP it? Journal of Faculty Development, 20(2), 87-94.

*Medsker, K. L. (1992). NETwork for excellent teaching: A case study in university instructional development. Performance Improvement Quarterly, 5, 35-48.

*Nasmith, L., Saroyan, A., Steinert, Y., Lawn, N., \& Franco, E. D. (1995). Long-term impact of faculty development workshops. Report of McGill University, Canada.

Norton, L., Richardson, J. T. E., Hartley, J., Newstead, S., \& Mayes, J. (2005). Teachers' beliefs and intentions concerning teaching in higher education. Higher Education, 50(4), 537-571.

*Nursing faculty development (1980). Final report. Atlanta, GA: Southern Regional Education Board.

*O'Hara, S., \& Pritchard, R. H. (2008). Meeting the challenge of diversity: professional development for teacher educators. Teacher Education Quarterly, 35(1), 43-61. 
*Persellin, D., \& Goodrick, T. (2010). Faculty development in higher education: long-term impact of a summer teaching and learning workshop. Journal of the Scholarship of Teaching and Learning, 10(1), $1-13$.

*Pinheiro, S. O., Rohrer, J. D., \& Heimann, C. F. L. (1998). Assessing change in the teaching practice of faculty in a faculty development program for primary care. Paper presented at the Annual Meeting of the American Educational Research Association, San Diego, CA, April 13-17, 1998.

*Postareff, L., Lindblom-Ylänne, S., \& Nevgi, A. (2007). The effect of pedagogical training on teaching in higher education. Teaching and Teacher Education, 23, 557-571.

*Postareff, L., Lindblom-Ylänne, S., \& Nevgi, A. (2008). A follow-up study of the effect of pedagogical training on teaching in higher education. Higher Education: The International Journal of Higher Education and Educational Planning, 56(1), 29-43.

*Quirk, M. E., DeWitt, T., Lasser, D., Huppert, M., \& Hunniwell, E. (1998). Evaluation of primary care futures: a faculty development program for community health center preceptors. Academic Medicine, 73, 705-707.

Rosenthal, R. (1979). The "File Drawer Problem" and the Tolerance for Null Results. Psychological Bulletin, 86(3), 638-641.

*Rothman, A. I., \& Robinson, S. (1977). Evaluation of a training course. Canadian Journal of Higher Education, 7, 19-35.

*Sarikaya, O., Kalaca, S., Yeen, B. C., \& Cali, S. (2010). The impact of a faculty development program: evaluation based on the self-assessment of medical educators from preclinical and clinical disciplines. Advances in Psychology Education, 34(2), 35-40.

*Schratz, M. (1993). Crossing the disciplinary boundaries: Professional development through action research in higher education. Higher Education Research and Development, 12(2), 131-142.

*Sheets, K. J, \& Henry, R. C. (1984). Assessing the impact of faculty development programs in medical education. Journal of Medical Education, 59, 746-748.

*Shteiman, Y., Gidron, A., Eilon, B., \& Katz, P. (2010). Writing as a journey of professional development for teacher educators. Professional Development in Education, 36(1-2), 339-356.

*Skeff, K. M., Stratos, G. A., Bergen, M. R., \& Regula, D. P. (1998). A pilot study of faculty development for basis science teachers. Academic Medicine, 73, 701-704.

*Slavit, D., Sawyer, R., \& Curley, J. (2003). Filling your plate: A professional development model for teaching with technology. TechTrends, 47, 35-38.

Steinert, Y., Mann, K., Centeno, A., Dolmans, D. H. J. M., Spencer, J., Gelula, M., \& Prideaux, D. (2006). A systematic review of faculty development initiatives designed to improve teaching effectiveness in medical education: BEME Guide No.8. Medical Teacher, 28, 497-526.

*Stepp-Greany, J. (2004). Collaborative teaching in an intensive Spanish course: a professional development experience for teaching assistants. Foreign Language Annals, 37, 417-426.

*Stes, A., Coertjens, L., \& Van Petegem, P. (2010a). Instructional development for teachers in higher education: impact on teaching approach. Higher Education, 60(2), 187-204.

Stes, A., Min-Leliveld, M., Gijbels, D., \& Van Petegem, P. (2010b). The impact of instructional development in higher education: The state-of-the-art of the research. Educational Research Review, 5(1), 25-49. 
*Sydow, D. L. (1998). Outcomes of the VCCS professional development initiative: 1993-1998. Big Stone Gap, VA: Mountain Empire Community College.

Taylor, L., \& Rege Colet, N. (2009). Making the shift from faculty development to educational development: A conceptual framework grounded in practice. In A. Saroyan, \& M. Frenay (Eds.), Building teaching capacities in higher education: A comprehensive international model. Sterling, VA: Stylus Publishing.

Weimer, M., \& Lenze, L. F. (1998). Instructional interventions: A review of the literature on efforts to improve instruction. In R. Perry, \& J. Smart (Eds.), Effective teaching in higher education (pp. 205240). New York: Agathon Press.

*Weurlander, M., \& Stenfors-Hayes, T. (2008). Developing medical teachers' thinking and practice: impact of a staff development course. Higher Education Research and Development, 27(2), 143-153. 
Chapter 8

General conclusions and discussion 


\section{Contributing to a better understanding and improvement of staff development}

What and how students learn not only influences their whole life, but can also change their and our world. Therefore, the task of the teacher is an important one. The influence of the expertise, the motivation, the creativity and the energy of the teacher cannot be overstated. Teacher quality influences student success (DarlingHammond, 1994; Fullan, 1993; Hattie, 2009; Hawley \& Valli, 1999; Kent, 2004; Marzano, 2003; McShannon \& Hynes, 2005; Slavit, Sawyer \& Curley, 2003; SteppGreany, 2004; Stoll \& Fink, 1996). The quality of the teacher is possibly the most significant factor in student success: low-achieving students improved their study results when they were taught by an effective teacher (Haycock, 1998). Unarguably, staff development is an important factor in the improvement of higher education.

The goal of staff development is to improve teacher practices to influence student learning positively. Teacher learning and development is a complex process that brings together a host of different factors (Avalos, 2011). Therefore, the studies presented in this dissertation were undertaken with the goal of contributing to a better understanding and improvement of this multi-factorial process of staff development in higher education. In this final chapter the results of the different studies are summarized and discussed. Furthermore, several practical implications for staff development practices, derived from the results of this dissertation, are presented.

\section{A shared language of different stakeholders}

With this dissertation we intended to contribute to a shared language of different stakeholders in staff development. Staff developers and teachers are important stakeholders.

Chapter 2 explores staff developers' underlying understanding of staff development. The main aim of the study was to provide a framework for understanding how staff developers experience staff development. Studying the conceptions of staff developers is an important contribution to the existing literature. The applied power of the phenomenographic approach lies in its explication of what expansion in awareness is needed to move from one way of understanding the phenomenon of staff development to another, more sophisticated, way. The hierarchy represents an expansion in awareness of different features of the phenomenon of staff development. The method part of the study builds bridges between the positivistic study approach and the phenomenographic study approach. 
Four main categories of description were distinguished. While each additional category has features in common with the previous categories, it also represents a new element in the experience of the staff developer. The following categories are the result of our study: staff development as functional development; staff development as organisational competence development; staff development as self-directed reflective development; staff development as continuous personalised and experience-based holistic development.

The composition of these four categories constitutes a process of gradual change from teacher-centred to learner-centred, from short periods of reflection to purposeful reflection, from limited self-directed learning to substantial self-directed learning, from unequal to equal levels, from no attention to considerable attention to learning transfer, from implicit beliefs and conceptions to explicit ones, from implicit prior knowledge and previously acquired competences to personal prior knowledge and previously acquired competences as the starting-point for further learning, and from brief and solitary staff development interventions to longitudinal ones. The work described in Chapter 2 results in increased conceptual clarity.

The third chapter focuses on perceptions of teachers. Smith (1992a, 1992b) distinguishes three macro models of staff development on the basis of who takes responsibility for implementing staff development activities: the management model, the shop-floor model and the partnership model. The study in Chapter 3 investigates whether these models are recognized by teachers. Furthermore, this study looked for the effects of those three staff development models as perceived by teachers in higher education. Addressing perceptions of teachers is necessary to support and encourage their continuous professionalisation. Teachers construct a meaningful personal reaction to staff development. Perceptions of teachers towards learning and teaching determine their actions. This aspect in the learning process of teachers must not be overlooked.

The results of this study show that all three macro models are recognized by the participants. In our study the difference between the three staff development models is visible in the level of satisfaction. This difference seems to have no effect in terms of applying newly gained knowledge, skills or conceptions in practice. Most of our respondents were aware of their own learning process during staff development sessions and respondents indicated that their conceptions changed after participation in staff development programmes. Moreover, it seems that teachers consider the change in conceptions of teaching as something obvious. Respondents notice a shift in conceptions to a more student centred approach. The results of the study allow us to conclude that teachers can handle the responsibility for identifying their own needs and suggesting actions to meet these needs. This study provides increased understanding of the conceptions of teachers and the barriers/opportunities perceived by teachers. 


\section{The implementation of a teaching portfolio}

Change does not come easily. Therefore investment in longitudinal staff development programmes is important. Teaching portfolios are seen as an important instrument within longitudinal staff development activities. To professionalise also means to express how things went; looking back and looking forward in the light of new knowledge and skills. It is about formulating new intentions for the future.

Aiming at a more holistic approach to staff development, one should first consider teachers' perceptions and conceptions before implementing teaching portfolios. In this holistic approach the emphasis of staff development is on becoming conscious of one's own practical knowledge and professional identity (Korthagen, 2004). Appropriate staff development initiatives must address different levels of change. Korthagen (2004) presents an 'onion model' of levels of change. The different levels influence each other. Beliefs and identity are part of the inner levels of change. Authors stress the importance of knowing what teachers think and what their beliefs are (Clark, 1986; Korthagen, 2004; Lindblom-Ylänne, Trigwell, Nevgi, \& Ashwin, 2006; Pajares, 1992). Chapters 4 and 5 are a contribution to this holistic approach of staff development.

Chapter 4 explores what teachers in higher education consider to be relevant content of a teaching portfolio and looks into teachers' conceptions and attitudes (pro or con) towards teaching portfolios.

Teachers find self-report and self-reflection important but do not value the reports of their colleagues. Their own vision of good educational practice is an important part of their portfolio. Teachers are aware of their subjective educational theory (Clark \& Peterson, 1986; Kelchtermans, 2005, 2009; Korthagen, 2004; Lasky, 2005). Furthermore, information about research activities is important teaching portfolio content. Teachers have support-oriented conceptions, career-oriented conceptions and anxiety-oriented conceptions towards the use of teaching portfolios. Those perceptions are not related to the background variables of the participants. Most of the teachers have a positive attitude towards teaching portfolios. Support-oriented conceptions seem to influence the attitude towards a teaching portfolio. Discussions and cooperation with others are a very important factor in the portfolio construction process (Orland-Barak \& Kremer-Hayon, 2001; Wray, 2007). Nonetheless, anxiety-oriented conceptions could hinder collaboration. A teaching portfolio could be a good instrument to counterpart research-minded appraisals in higher education. A good instrument alone is not enough to make a change, however. A lot more than a good instrument is needed.

Chapter 5 deals with the following research question: 'Are teaching portfolios really used in higher education, and if so what effects could they bring about?'. Although the majority of the respondents do not use a teaching portfolio, they are 
in favour of their use. Teachers consider the portfolio process as a way to improve not only the quality of their own education but also the quality of the educational institution. A teaching portfolio is seen as an instrument that could bring about some important positive effects. Owing to the use of portfolios teachers were stimulated to reflect on their own teaching, to actualise the learning content, to improve course materials, to search for alternative educational methods, etc. Additionally, teaching portfolios are very useful for appraisals and make clear what the efforts of the teacher are. Teachers reap certain benefits from the use of portfolios.

Teaching portfolios are not the ideal assessment instrument for all teachers, however. It is possible that some teachers are more stimulated to reflect on their professional actions and competences, and optimise their teaching more effectively, with other instruments. When teachers are using teaching portfolios it is important that, besides the possible negative effects, they also experience positive effects. If this is not the case, teachers will see the teaching portfolio only as an extra administrative inconvenience. It is important to realize that the use of teaching portfolios is not exclusively allied with positive effects for teachers. Moreover, making a teaching portfolio is very time-consuming. If a teaching portfolio is used for summative purposes, teachers must know in advance which aspects of their portfolio will be evaluated.

\section{Using the principles of staff development with regard to peer tutoring}

A recurring question is whether student tutors are able to fulfil the complex responsibilities of a tutor in problem-based learning. Our study on peer tutors in PBL in Chapter 6 of this dissertation is characterised by the incorporation of a comprehensive training process for student tutors and staff tutors and by the rigorous selection of student tutors.

The study in Chapter 6 shows that carefully selected and trained student tutors have neither a positive nor a negative impact. Student tutors are inevitably less experienced than staff tutors, but in the first curricular year this apparently does not translate as poorer exam results. There appears to be no difference between staff tutors and rigorously selected and well-trained student tutors with respect to students' achievements and perceptions. This study proves that well-selected and well-trained student tutors are ready to successfully undertake complex tutor responsibilities.

Our research on effectiveness of student tutors is progressive for several reasons. First, the positive effects of peer learning are stressed in educational research (Johnson, Johnson, \& Smith, 2007). Research on different forms of peer learning could fine-tune the general assumptions. Student tutors in PBL are such a 
form of peer learning. Second, in times of resource constraints educational management opts for cost-effective alternatives without a decrease of educational quality. Research could suggest successful formulas for working with peer tutors. Third, more and more educational institutions are offering their best and most motivated students the opportunity to follow an additional programme besides their regular curriculum. A student tutor programme is an example. In the national and international battle for students, educational institutions try to create an attractive learning environment for their best and most motivated students by offering those additional opportunities. Research on the effects of these additional programmes is needed.

\section{Transfer}

The goal of staff development is a change in teacher practices to positively influence student learning. In other words, the goal is transfer of learning to the workplace. Research illuminates that this transfer of learning to the workplace is really a complex issue.

Considerable growth in the amount of empirical research studying the impact of staff development is a fact but this growing body of evidence only brings limited clarity to the process of transfer. To make an accurate assessment of staff development initiatives one must consider the variety of factors that can influence the learning of teachers. We must consider what works for whom and under what conditions. Unless we understand which factors are influencing the impact of staff development on transfer of learning it will be challenging to improve staff development. We need to understand which predictors actually lead to consequential effects. Furthermore, we have to gain insight into moderators in the relationship between predictors and transfer of learning.

With the interdisciplinary review in Chapter 7 we combine the findings of management, human resource development (HRD), and organisational psychological research with educational research. We attempt to generate guidelines for further research to improve staff development by revealing gaps in earlier research on the impact of staff development.

Our review contributes to the existing literature because of the interdisciplinary approach, the critique on existing research and the proposal for more realistic and explanatory research on transfer of learning in staff development.

The results of our review show that educational researchers studying the impact of staff development have to alter their course. Research on impact of staff development has to change. A new research approach is needed. In our review we present a conceptual framework that could guide researchers towards more realistic and explanatory research on transfer of learning in staff development. 
Further research on the impact of staff development should carefully describe trainee characteristics, intervention characteristics and context characteristics such as working environment. Educational research on the following predictors of transfer is needed most: motivation to learn, motivation to transfer, needs analysis, active learning, self-management strategies, strategic link, transfer climate, supervisory support, amount of experience, nature of the intervention, amount of training time spent and learning climate.

\section{A shift in emphasis}

Staff development has been characterised by a shift in emphasis during the past few years. The role of the teacher in the process of staff development has also changed. Teachers are responsible professionals, taking an active role in their own developmental process. Teachers are competent to define personal learning needs and learning goals. Teachers are developers of their own teaching approaches. Teachers are reflective practitioners and producers of their own knowledge towards teaching. The emphasis of staff development is not on the teacher as a target of change but on the teacher as a source and facilitator of change. The emphasis is not on the staff developer as an educator but on the staff developer as facilitator, consultant, or coach (Dass \& Yager, 2009). The fourth category, 'Staff development as continuous, personalised and experience-based holistic development', presented in Chapter 2 of this dissertation, represents this shift in emphasis. The success of the shop-floor model and the partnership model as described in Chapter 3 of the dissertation prove that teaches can handle the responsibility for steering their own learning process.

This shift in emphasis has led to a wide range of staff development activities. Staff development activities extended over time gain importance. Traditional onetime off-the-job workshops are still useful for certain goals, such as PowerPoint training. On-the-job learning forms such as learning communities, teaching portfolios or coaching are also effective. Learning on the job is a successful formula in adult learning.

The attention to conceptions of different stakeholders is common sense in this holistic view on staff development.

\section{An intertwined process of change?}

A continuing discussion in the literature is whether change in conceptions precedes change in knowledge and skills (Ho, Watkins, \& Kelly, 2001; Kirkpatrick, 1998; Oosterheert \& Vermunt, 2003) or vice versa (Eley, 2006; Guskey, 1986, 2000). 
One hypothesis is that the change in conceptions and change in knowledge and skills is a gradually intertwined process. When teachers are not aware of better teaching practices they may feel that they are good teachers. They do not feel the need to change their conceptions towards learning and teaching, but they could increase their teaching experience and gain knowledge and skills. Teachers' conceptions could but do not necessarily develop with this increased teaching experience (Norton, Richardson, Hartley, Newstead, \& Mayes, 2005; Richardson, 2005). When teachers are confronted with a problematic teaching situation or participating in a staff development initiative, however, their images of themselves may collapse (Postareff, Lindblom-Ylänne, \& Nevgi, 2007). As a result of this they will change their conceptions towards learning and teaching and they might feel the need to gain new knowledge and skills and adapt their teaching practices. Change is a complex and slow process with a lot of influencing factors.

\section{Suggestions for further research}

With this dissertation we tried to contribute to a better understanding and an improvement of the multifactorial process of staff development in higher education. Although different aspects of staff development are touched upon, there is still a large uncultivated area of research on staff development. Further studies to optimise staff development and explore opportunities for teachers to develop themselves are still needed. The remaining discussion as presented in the previous section is an interesting topic for initiating further research. The results and limitations of the studies presented in this dissertation evoke more questions for further research.

A shared language turned out to be an important factor in improving staff development. Further research could focus on a continuing analysis of the relationship between the four different categories of staff development formulated in this dissertation (Chapter 2). It would be useful to explore and compare the conceptions held by other stakeholders in staff development. Moreover, it would be interesting to investigate whether teachers recognize the four categories of staff development. In practice, the four different visions of staff development which have been discovered as a result of this dissertation (see Chapter 2) could affect the approach of staff developers. It would be useful to evaluate these different approaches using our four categories. A further study on the four different categories of staff development could combine data sources such as learning outcomes of teachers, observations of teacher practices, interviews with teachers and the learning outcomes of students. Furthermore, it would be interesting to gain more insight into the beliefs of staff developers with regard to transfer. A focus interview could focus on the multiple factors and influences that could affect 
transfer. In addition, a phenomenographic study aiming to define transfer of learning in staff development could provide further insight into transfer and staff development activities.

Further research on perceptions regarding the three staff development models could differentiate between on-the-job and off-the-job staff development initiatives.

The issue of teachers' perceptions and conceptions towards teaching portfolios are of vital importance for the understanding of teachers' learning through portfolio use. It would be an interesting goal for further research to find out to what extent guidance, supervision, and peer learning could play a beneficial role in learning through the portfolio process and how those stimuli are reflected in the conceptions of teachers. Furthermore, it would be interesting to gain deeper understanding of the conceptions presented and studied in this dissertation by using narrative research methods.

Further research on peer tutoring could focus on the level of interactivity in the groups, motivation, quality of course materials, expertise or the effects of reflective thinking. Also, it would be very interesting to analyse tutors' contributions in this research setting in a future study. Furthermore, research on differences in deep and surface approaches to learning between the student tutor and staff tutor condition would be useful. Taking the study achievements of students as an indicator of the quality of tutors, it is interesting to ask the question whether increasing grades over time and course could be attributed to the growth in expertise of the student tutor. It is also a challenge to find out whether working with other assessment forms within a PBL setting shows similar results. New studies should try to verify our findings by involving other knowledge domains and other educational settings. Furthermore, it would be very interesting to look at the effects for the student tutors as well. The individual characteristics of student tutors, such as experience in working with groups, are another possibility for future research.

With our review results we drew attention to a possible positive outcome bias in the research on transfer of learning and impact of staff development. Therefore, our suggestion for further research is to publish negative outcome studies. Further research could focus on some important predictors of transfer and incorporate a real measure of these predictors in the study design.

A recurring question in this dissertation and in past educational research is whether change in conceptions or change in behaviour comes first. Further research could try to solve this chicken-and-egg question. 


\section{Practical implications}

As regards effective learning and effective teaching there is no one recipe for successful staff development. This means that the task of the staff developer is a challenging one. Several practical ideas for meeting this challenge can be derived from this dissertation. Staff development is most successful if the following are taken into account. Teachers have to participate on a voluntary basis or participants must be carefully selected (motivation, career planning). A staff development intervention must focus on current needs. Needs analysis contributes to right-ontime staff development. Teachers are capable of determining their own developmental needs and an appropriate design to fulfil those learning needs. Teachers themselves should be involved in the design process. During staff development initiatives one must focus on best practices (of colleagues) as soon as possible (behavioural modelling, error-based examples, content relevance, peer support). Clear learning goals must be set and communicated. A staff development intervention must be tied to the strategic goals of the organization (strategic link). Supervisors must be involved in the design, planning or enactment of the intervention. The teacher will perceive this involvement as supervisory support. Furthermore, the gained visibility may increase the perceived utility and value associated with staff development. Participants need to share progress and report on final accomplishments. It is important to engage colleagues, supervisors and management in this process (transfer climate, supervisory support, peer support, accountability). It is good to focus on the strengths of the teachers and further development of those talents (learning climate appreciative approach). Staff development is a continuing process. As change is a slow process and changes have to persist over time we need to keep working on staff development (generalization, maintenance, opportunity to perform, amount of time spent). Staff development initiatives extended over time are preferable. Good staff development initiatives ensure that materials can be dynamically adapted to the characteristics of the learner (novice versus experienced learner, prior knowledge). Experience exchange, working in small groups, the input of an expert, receiving feedback, a good balance between explanation and interaction and a broad range of staff development initiatives are important ingredients for appreciated staff development interventions. Staff development activities and results must be published (in the organization or in scientific journals) to increase perceived utility. As conceptions of teachers influence their developmental process and their teaching practices, conceptions may not be overlooked in staff development initiatives. Staff development plays an important role in a well-designed peer-learning context. The description of the four categories of staff development is a useful framework for staff developers to question their personal understanding of staff development. 


\section{Conclusion}

To conclude, this dissertation showed that staff development in higher education is an important but complex and multifactorial process. Many factors influence the transfer of learning to the workplace. To make staff development successful a shared language is of the utmost importance. Staff development is characterised by a shift to a more holistic approach, where conceptions and perceptions of different stakeholders are the glasses through which people perceive and interpret the world (Pratt, 1992). Teachers are reflective practitioners with their own professional identity. Teachers are capable of steering their own learning process. To scaffold, guide and coach the teacher in their personal learning process is the task of peers, supervisors and staff developers. Several factors influencing this collaborative and collegial learning approach and the impact of staff development are presented in this dissertation. A whole world is still open for future research if we desire complete understanding of staff development.

\section{References}

Avalos, B. (2011) Teacher professional development in teaching and teacher education over ten years. Teaching and Teacher Education, 27(1), 10-20.

Clark, C.M. (1986). Ten years of conceptual development in research on teacher thinking. In M. BenPeretz, R. Bromme, \& R. Halkes (Eds.), Advances of research on teacher thinking (pp.7-20). Lisse, the Netherlands: Swets \& Zeitlinger.

Clark, C.M., \& Peterson, P.L. (1986). Teachers' thought processes. In M.C.Wittrock (Ed.), Handbook of research on teaching (pp.255-296). NY: MacMillan.

Darling-Hammond, L. (1994) Professional development schools: Schools for developing a profession. New York, NY: Teachers College Press.

Dass, P. M., \& Yager, R. E. (2009). Professional development of science teachers: History of reform and contributions of the STS-based lowa Chautauqua program. The Science Education Review, 8, 99-111.

Eley, M.G. (2006). Teachers' conceptions of teaching and the making of specific decisions in planning to teach. Higher Education, 51(2), 191-214.

Fullan, M. (1993). Change forces: Probing the depths of educational reform. London: Falmer Press.

Guskey, T. R. (1986). Staff development and the process of teacher change. Educational Researcher, 15(5), 5-12.

Guskey, T. R. (2000). Evaluating professional development. Thousand Oaks, CA: Corwin Press.

Hattie, J. (2009). Visible learning: a synthesis of over 800 meta-analyses relating to achievement. London: Routledge.

Hawley, W., \& Valli, L. (1999). The essentials of effective professional development: A new consensus. In L. Darling-Hammond \& G. Sykes (Eds.), Teaching as the learning profession: Handbook of policy and practice (pp. 127-150). San Francisco, CA: Jossey-Bass. 
Haycock, K. (1998). Good teaching matters. Washington, DC: Education Trust.

Ho, A., Watkins, D., \& Kelly, M. (2001). The conceptual change approach to improving teaching and learning: An evaluation of a Hong Kong staff development programme. Higher Education, 42, 143169.

Johnson, D. W., Johnson, R. T., \& Smith, K. (2007). The state of cooperative learning in postsecondary and professional settings. Educational Psychology Review, 19, 15-29.

Kelchtermans, G. (2005). Teachers' emotions in educational reforms: self-understanding, vulnerable commitment and micropolitical literacy. Teaching and Teacher Education, 21(8), 995-1006.

Kelchtermans, G. (2009). Who I am in how I teach is the message. Self-understanding, vulnerability and reflection. Teachers and Teaching: Theory and Practice, 15(2), 257-272.

Kent, A.M. (2004). Improving teacher quality through professional development. Education, 124(3), 427435.

Kirkpatrick, D.L. (1998). Evaluating training programs: the four levels. San Francisco, CA: Benett-Koehler.

Korthagen, F.A.J. (2004). In search of the essence of a good teacher: Towards a more holistic approach in teacher education. Teaching and Teacher Education, 20(1), 77-97.

Lasky, S. (2005). A sociocultural approach to understanding teacher identity, agency and professional vulnerability in a context of secondary school reform. Teaching and Teacher Education, 21, 899-916.

Lindblom-Ylänne, S., Trigwell, K., Nevgi, A., \& Ashwin, P. (2006). How approaches to teaching are affected by discipline and teaching context. Studies in Higher Education, 31(3), 285-298.

Marzano, R. J. (2003). What works in schools: Translating research into action. Alexandria, VA: Association for Supervision and Curriculum Development.

McShannon, J., \& Hynes, P. (2005). Student achievement and retention: Can professional development programs help faculty GRASP it? Journal of Faculty Development, 20(2), 87-94.

Norton, L., Richardson, J. T. E., Hartley, J., Newstead, S., \& Mayes, J. (2005). Teachers' beliefs and intentions concerning teaching in higher education. Higher Education, 50, 537-571.

Oosterheert, I. E., \& Vermunt, J. D. (2003). Knowledge construction in learning to teach: The role of dynamic sources. Teachers and Teaching: Theory and Practice, 9, 157-173.

Orland-Barak, L., \& Kremer-Hayon, L. (2001). Portfolios as evidence of learning: And what remains 'untold'. Paper presented at the biennial meeting of the European Association for research on learning and instruction, Fribourg, August.

Pajares, M.F. (1992). Teachers' beliefs and educational research: Cleaning up a messy construct. Review of Educational Research, 62(3), 307-332.

Postareff, L., Lindblom-Ylänne, S., \& Nevgi, A. (2007). The effect of pedagogical training on teaching in higher education. Teaching and Teacher Education, 23, 557-571.

Pratt, D. D. (1992). Conceptions of teaching. Adult Education Quarterly, 42, 203-220.

Richardson, J. T. E. (2005). Students' approaches to learning and teachers' approaches to teaching in higher education. Educational Psychology, 25, 673-680.

Slavit, D., Sawyer, R., \& Curley, J. (2003). Filling your plate: A professional development model for teaching with technology. TechTrends, 47, 35-38. 
Smith, G. (1992a). A categorisation of models of staff development in higher education. British Journal of Educational Technology, 23(1), 39-47.

Smith, G. (1992b). Responsibility for staff development. Studies in Higher Education, 17(1), 27-41.

Stepp-Greany, J. (2004). Collaborative teaching in an intensive Spanish course: A professional development experience for teaching assistants. Foreign Language Annals, 37, 417-426.

Stoll, L., \& Fink, D. (1996). Changing our schools: Linking school effectiveness and school improvement. Buckingham: Open University Press.

Wray, S. (2007). Teaching portfolios, community, and pre-service teachers' professional development. Teaching and Teacher Education, 23(7), 1139-1152. 

Summary 
Teacher learning and development is a complex process. Therefore, the studies presented in this dissertation were undertaken with the goal of contributing to a better understanding and an improvement of the multifactorial process that typifies staff development in higher education.

Chapter 1 of this dissertation gives an introduction to the different studies, a short description of the studies and an overview of the research questions.

With Chapter 2 and 3 of this dissertation we emphasize the importance of a shared language between different stakeholders of staff development. Staff developers (Chapter 2) and teachers (Chapter 3 ) are important stakeholders.

The aim of the study in Chapter 2 is providing a framework for understanding the way staff developers experience staff development.

Four main categories of description, which represent qualitatively different conceptions of staff development were distinguished: staff development as functional development; staff development as organisational competence development; staff development as self-directed reflective development; staff development as continuous personalised and experience-based holistic development. While each additional category has features in common with the previous categories, it also presents a new element in the experience of the staff developer.

The composition of these four categories contains a process of gradual change from teacher-centred to learner-centred, from involving small amounts of reflection to purposeful reflection, from limited self-directed learning to substantial selfdirected learning, from unequal to equal levels between learner and staff developer, from no attention to a lot of attention being paid to learning transfer, from implicit beliefs and conceptions to explicit ones, from implicit prior knowledge and previously acquired competences to personal prior knowledge and previously acquired competences as the starting point for further learning, and from brief and solitary staff development interventions to longitudinal ones.

The third chapter is focussing on perceptions of teachers. Teachers construct a meaningful personal reaction to staff development. Furthermore, perceptions of teachers towards learning and teaching determine their actions. Therefore, addressing perceptions of teachers affecting teacher professionalisation is necessary to support and encourage the continuous professionalisation of teachers.

In educational literature three macro models of staff development are distinguished: the management model, the shop-floor model and the partnership model. The differentiation is on the basis of who takes responsibility for implementing staff development activities. The study in this chapter investigates 
whether these models are recognised by teachers. Furthermore this research is looking for effects, of those three staff development models, perceived by teachers in higher education.

The results show that all three macro models are recognised by the participants. In our study the difference between the three staff development models is visible in the level of satisfaction. This difference in satisfaction seems to have no effect on applying new gained knowledge, skills or conceptions in practice. Most of our respondents are aware of their own learning process during staff development sessions and respondents indicate that their conceptions changed after participating in staff development programmes. Moreover, it seems that teachers consider the change in conceptions of teaching as something obvious.

Chapter 4 and 5 concentrates on teaching portfolios. Change will not come easily. Therefore investing in longitudinal staff development programs is important. Teaching portfolios are seen as an important instrument within those longitudinal staff development initiatives. To professionalise also means to express how things went; look back and look forward based on new knowledge and skills. It is about formulating new intentions for the future.

Aiming a more holistic approach to staff development, one should first consider teachers perceptions and conceptions before implementing teaching portfolios. Researchers stress the importance of knowing what teachers think and what their beliefs are.

Chapter 4 explores what teachers in higher education consider relevant content of a teaching portfolio and looks into teachers' conceptions and attitudes (pro or con) towards teaching portfolios.

Results indicate that teachers find self report and self reflection important but do not value the feedback reports of their colleagues. Their own vision of good educational practice is an important part of their portfolio. Teachers are aware of their subjective educational theory. Furthermore, information about research activities is an important teaching portfolio content. The results show that teachers have support-oriented conceptions, career-oriented conceptions and anxietyoriented conceptions towards the use of teaching portfolios. Teachers with supportoriented conceptions realize that a teaching portfolio contributes to development. Teachers with career-oriented conceptions witness how a teaching portfolio can steer their career. Teacher with anxiety-oriented conceptions are worried about the workload and the negative consequences that a teaching portfolio could bring. Most of the teachers have a positive attitude towards teaching portfolios. Supportoriented conceptions seem to influence the attitude towards a teaching portfolio. Previous research shows that discussions and cooperation with others are a very important factor in the portfolio construction process. However, our results suggest 
that anxiety-oriented conceptions could hinder collaboration. The results of this study suggest that a teaching portfolio could be a good instrument to counterpart the research minded appraisals in higher education. However, a good instrument alone is not enough to make a change. A lot more than a good instrument is needed.

Chapter 5 deals with the following research question: 'Are teaching portfolios really used in higher education, and if so, which effects could they bring about?'.

Our results show that the use of teaching portfolio's in not yet a certainty in higher education. However, the respondents are in favour of the use of teaching portfolios. Teachers consider the portfolio process as a way to improve the quality of their own education but also the quality of the educational institution. A teaching portfolio is seen as an instrument that could bring about some important positive effects. Due to the use of portfolios teachers were stimulated to reflect on their own teaching, to actualise the learning content, to improve course materials, to search for alternative educational methods, etc. Additionally, the results show that teaching portfolios are very useful for appraisals and make clear what the efforts of the teacher are. Teachers have certain benefits from the use of portfolios. However, teaching portfolios are not the ideal instrument for all teachers. It is important to realise that the use of teaching portfolios does not only have positive effects for teachers. Moreover, making a teaching portfolio is very time consuming. To conclude, if a teaching portfolio is used for summative purposes, teachers must know in advance which aspects of their portfolio will be evaluated.

In Chapter 6 we focus on extensive use of staff development, as an extra ingredient in the formula of peer learning, to improve higher education. The study takes place in a learning environment that is characterised by Problem Based Learning. The following research question was formulated: Is there a difference between staff tutors and rigorously selected and well trained student tutors with respect to students' achievements and perceptions?

Our study shows that carefully selected and trained student tutors have neither a positive nor a negative impact. Student tutors are inevitably less experienced than staff tutors, but in the first curricular year this apparently does not translate to poorer exam results. There appears to be no difference between staff tutors and rigorously selected and well trained student tutors with respect to students' achievements and perceptions. First-year students do not attach great importance to the tutor's domain specific expertise. Students have the opinion that student tutors' strong cognitive congruency compensates for their lack of domain specific expertise. Students agree that the stimulating function of the tutor is very important. However students see no differences between student and staff tutors in this respect. Differences between staff and student tutors in domain specific 
expertise and cognitive and social congruency do not affect students' general perceptions of tutors. Finally, it appears that students see the tutor role as very important to their learning and think that staff and student tutors are equally able to perform this role effectively. In general, students showed no preference for either group of tutors.

This study proves that well selected and well trained student tutors are ready to successfully undertake complex tutor responsibilities in problem based learning environments.

In Chapter 7 we study transfer of learning to the workplace. The interdisciplinary review in this chapter deals with the following research questions. Which influencing factors - revealed in management, HRD and organisational psychology research - have an impact on transfer of learning? Which moderating factors revealed in management, HRD and organisational psychology research - have an impact on the relationship between predictors and transfer of learning? Which of these influencing factors can be of importance within the context of staff development in higher education? Which of these moderating factors can be of importance within the context of staff development in higher education? Which influencing factors, additional to those found in management, HRD and organisational psychology research, can be found by studying the impact of staff development on transfer of learning to the workplace within the context of staff development in higher education?

It is highly curious that such limited documentation about factors influencing transfer is presented in studies measuring the impact of staff development. To gain new insights in this process of transfer, evidence from solid research is required. Educational researchers have to alter their course. Research on impact of staff development has to change. A new research approach is needed. In our review we present a conceptual framework that could guide researchers towards more realistic and explanatory research on transfer of learning in staff development. Further research on impact of staff development should carefully describe trainee characteristics, intervention characteristics and context characteristics such as work environment. Educational research on the following predictors of transfer is most needed: motivation to learn, motivation to transfer, needs analysis, active learning, self-management strategies, strategic link, transfer climate, supervisory support, amount of experience, nature of the intervention, amount of training time spent and learning climate.

Chapter 8 summarises and discusses the results of the different studies.

This dissertation showed that many factors influence the complex process of transfer of learning to the workplace. Furthermore, we emphasise that to make staff development successful a shared language is of the utmost importance. 
Accentuating perceptions and conceptions of different stakeholders contributes to the improvement of staff development. In the discussion part the shift in emphasis towards staff development and the complex and slow process of change is touched. Although, the golden rule in staff development is that there is no golden rule, our practical implications could help staff developers to achieve their goal to improve capabilities and practices of educators. 
Samenvatting 
Onderwijskundige professionalisering voor docenten is een complex gegeven. Met dit proefschrift trachten we bij te dragen tot een beter begrip en een verbetering van het multifactorieel proces dat onderwijskundige professionalisering voor docenten typeert.

In Hoofdstuk 1 van dit proefschrift wordt een introductie, een korte beschrijving van de studies en een overzicht van de onderzoeksvragen gegeven.

Met Hoofdstuk 2 en 3 benadrukken we het belang van een gemeenschappelijke taal tussen verschillende partijen die betrokken zijn bij onderwijskundige professionalisering. De deskundige inzake onderwijskundige professionalisering voor docenten (Hoofdstuk 2) en de docent (Hoofdstuk 3) staan centraal.

Aan de hand van de studie in Hoofdstuk 2 trachten we een kader te ontwerpen om ons inzicht in de wijze waarop deskundigen inzake onderwijskundige professionalisering voor docenten deze professionalisering ervaren, te vergroten.

Onze studie resulteert in vier verschillende categorieën, zijnde: onderwijskundige professionalisering als functionele ontwikkeling; onderwijskundige professionalisering als organisatiegerichte competentie ontwikkeling; onderwijskundige professionalisering als zelfgestuurde reflectieve ontwikkeling; onderwijskundige professionalisering als continue, persoonlijke en ervaringsgestuurde ontwikkeling. Elke categorie heeft kenmerken van de vorige categorie, maar wordt voorts gekenmerkt door een nieuw element.

De samenstelling van deze vier categorieën toont ons een graduele opbouw van docent gecentreerd tot student gecentreerd leren, van weinig reflectie tot doelgerichte reflectie als vorm van leren, van beperkte zelfsturing tot wezenlijke zelfsturing tijdens het leerproces, van ongelijke tot gelijke niveaus tussen lerende en deskundige, van geen aandacht naar aanzienlijke aandacht voor transfer van het geleerde naar de werkplek, van geen aandacht voor persoonlijke opvattingen naar aandacht voor het expliciteren van opvattingen, van impliciete voorkennis en eerder verworven competenties tot aandacht voor persoonlijk voorkennis en eerder verworven competenties als een beginpunt voor het verdere leerproces, en van korte en op zichzelf staande tot longitudinale initiatieven voor onderwijskundige professionalisering.

Het derde hoofdstuk zoomt in op percepties van docenten. Docenten construeren een betekenisvolle en persoonlijke reactie ten opzichte van onderwijskundige professionalisering. Verder bepalen de percepties van docenten aangaande leren en doceren hun onderwijsactiviteiten. Als we een constante professionalisering van docenten willen ondersteunen en aanmoedigen is het daarom belangrijk om 
aandacht te schenken aan docentpercepties ten aanzien van onderwijskundige professionalisering.

In de literatuur worden drie macromodellen onderscheiden in de onderwijskundige professionalisering voor docenten: het managementmodel, het werkvloermodel en het partnermodel. Het onderscheid wordt bepaald door wie verantwoordelijk is voor het initiëren van de onderwijskundige professionalisering.

De studie in Hoofdstuk 3 onderzoekt of docenten in hoger onderwijs deze drie modellen herkennen. Verder wordt nagegaan welke effecten docenten percipiëren naargelang de drie macromodellen.

Het resultaat van de studie toont dat docenten de drie macromodellen herkennen. Het verschil tussen de drie modellen is zichtbaar in de mate waarin docenten tevreden zijn over het professionaliseringsinitiatief. Dit verschil zet zich niet door naar het toepassen van de nieuw verworven kennis, vaardigheden en opvattingen in de praktijk. De meeste respondenten zijn zich bewust van hun eigen leerproces tijdens de onderwijskundige professionalisering. Verder geven docenten aan dat hun opvattingen veranderen na deelname aan activiteiten voor onderwijskundige professionalisering. Sterker nog, het lijkt erop dat docenten de verandering in opvattingen als vanzelfsprekend zien.

Hoofdstuk 4 en 5 nemen docentportfolio's onder de loep. Verandering is geen gemakkelijk proces. Mede daarom is het belangrijk om te investeren in longitudinale initiatieven voor onderwijskundige professionalisering.

Docentportfolio's worden gezien als belangrijke instrumenten in een dergelijk longitudinaal traject. Professionalisering betekent onder meer verwoorden hoe dingen gegaan zijn; terugblikken en vooruitblikken bij het verwerven van nieuwe kennis en vaardigheden. Het betreft nieuwe doelstellingen voor de toekomst formuleren.

Wanneer we een meer holistische aanpak bij onderwijskundige professionalisering nastreven is het belangrijk om percepties en opvattingen van docenten te bestuderen alvorens docentportfolio's te implementeren in de onderwijsorganisatie. Onderzoekers benadrukken hoe belangrijk het is om het denken en de opvattingen van docenten niet te negeren.

In Hoofdstuk 4 wordt bestudeerd welke inhoudselementen docenten, in het hoger onderwijs, in hun portfolio wensen op te nemen. Verder wordt gekeken naar de opvattingen en houding (voor of tegen) aangaande docentportfolio's.

De resultaten van deze studie tonen aan dat docenten zelfrapportage en zelfreflectie belangrijk vinden. Anderzijds hechten ze minder belang aan feedbackverslagen van hun collega's. Hun persoonlijke visie op goed onderwijs is een belangrijk onderdeel van het portfolio. Docenten zijn zich bewust van hun eigen 
subjectieve onderwijstheorie. Verder wordt ook informatie over onderzoeksactiviteiten als een belangrijk inhoudselement gewaardeerd.

Onze resultaten tonen dat docenten zowel op ondersteuning gerichte opvattingen, als carrière gerichte opvattingen en angst georiënteerde opvattingen ten aanzien van een docentportfolio hebben. Bij op ondersteuning gerichte opvattingen zien docenten hoe een docentportfolio een bijdrage kan leveren aan ontwikkeling. Docenten met carrière gerichte opvattingen zien vooral hoe een docentportfolio richting kan geven aan hun loopbaan. Bij angst georiënteerde opvattingen zijn docenten vooral bezorgd over werkdruk en negatieve gevolgen van een docentportfolio. De meeste docenten hebben een positieve houding tegenover docentportfolio's (voorstander). Op ondersteuning gerichte opvattingen lijken de houding ten aanzien van een portfolio te beïnvloeden. Eerder onderzoek toont dat overleg en samenwerking met anderen een belangrijke factor is in het portfolio constructieproces. Onze resultaten doen vermoeden dat angst georiënteerde opvattingen deze belangrijke fase van samenwerking kunnen hinderen. De resultaten van onze studie laten blijken dat docentportfolio's een goed instrument zijn om tegenwicht te geven aan de op onderzoek gerichte docentbeoordelingen in hoger onderwijs. Echter, een goed instrument alleen is onvoldoende om verandering te brengen in een cultuur waar onderzoek dominant is.

Hoofdstuk 5 behandelt de volgende onderzoeksvraag: "Worden docentportfolio's gebruikt in hoger onderwijs, en welke effecten brengen zij dan teweeg?".

Ons onderzoek toont aan dat werken met docentportfolio's in hoger onderwijs nog geen vanzelfsprekendheid is. Toch zijn de respondenten van onze studie hoofdzakelijk voorstander van portfoliogebruik. Docenten zien het portfolioproces als een manier om de kwaliteit van hun eigen onderwijs en de kwaliteit van de onderwijsorganisatie te verbeteren.

Een docentportfolio wordt gezien als een instrument dat belangrijke positieve effecten teweeg kan brengen. Door het gebruik van portfolio's worden docenten gestimuleerd om te reflecteren op hun eigen onderwijs, de inhoud van hun onderwijs te actualiseren, onderwijsmateriaal te verbeteren, te zoeken naar alternatieve onderwijsmethoden, enzovoort. Verder tonen onze resultaten dat docentportfolio's bijzonder bruikbaar zijn bij beoordelingsgesprekken. Ze maken duidelijk welke inspanningen de docent levert. Docenten halen bepaalde voordelen uit het gebruik van docentportfolio's, maar portfolio's zijn niet het ideale instrument voor alle docenten. Het is belangrijk dat we ons realiseren dat het gebruik van portfolio's niet enkel positieve effecten heeft voor docenten. Het werken met een portfolio is met name een tijdrovend proces. Tenslotte, wanneer portfolio's gebruikt worden voor summatieve doeleinden is het belangrijk dat docenten op voorhand weten hoe het portfolio geëvalueerd zal worden. 
Het uitgebreid inzetten van onderwijskundige professionalisering als extra ingrediënt bij 'peer learning' - in een leeromgeving die gekenmerkt wordt door Probleem Gestuurd Onderwijs - is onderwerp van Hoofdstuk 6. De volgende onderzoeksvraag was onderwerp van de studie: Is er, op vlak van leerresultaten en percepties van studenten, een verschil tussen staftutoren en streng geselecteerde en goed geprofessionaliseerde studenttutoren?

Onze studie toont aan dat goed geselecteerde en geprofessionaliseerde studenttutoren het beter, noch slechter doen ten opzichte van hun collega staftutoren. Studenttutoren zijn uiteraard minder deskundig dan staftutoren. Echter, in het eerste jaar van de studie vertaalt zich dit niet in minder goede studieresultaten of negatieve percepties bij studenten. Studenten in het eerste jaar van de studie hechten geen bijzonder groot belang aan de domeinspecifieke expertise van tutoren. Studenten zijn van mening dat studenttutoren een sterke cognitieve congruentie vertonen en dit compenseert voor het gebrek aan domeinspecifieke kennis. Studenten vinden de stimulerende functie van de tutor belangrijk. Studenten merken hierin geen verschil tussen studenttutoren en staftutoren. Het verschil in domeinspecifieke kennis, cognitieve en sociale congruentie tussen studenttutoren en staftutoren heeft geen effect op het totale beeld dat studenten hebben van de tutor. Studenten vinden de rol van de tutor erg belangrijk in hun leerproces. Maar deze betekenisvolle rol is zowel voor studenttutoren als staftutoren weggelegd.

Onze studie bewijst dat goed geselecteerde en geprofessionaliseerde studenttutoren de complexe verantwoordelijkheid van tutoren in probleem gestuurd onderwijs aan kunnen.

In Hoofdstuk 7 verdiepen we ons in transfer van leren naar de werkplek. De interdisciplinaire review in dit hoofdstuk beantwoordt volgende onderzoeksvragen: "Welke voorspellende factoren spelen een rol bij transfer van leren volgens onderzoek in het veld van management, Human Research Development (HRD) en organisatiepsychologie?"; "Welke factoren hebben - volgens onderzoek in het veld van management, HRD en organisatiepsychologie- een modererende invloed op de relatie tussen voorspellende factoren en transfer van leren naar de werkplek?"; "Welke van deze voorspellende factoren kunnen van belang zijn in de context van onderwijskundige professionalisering in hoger onderwijs?"; "Welke van deze modererende factoren kunnen van invloed zijn in de context van onderwijskundige professionalisering in hoger onderwijs?"; "Welke voorspellende factoren additioneel aan de factoren die naar voor komen uit onderzoek in het veld van management, HRD en organisatiepsychologie - kunnen een rol spelen bij transfer van leren naar de werkplek bij onderwijskundige professionalisering?".

Het is opmerkelijk dat in studies naar impact van onderwijskundige professionalisering voor docenten slechts zo weinig informatie wordt gegeven over 
de factoren die van invloed zijn op transfer van leren. Opdat we nieuwe inzichten kunnen verwerven in het proces van transfer is meer bewijsmateriaal nodig uit degelijk onderwijskundig onderzoek. Onderzoek naar de impact van onderwijskundige professionalisering voor docenten moet anders aangepakt worden. In dit hoofdstuk presenteren we een conceptueel kader dat onderzoekers kan leiden naar realistisch en verklarend onderzoek op vlak van transfer van leren bij onderwijskundige professionalisering. Verder onderzoek naar de impact van onderwijskundige professionalisering dient kenmerken van de deelnemers, de interventies en de context zoals bijvoorbeeld de werkomgeving zorgvuldig te beschrijven. Onderwijskundig onderzoek dient zich vooral te richten op motivatie om te leren, motivatie voor transfer, behoefteanalyse, actief leren, zelfmanagementstrategieën, strategische links, transferklimaat, effect van de ondersteuning van de leidinggevende, mate van ervaring, aard van de interventie, lengte van het professionaliseringsinitiatief en het leerklimaat als mogelijke voorspellende factoren van transfer van leren naar de werkplek bij onderwijskundige professionalisering voor docenten.

In Hoofdstuk 8 worden de resultaten uit de verschillende studies in dit proefschrift samengevat en bediscussieerd. Uit dit proefschrift blijkt dat verschillende factoren van invloed zijn bij het complex proces van transfer van leren naar de werkplek. Verder benadrukken we met dit proefschrift dat een gemeenschappelijke taal uitermate belangrijk is bij onderwijskundige professionalisering. Door aandacht te schenken aan de percepties en concepties van verschillende betrokken partijen dragen we bij aan de ontwikkeling van onderwijskundige professionalisering. In de discussie wordt de evolutie van onderwijskundige professionalisering en het complex en langzaam proces van verandering in de verf gezet. Ook worden in dit hoofdstuk suggesties voor verder onderzoek en voor de praktijk gegeven. Al bestaat er geen gouden formule die toepasbaar is bij elk initiatief voor onderwijskundige professionalisering, toch kunnen onze praktijksuggesties de deskundigen inzake onderwijskundige professionalisering voor docenten helpen in hun uitdagende werk om de bekwaamheid en de onderwijspraktijk van docenten te verbeteren. 


\section{Dankwoord}

Niet alleen vandaag prijs ik me meer dan gelukkig.

Gelukkig, omdat ik deel uitmaak van een fantastisch gezin. Nicolas, Marie-Eline, wat kan ik meer wensen dan het geluk van jullie om me heen te hebben. Ik voel me rijk in jullie gezelschap.

Gelukkig, want ik geniet van de vriendschap van familie en vrienden. Ik ben blij met de bijzondere band die we hebben.

Gelukkig, omdat er zo veel kansen op me af komen.

Gelukkig, met de inspirerende, bevlogen en aanmoedigende momenten met mijn promotoren.

Gelukkig, vanwege de bezielende maar ook geanimeerde gesprekken met collega's en co-auteurs.

Gelukkig, vanwege dit proefschrift, waarin ik mijn interesse in staff development kon botvieren.

ledereen die bijdraagt aan dit gevoel van geluk wil ik hartelijk danken.

Dankjewel! 



\section{Curriculum Vitae}

Catherine De Rijdt was born on $18^{\text {th }}$ September 1972 in Lier (Belgium). She obtained a degree in pedagogical higher education at the katholieke hogeschool kempen in Vorselaar (Belgium) in 1994, a master degree in educational sciences at the University of Leuven (Belgium) and a teaching degree at the University of Leuven (Belgium) in 1999. In that year she started as an assistant professor at the Maastricht University, Faculty of Law, department Educational Development and Information Technology. Currently she is given the opportunity to coordinate Staff Development, University Teaching Qualification and Talent scouting at the same department. 